Supporting Information

\title{
Palladium-Catalyzed Regiospecific Decarboxylative Allylation of (Cyclohexadienylidene)malononitriles: Access to $\alpha$-Allyl- $\alpha$-aryl Malononitriles
}

Cheng-En Hsieh, Chih-Yao Tsao, Cheng-Huan Chuang, Liang-Wei Chen, and Chih-Ming Chou*

Department of Applied Chemistry, National University of Kaohsiung, 700, Kaohsiung University Road, Nanzih District, 81148 Kaohsiung, Taiwan

E-mail: cmchou@nuk.edu.tw 
Table of Contents

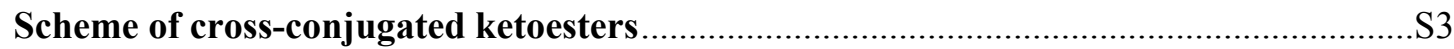

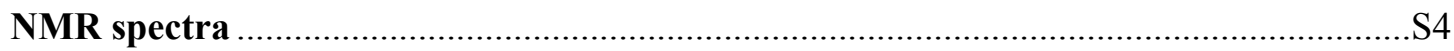

Table S1. Optimization of Enantioselective Decarboxylative C-Allylation ${ }^{a}$....................S54

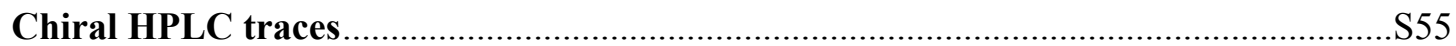


Scheme of cross-conjugated ketoesters<smiles>C=CCOC(=O)C1(C)C=CC(=O)C=C1</smiles><smiles>C=CCOC(=O)C1(CC(C)C)C=CC(=O)C=C1</smiles><smiles>C=CCOC(=O)C1([18OH])C=CC(=O)C=C1</smiles><smiles>C=CCOC(=O)C1([18OH])C=CC(=O)C=C1C</smiles><smiles>C=CCOC(=O)C1(C(C)C)C=CC(=O)C=C1</smiles><smiles>C=CCOC(=O)C1(C(C)C)C=CC(=O)C=C1C</smiles><smiles>C=CCOC(=O)C1(C(C)C)C=CC(=O)C(C)=C1</smiles><smiles>C=CCOC(=O)C1(C(C)C)C=CC(=O)C(F)=C1</smiles><smiles>C=CCOC(=O)C1(CC(=O)OC)C=CC(=O)C=C1</smiles><smiles>C=CCOC(=O)C1(Cc2ccccc2)C=CC(=O)C=C1C</smiles><smiles>C=CCOC(=O)C1(CC(=O)OC)C=CC(=O)C=C1C</smiles><smiles>C=CCOC(=O)C1(C(C)C)C=CC(=O)c2ccccc21</smiles><smiles>C=CCOC(=O)C1(Cc2ccccc2)C=CC(=O)C=C1</smiles>

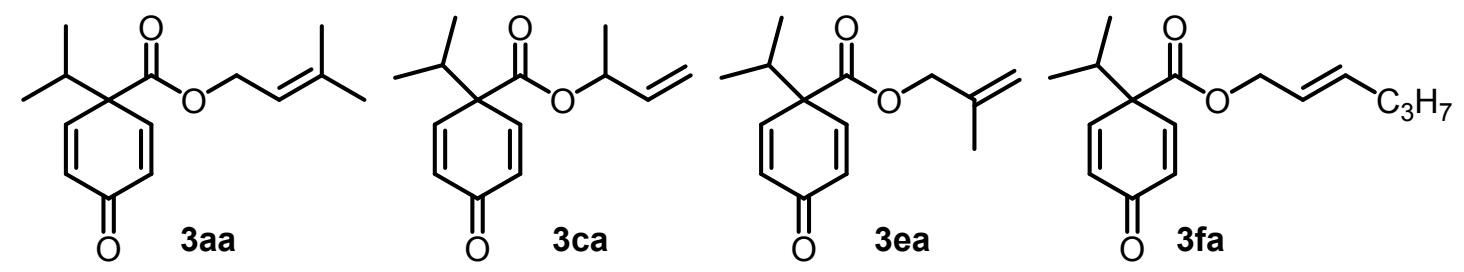<smiles>C=CC(C)OC(=O)C1(C(C)C)C=CC(=O)C=C1</smiles><smiles>CC(C)C1(C(=O)OC/C=C/c2ccccc2)C=CC(=O)C=C1</smiles><smiles>C=CC(OC(=O)C1(C(C)C)C=CC(=O)C=C1)c1ccccc1</smiles> 
NMR spectra

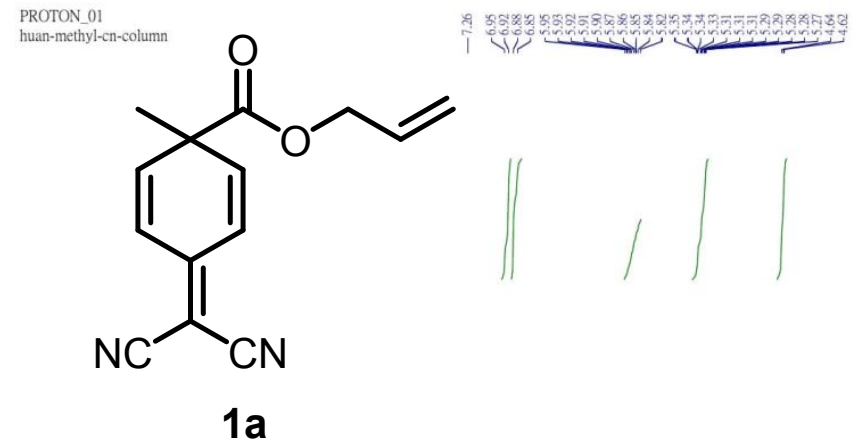

${ }^{1} \mathrm{H}$ NMR, $300 \mathrm{MHz}, \mathrm{CDCl}_{3}$
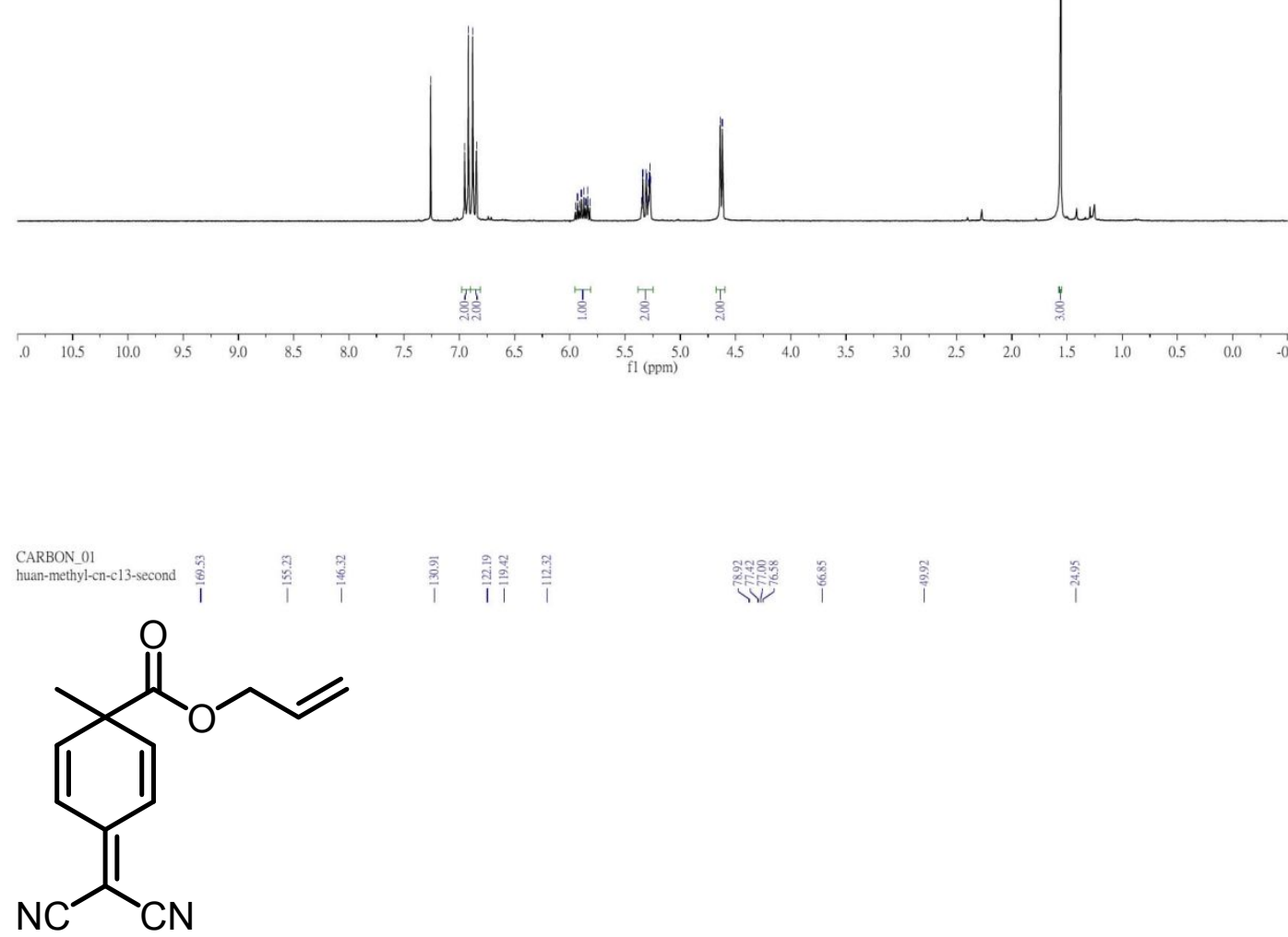

$1 \mathrm{a}$

${ }^{13} \mathrm{C}\left\{{ }^{1} \mathrm{H}\right\}$ NMR $75 \mathrm{MHz}, \mathrm{CDCl}_{3}$
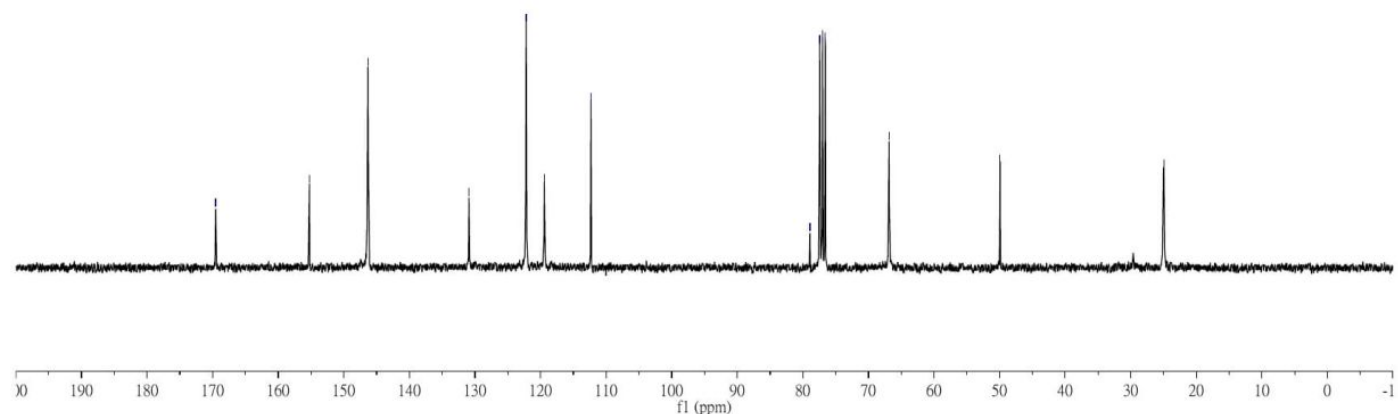
<smiles>C=CCOC(=O)C1(CC(C)C)C=CC(=C(C#N)C#N)C=C1</smiles>

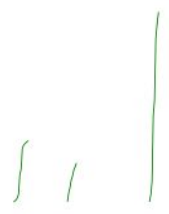

1b

${ }^{1} \mathrm{H}$ NMR, $300 \mathrm{MHz}, \mathrm{CDCl}_{3}$
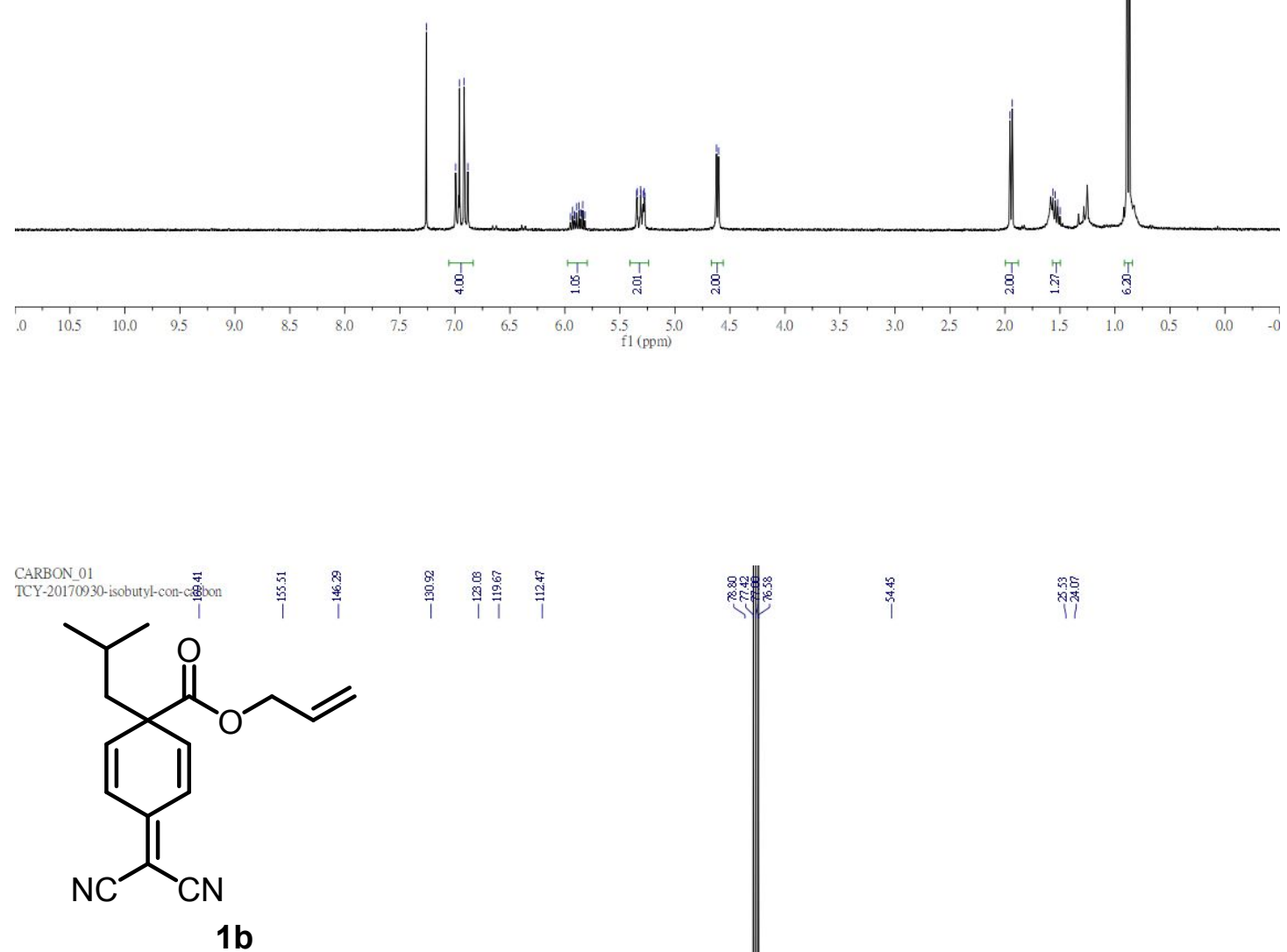

${ }^{13} \mathrm{C}\left\{{ }^{1} \mathrm{H}\right\}$ NMR $75 \mathrm{MHz}, \mathrm{CDCl}_{3}$

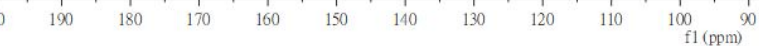



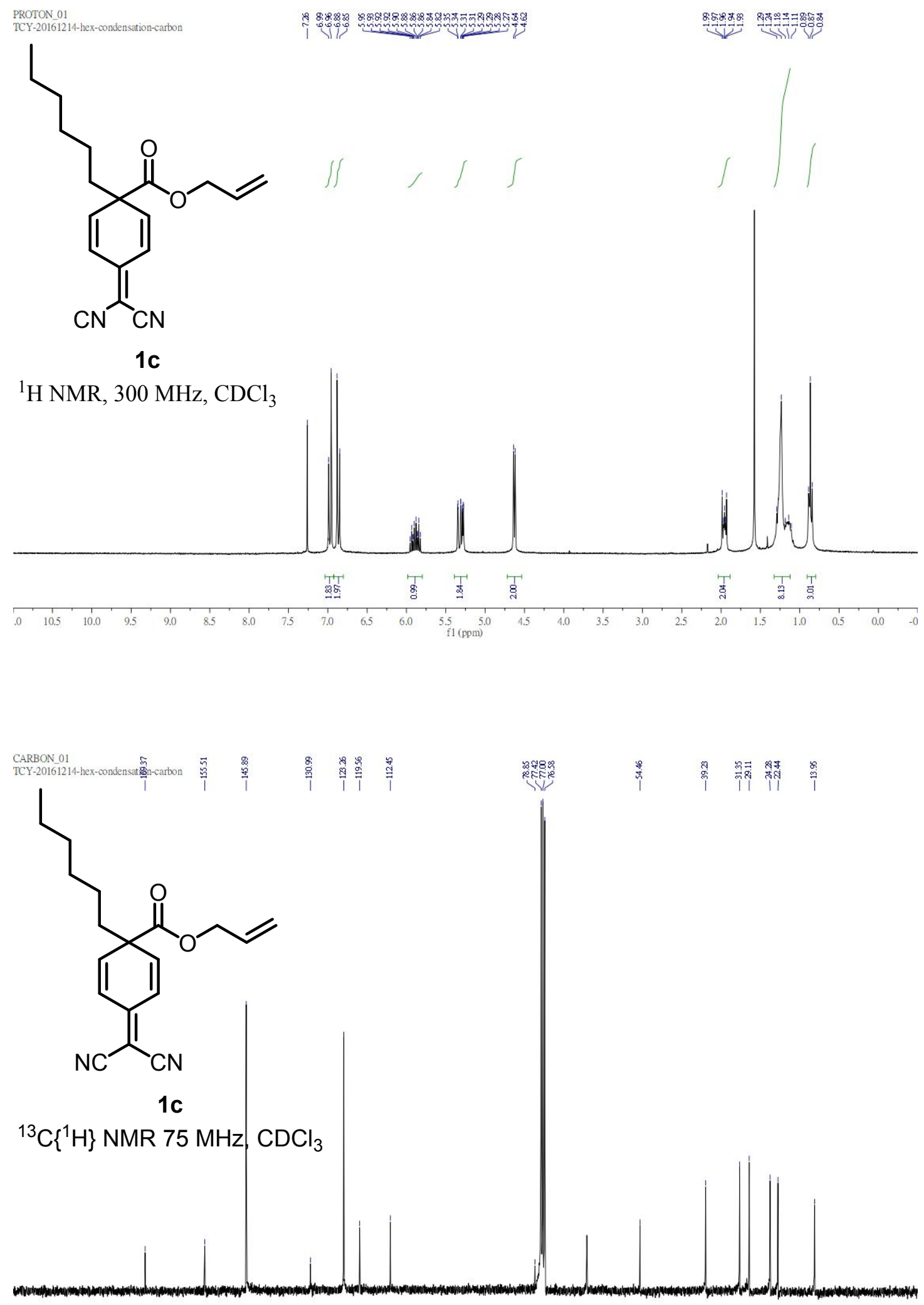


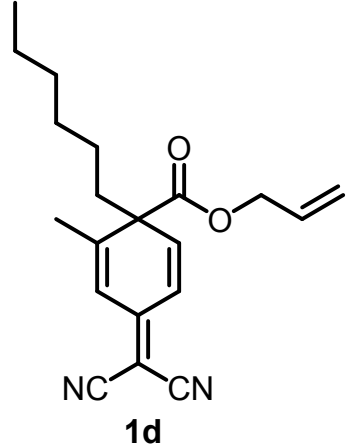

${ }^{1} \mathrm{H} \mathrm{NMR}, 300 \mathrm{MHz}, \mathrm{CDCl}_{3}$
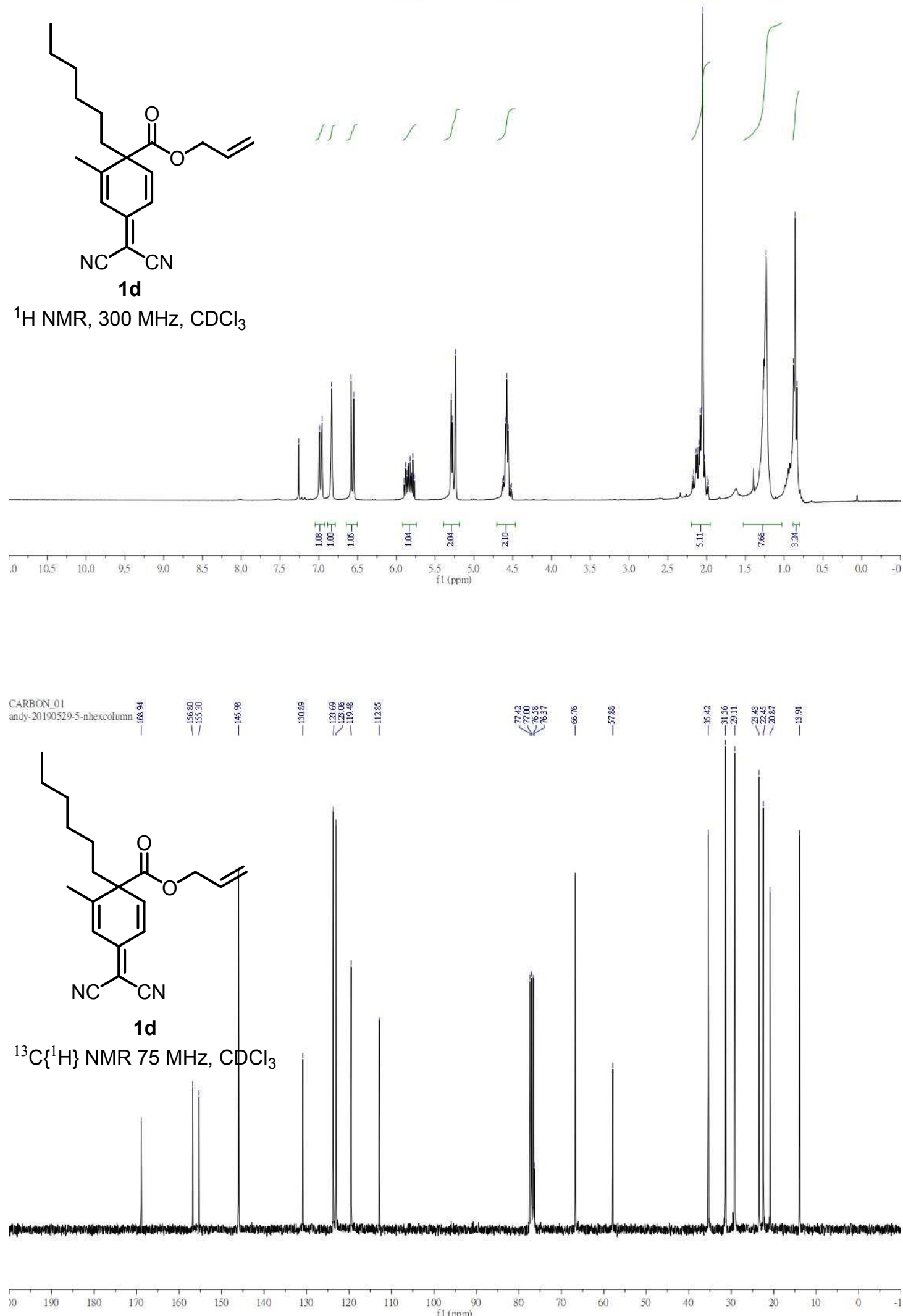

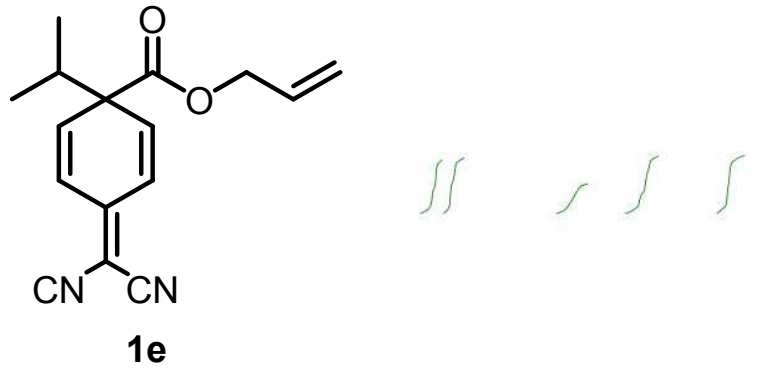

${ }^{1} \mathrm{H} \mathrm{NMR}, 300 \mathrm{MHz}, \mathrm{CDCl}_{3}$

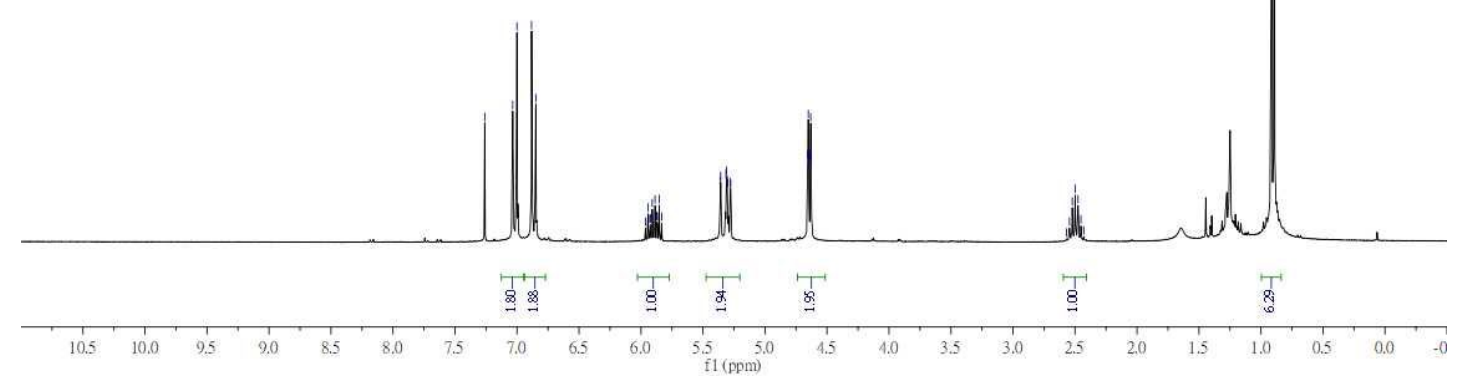

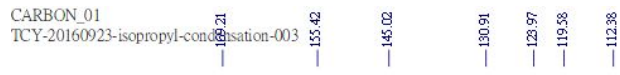

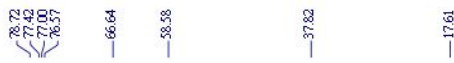

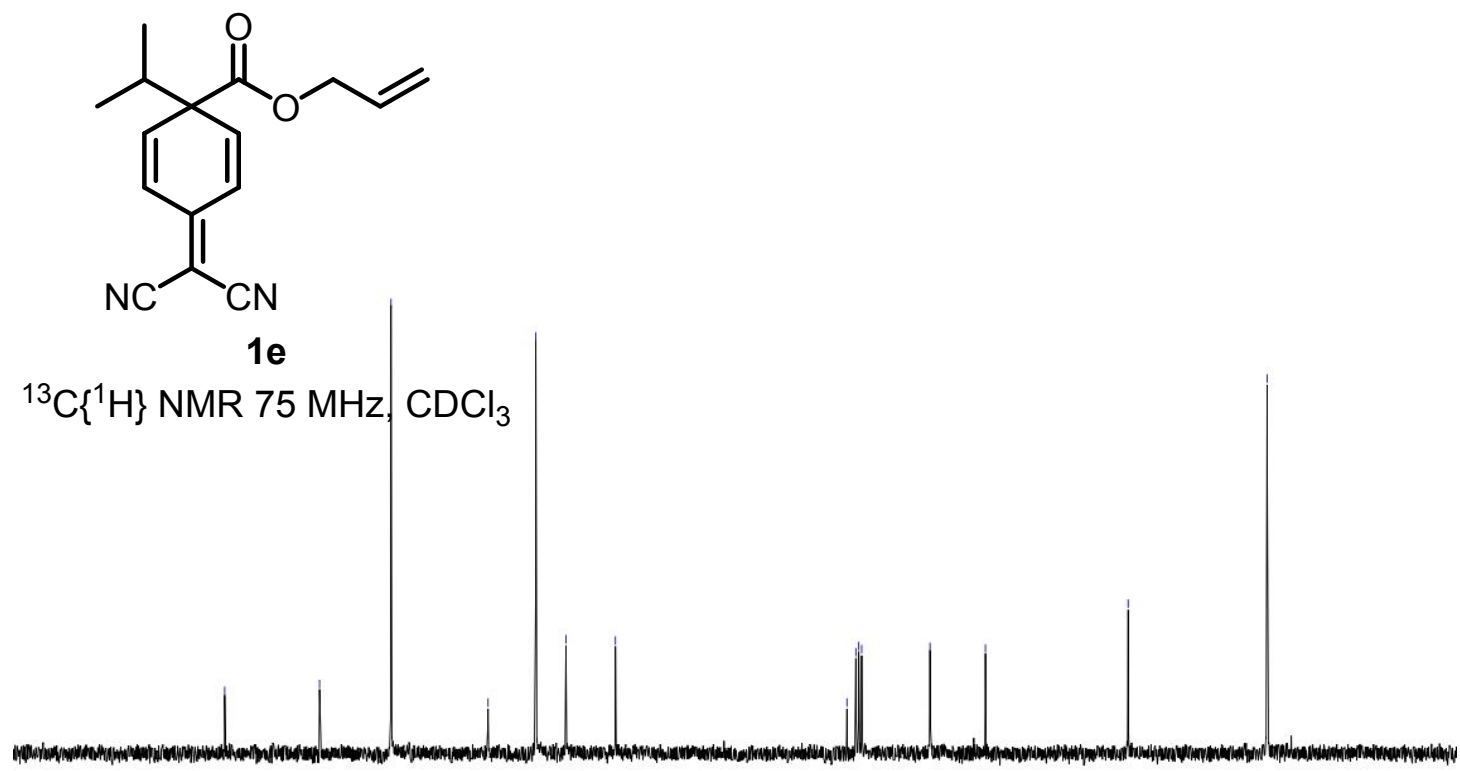

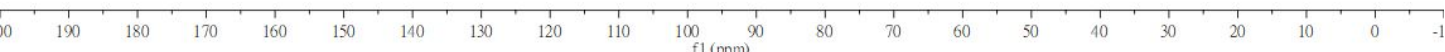




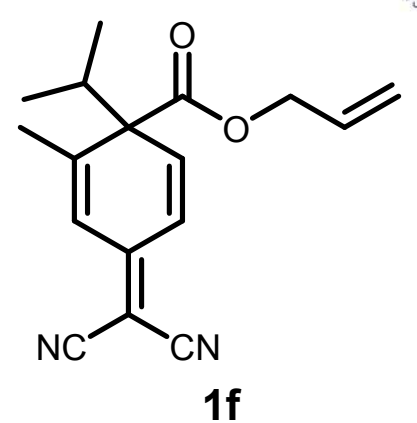

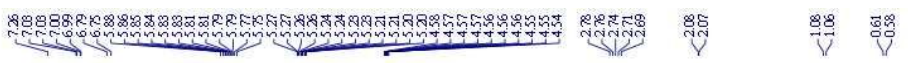

$1 f$

${ }^{1} \mathrm{H} \mathrm{NMR}, 300 \mathrm{MHz}, \mathrm{CDCl}_{3}$
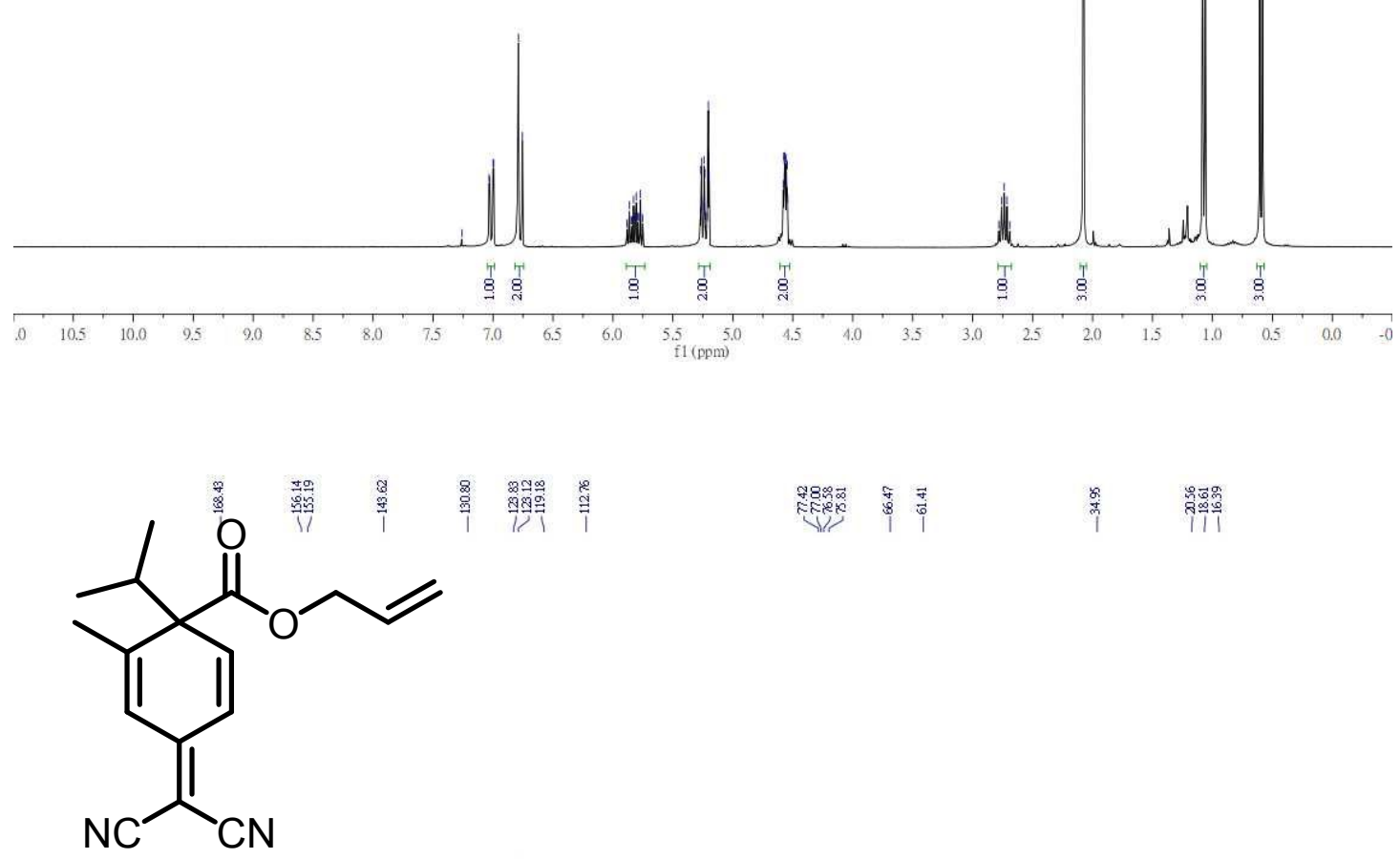

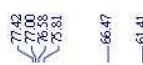

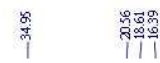

$1 f$

${ }^{13} \mathrm{C}\left\{{ }^{1} \mathrm{H}\right\} \mathrm{NMR} 75 \mathrm{MHz}, \mathrm{CDCl}_{3}$

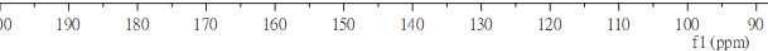



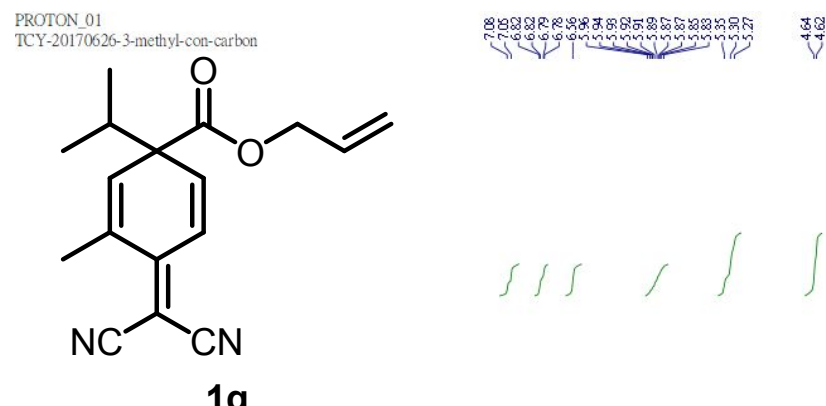

${ }^{1} \mathrm{H} \mathrm{NMR}, 300 \mathrm{MHz}, \mathrm{CDCl}_{3}$
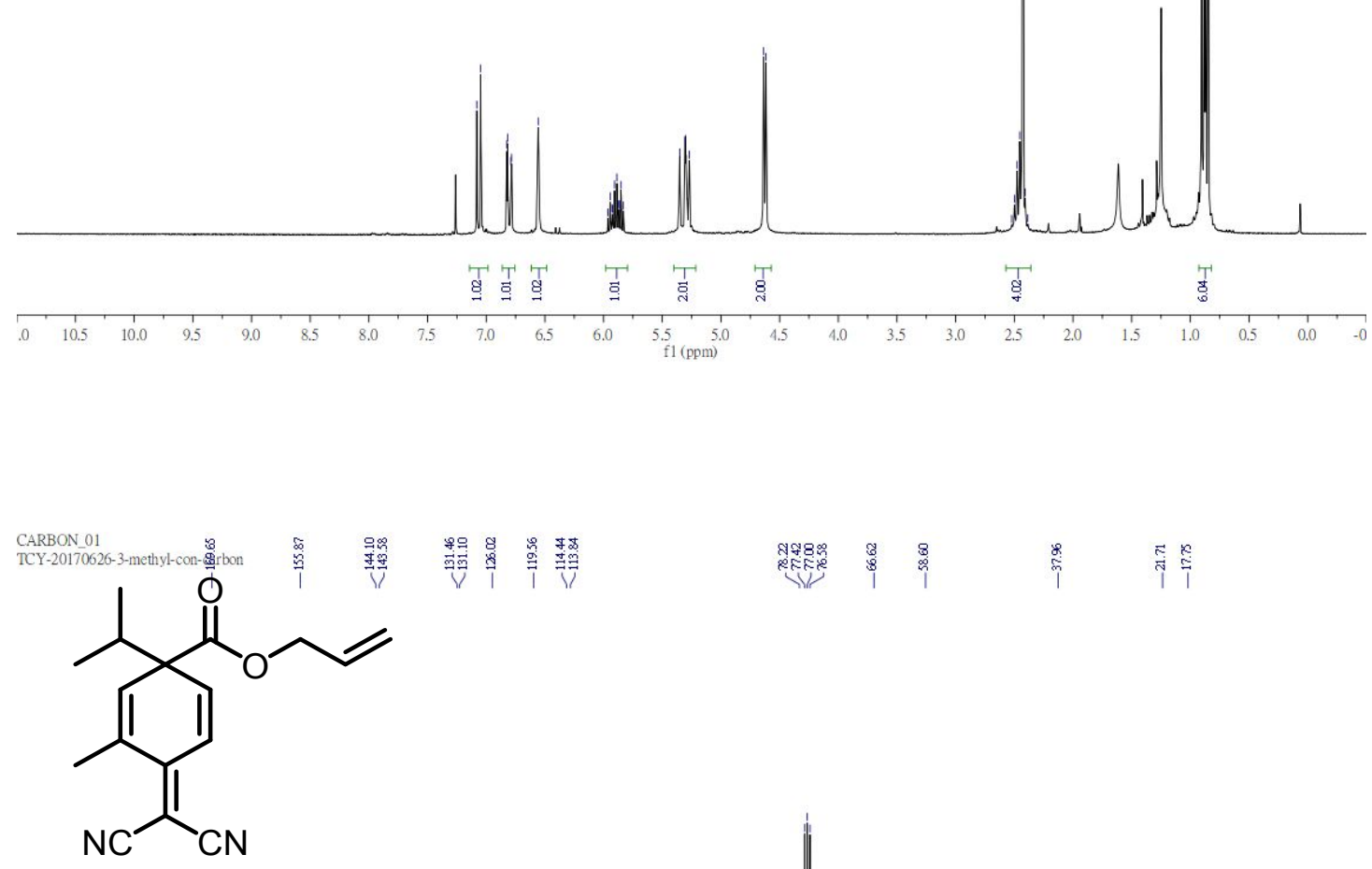

$1 \mathrm{~g}$

${ }^{13} \mathrm{C}\left\{{ }^{1} \mathrm{H}\right\} \mathrm{NMR} 75 \mathrm{MHz}, \mathrm{CDCl}_{3}$

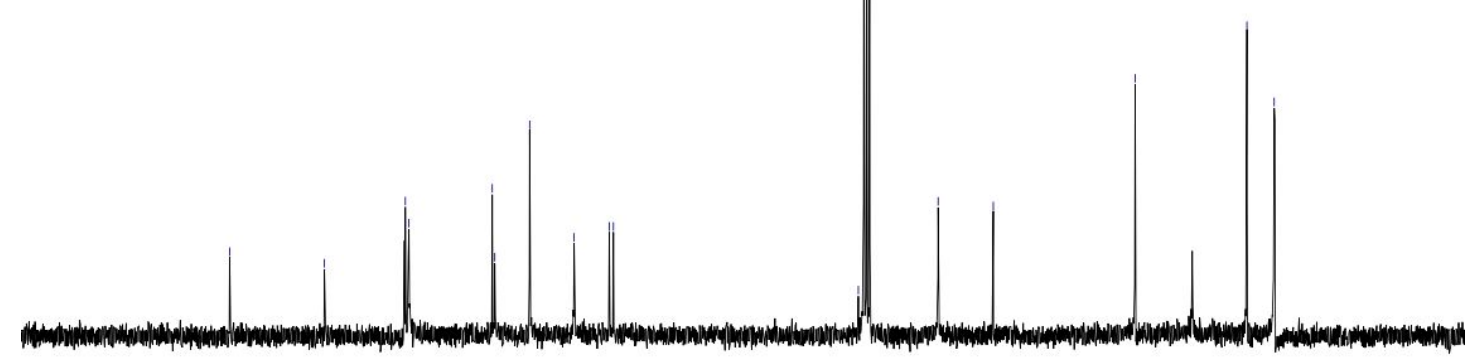

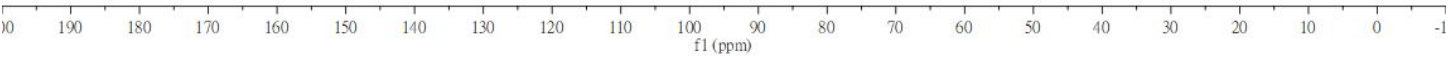




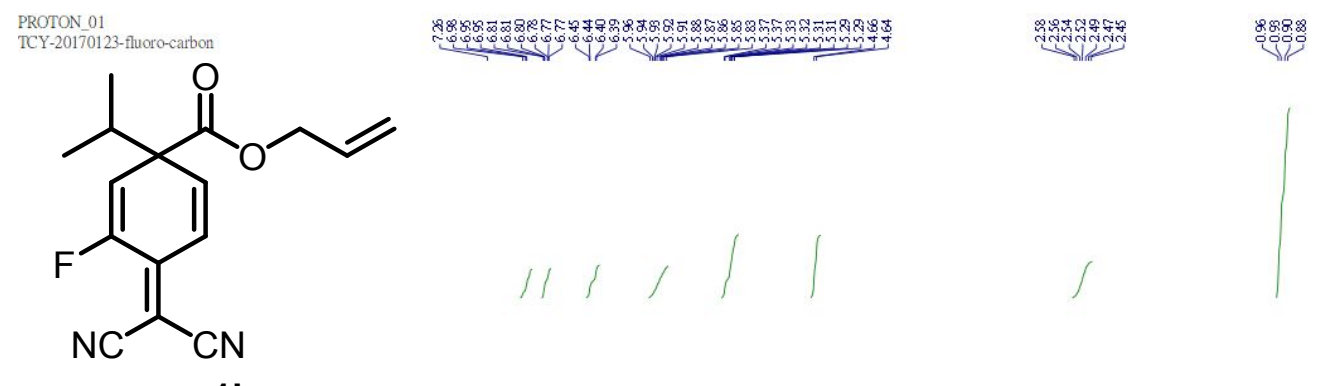

$1 \mathrm{~h}$

${ }^{1} \mathrm{H} \mathrm{NMR}, 300 \mathrm{MHz}, \mathrm{CDCl}_{3}$
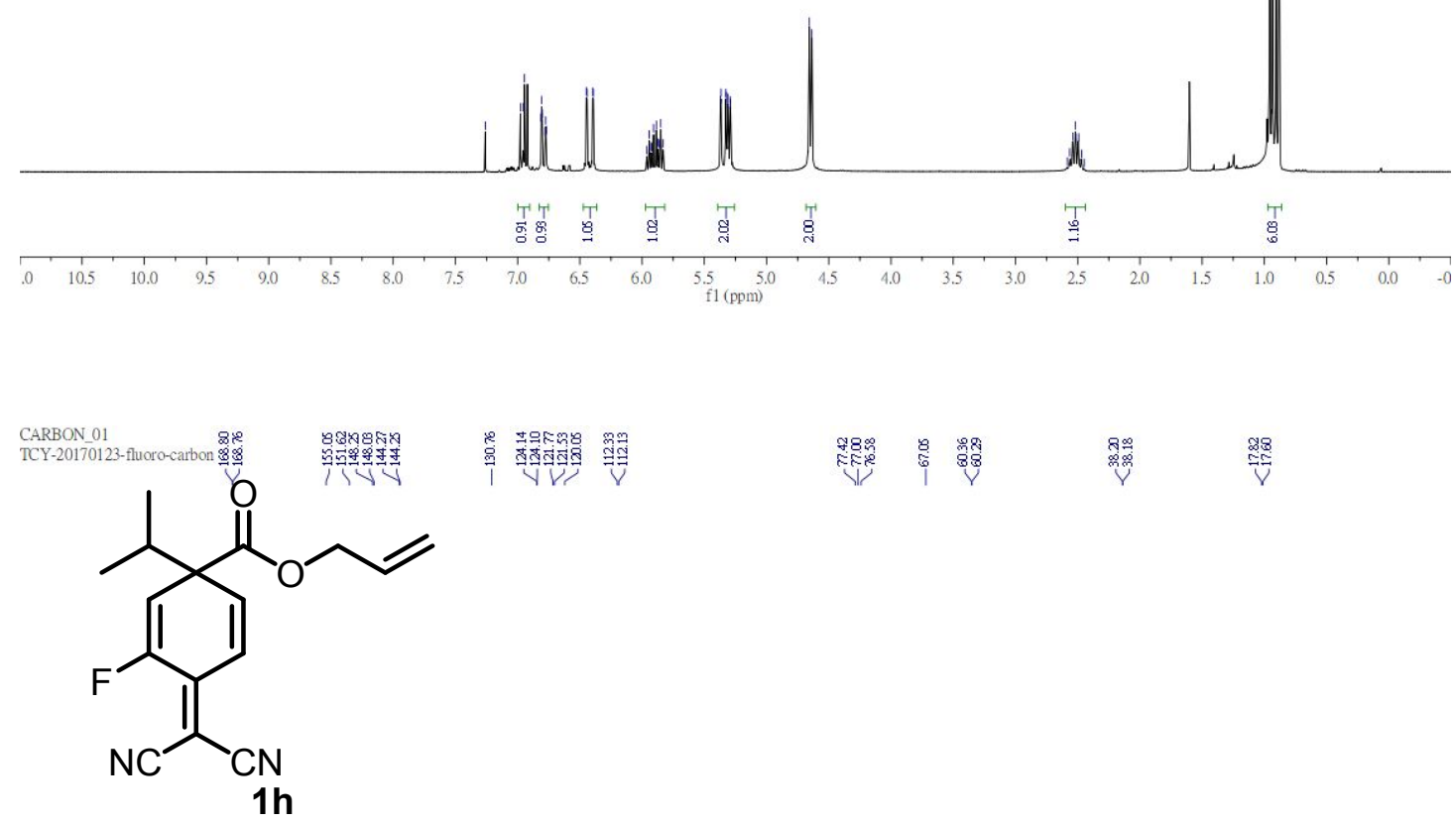

${ }^{13} \mathrm{C}\left\{{ }^{1} \mathrm{H}\right\}$ NMR $75 \mathrm{MHz}, \mathrm{CDCl}_{3}$

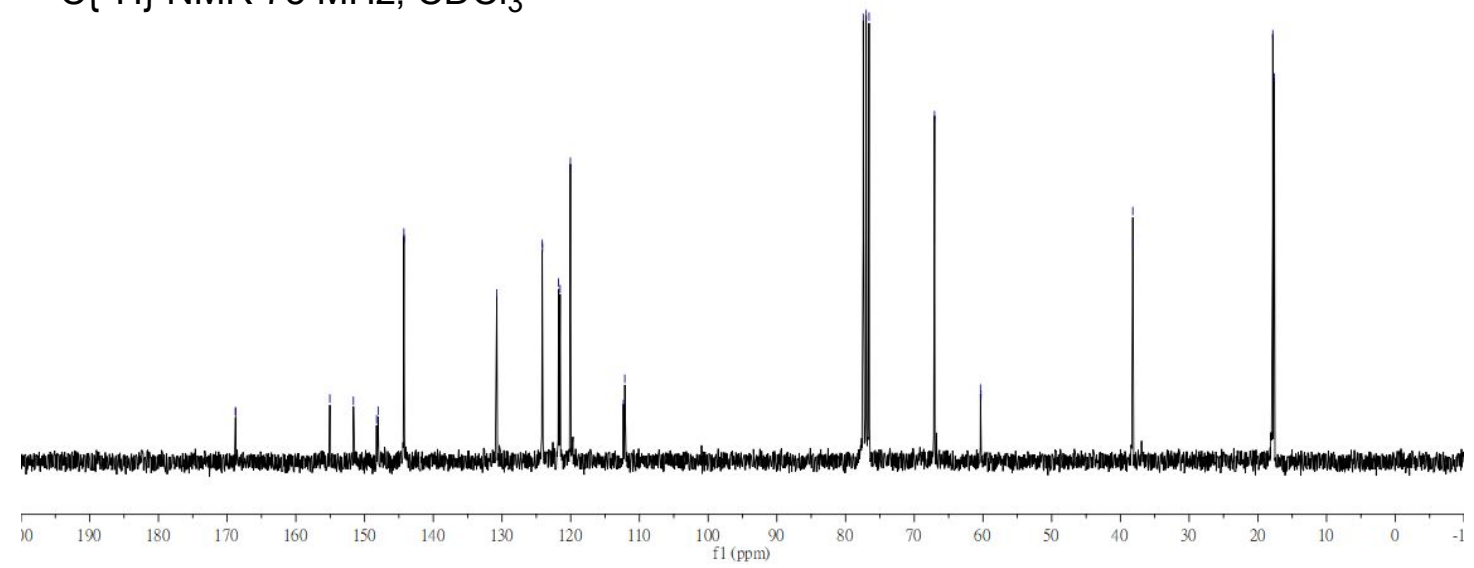




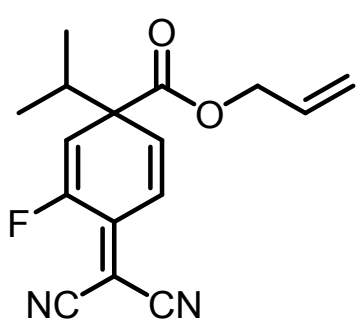

1h

${ }^{19} \mathrm{~F} \mathrm{NMR}, 282 \mathrm{MHz}, \mathrm{CDCl}_{3}$

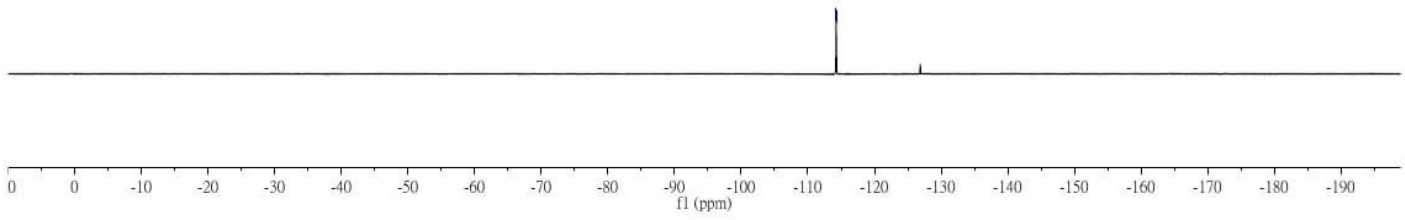




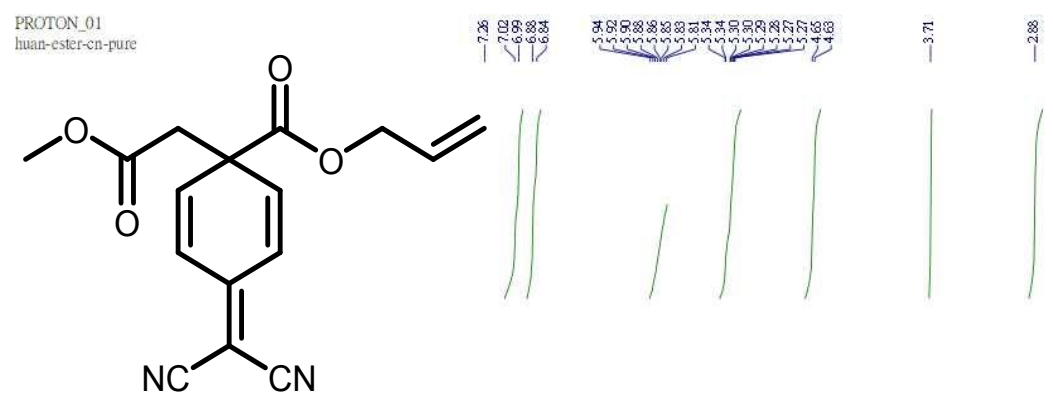

$1 \mathrm{i}$
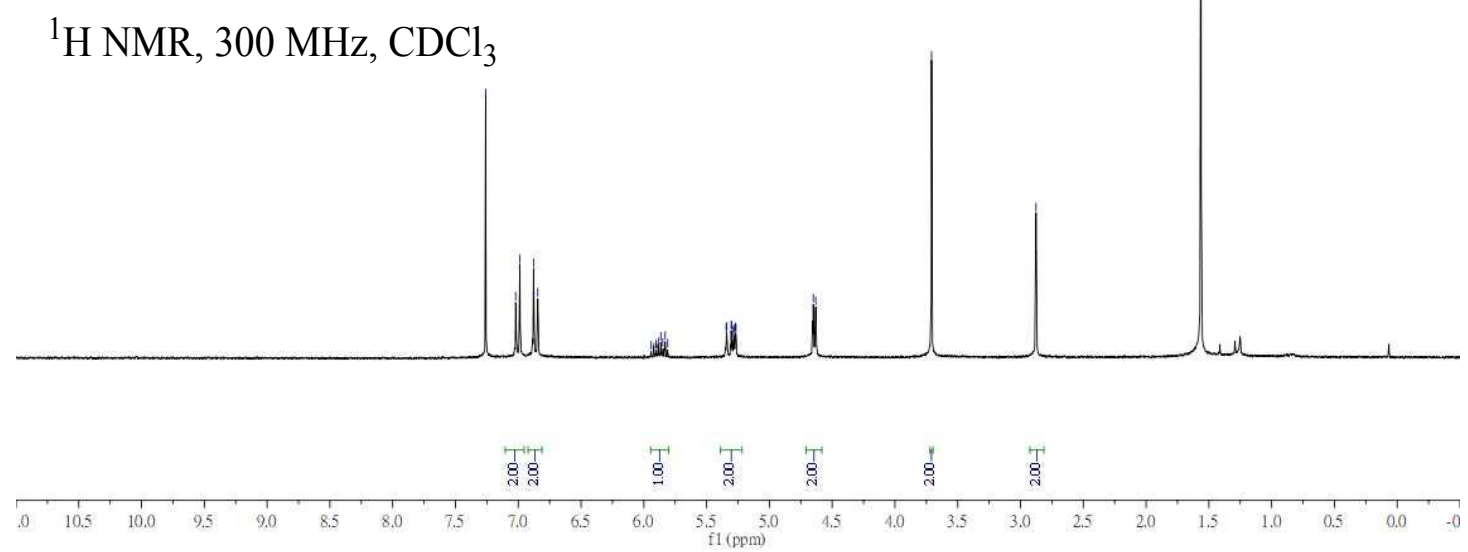

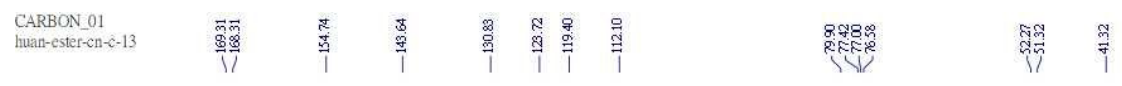<smiles>C=CCOC(=O)C1(CC(=O)OC)C=CC(=C(C#N)C#N)C=C1</smiles>

$1 \mathrm{i}$

${ }^{13} \mathrm{C}\left\{{ }^{1} \mathrm{H}\right\}$ NMR $75 \mathrm{MHz}, \mathrm{CDCl}{ }_{3}$

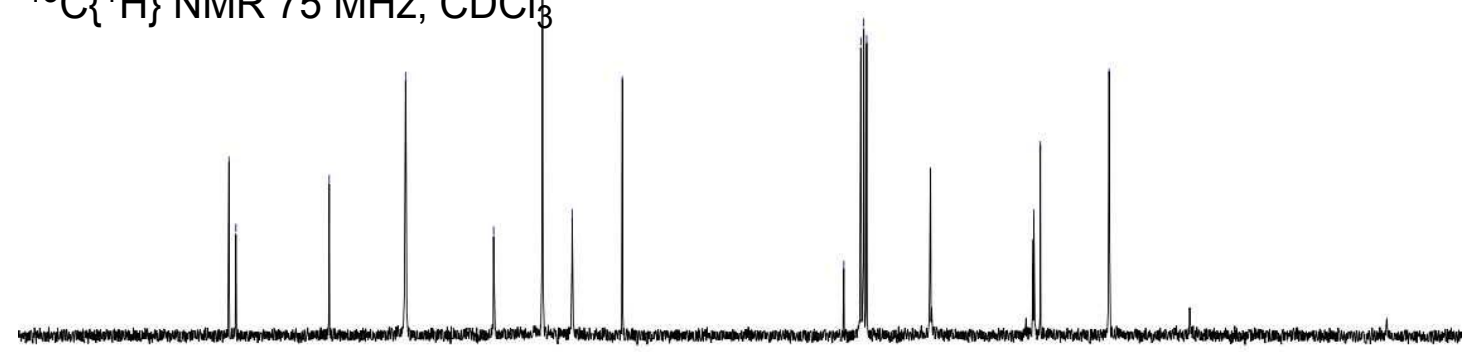




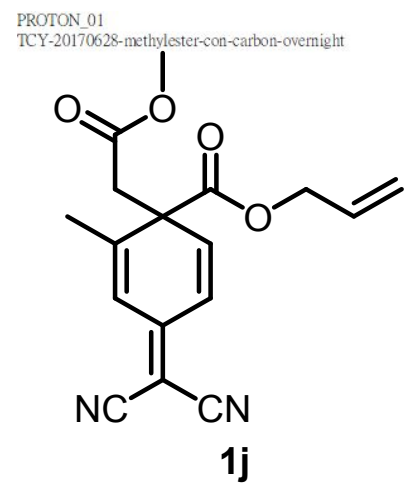

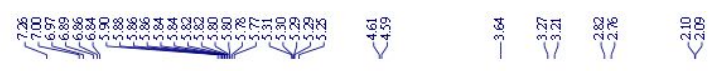

${ }^{1} \mathrm{H}$ NMR, $300 \mathrm{MHz}, \mathrm{CDCl}_{3}$
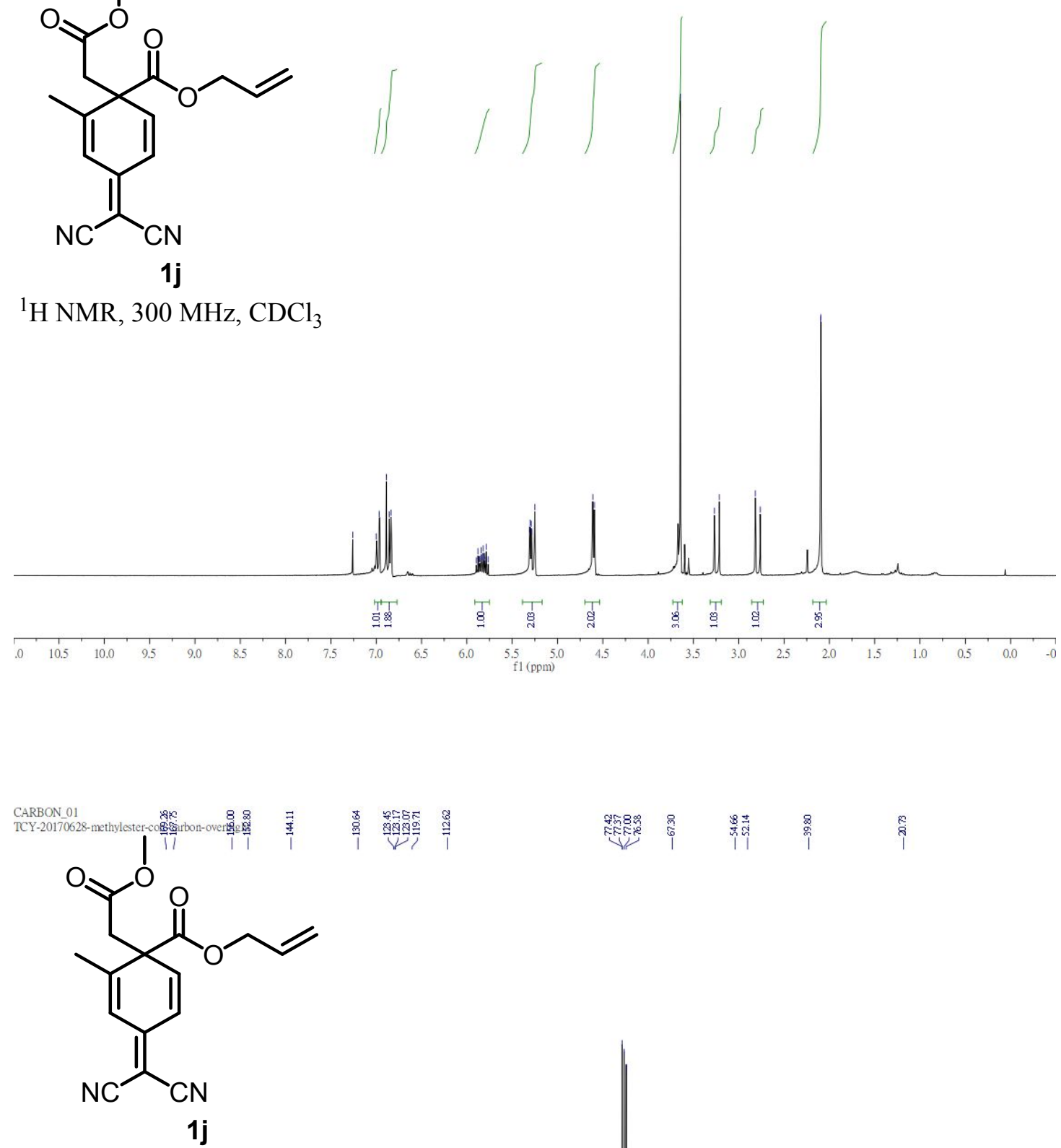

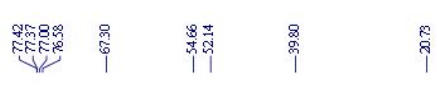

${ }^{13} \mathrm{C}\left\{{ }^{1} \mathrm{H}\right\}$ NMR $75 \mathrm{MHz}, \mathrm{CDCl}_{3}$

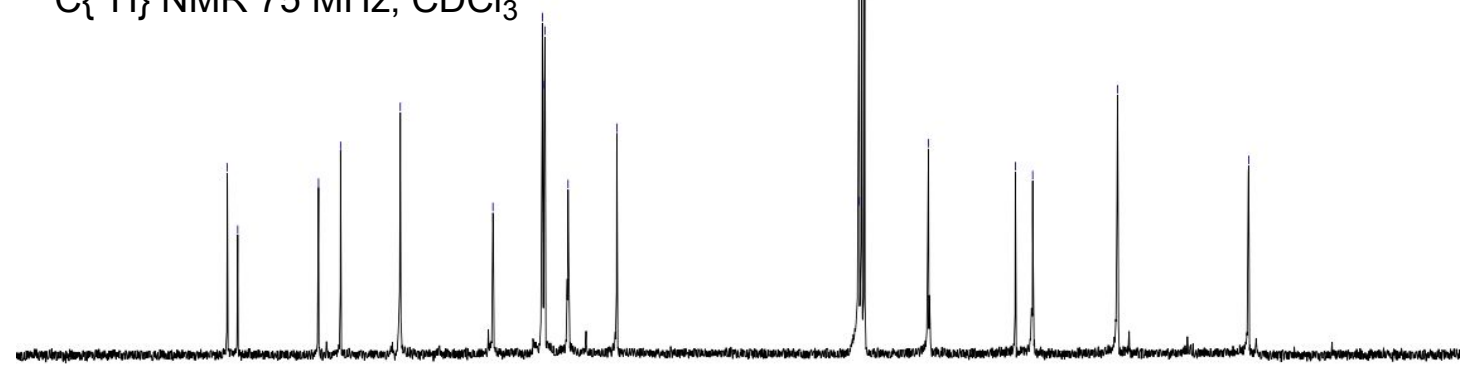




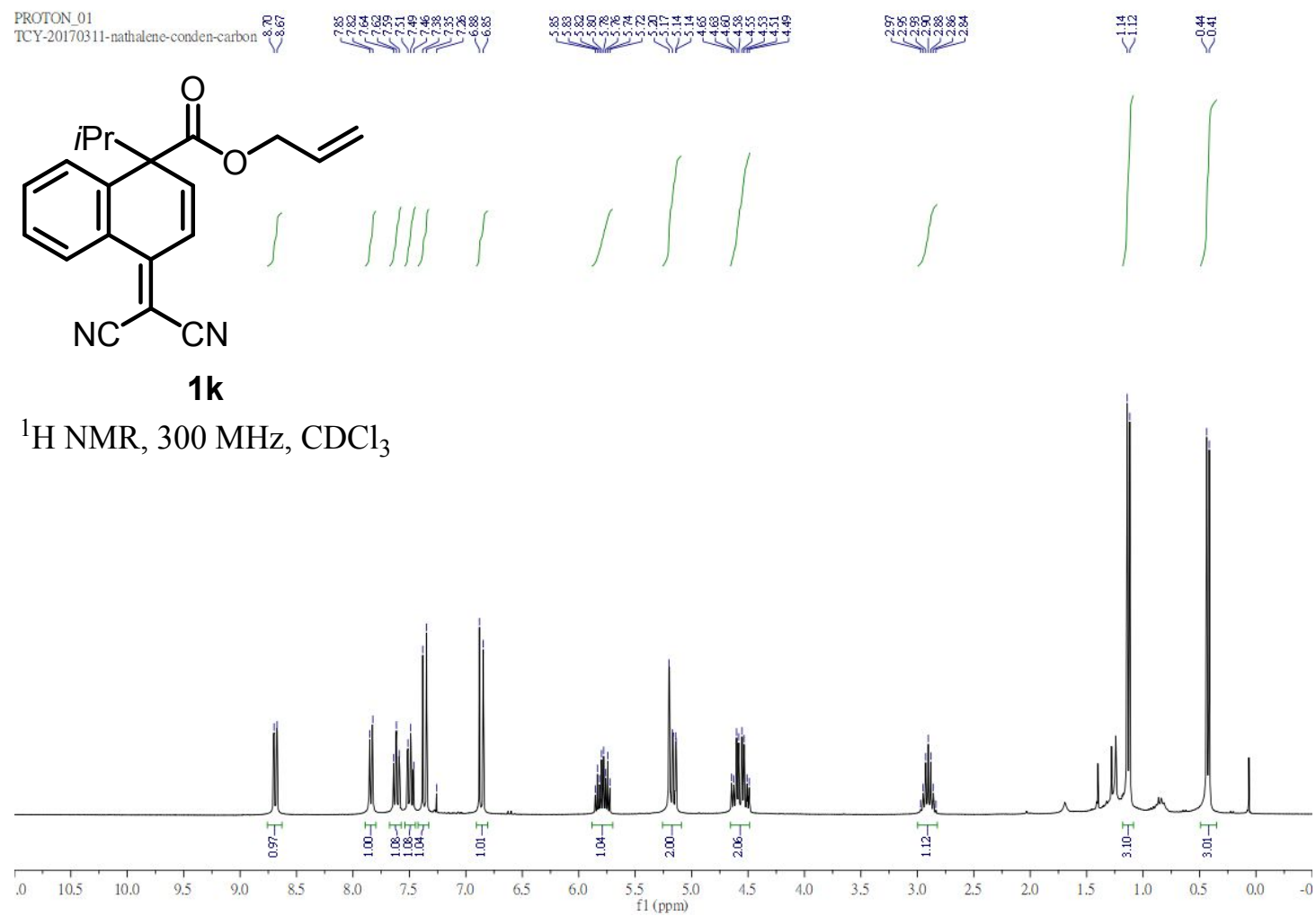

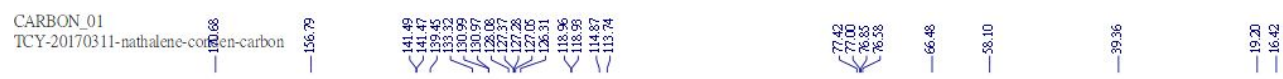

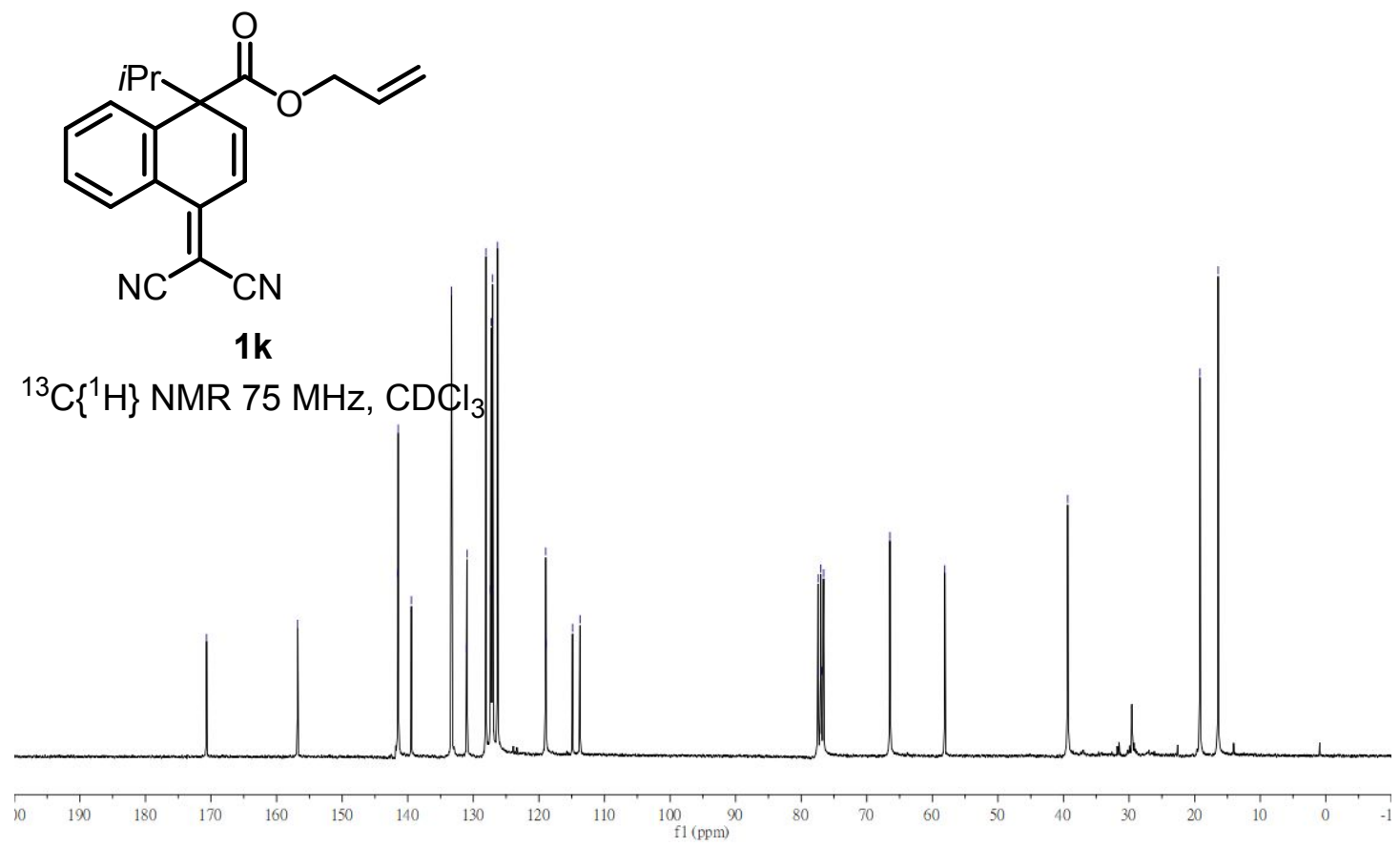


<smiles>C=CCOC(=O)C1(Cc2ccccc2)C=CC(=C(C#N)C#N)C=C1</smiles>

1 I

${ }^{1} \mathrm{H} \mathrm{NMR}, 300 \mathrm{MHz}, \mathrm{CDCl}_{3}$
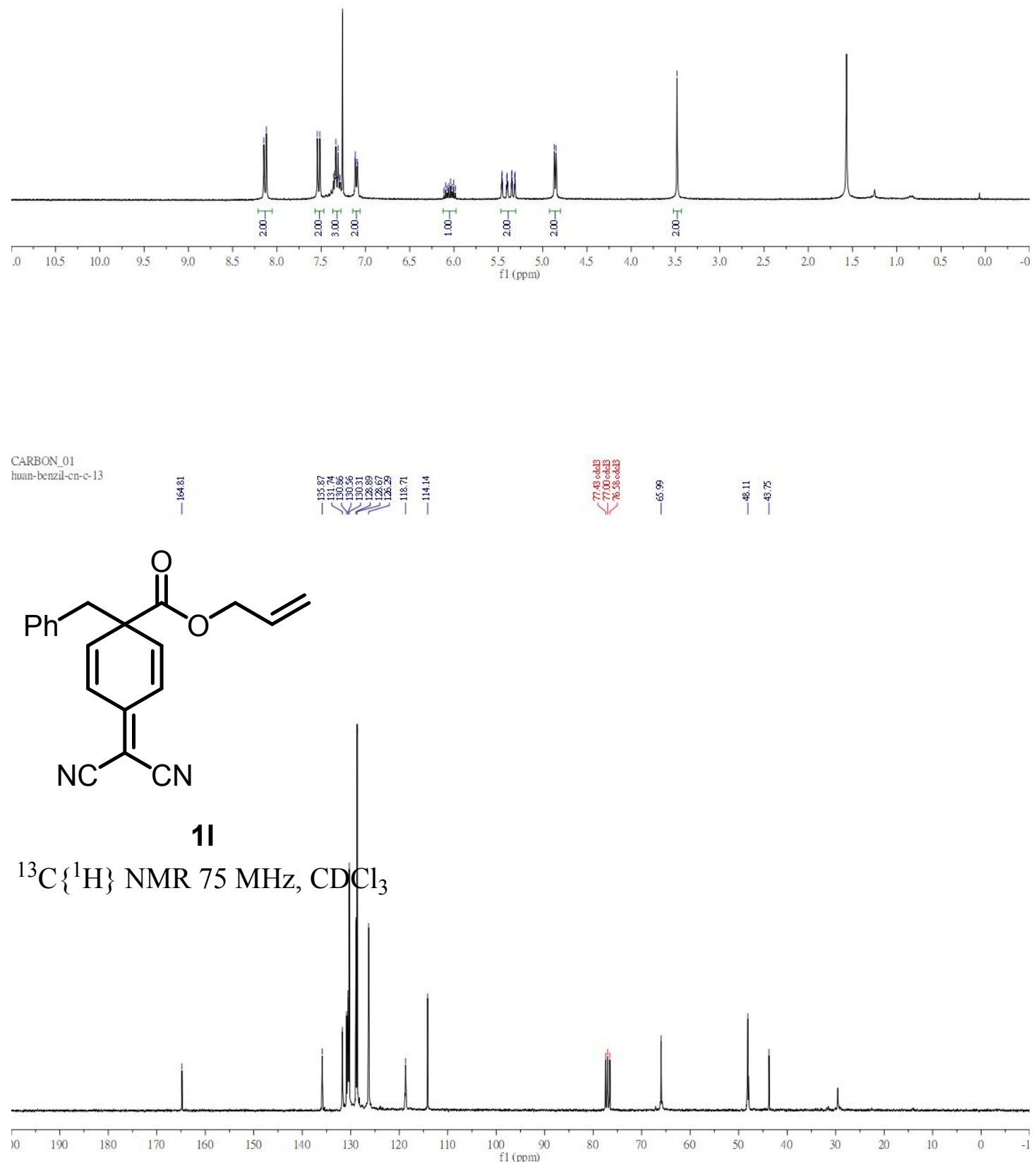


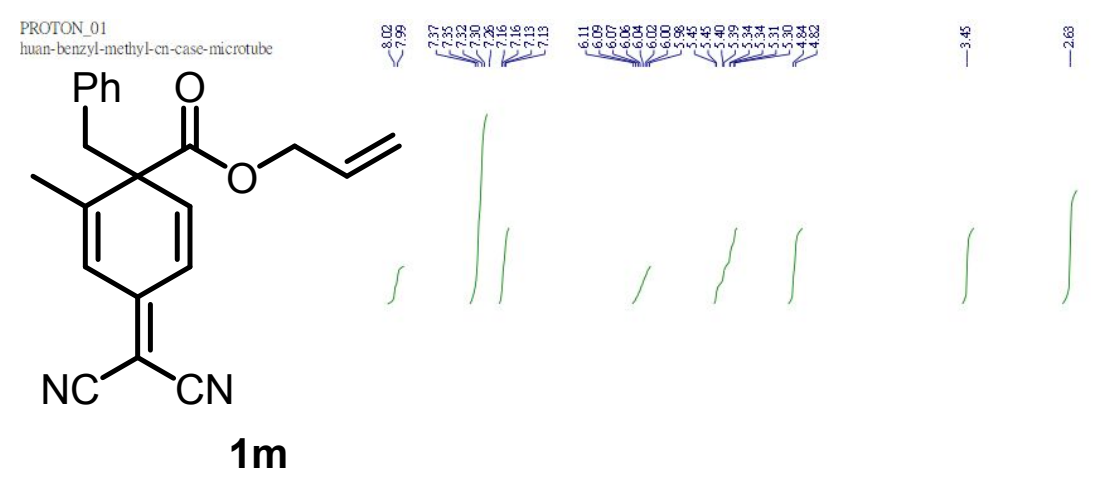

${ }^{1} \mathrm{H} \mathrm{NMR}, 300 \mathrm{MHz}, \mathrm{CDCl}_{3}$
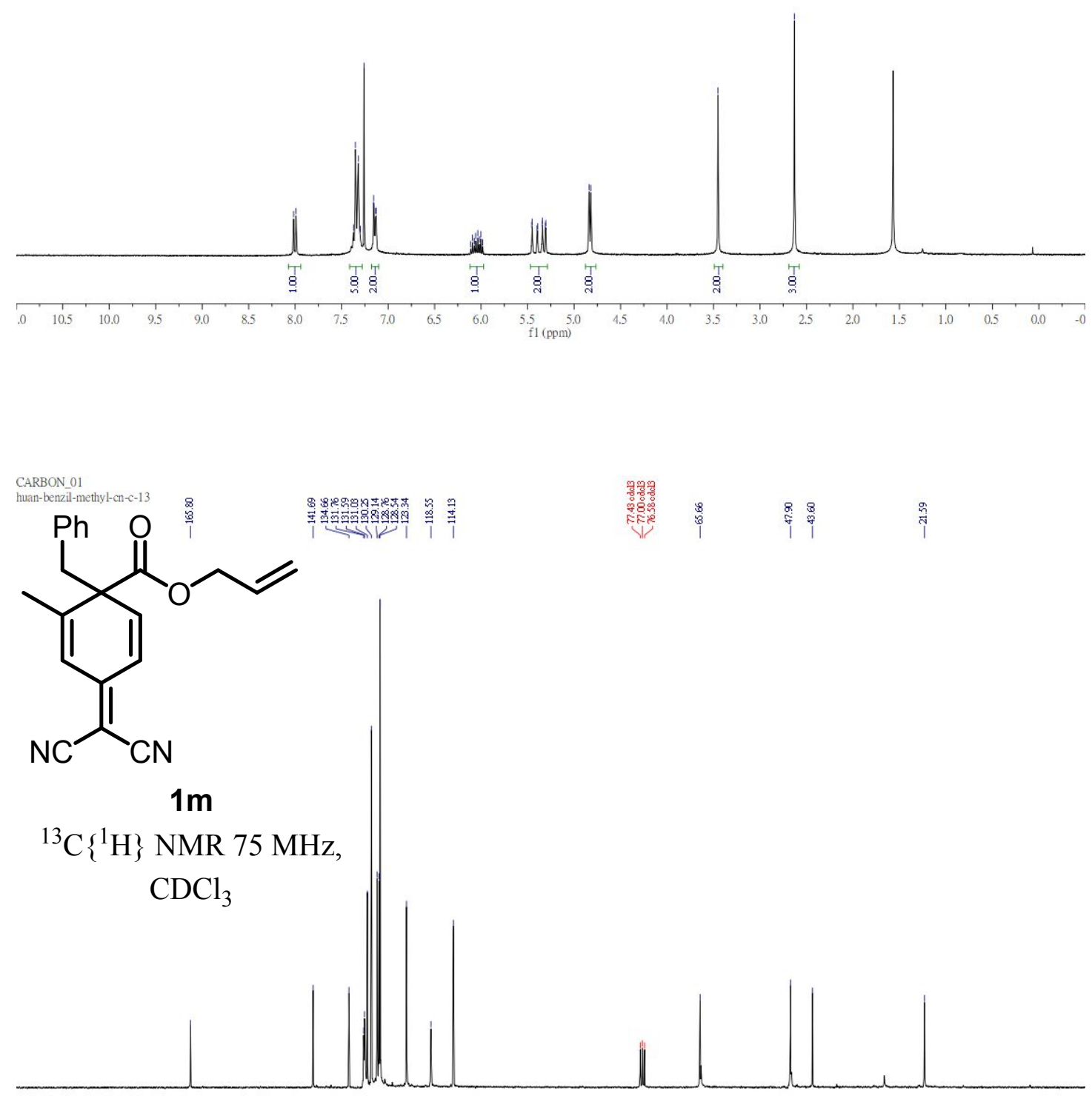


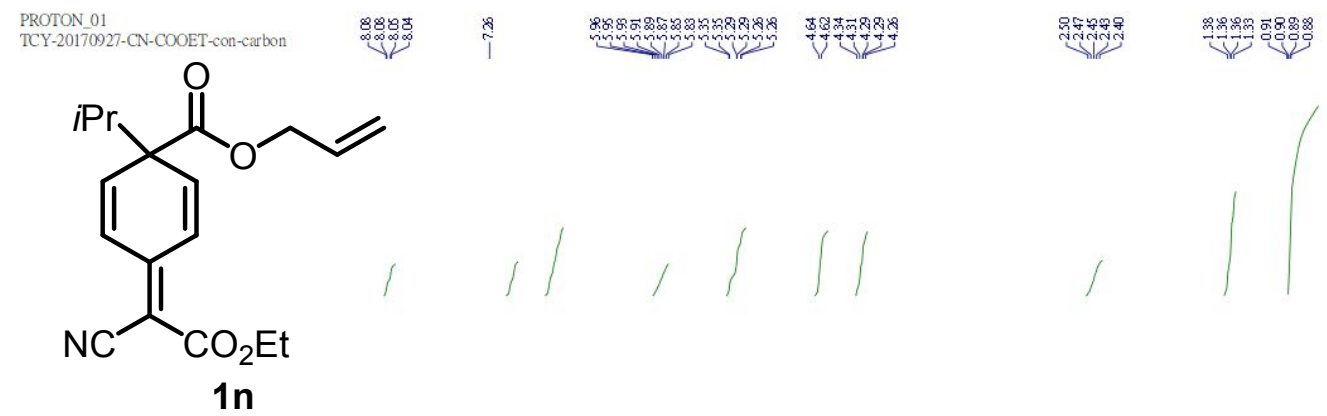

${ }^{1} \mathrm{H} \mathrm{NMR}, 300 \mathrm{MHz}, \mathrm{CDCl}_{3}$

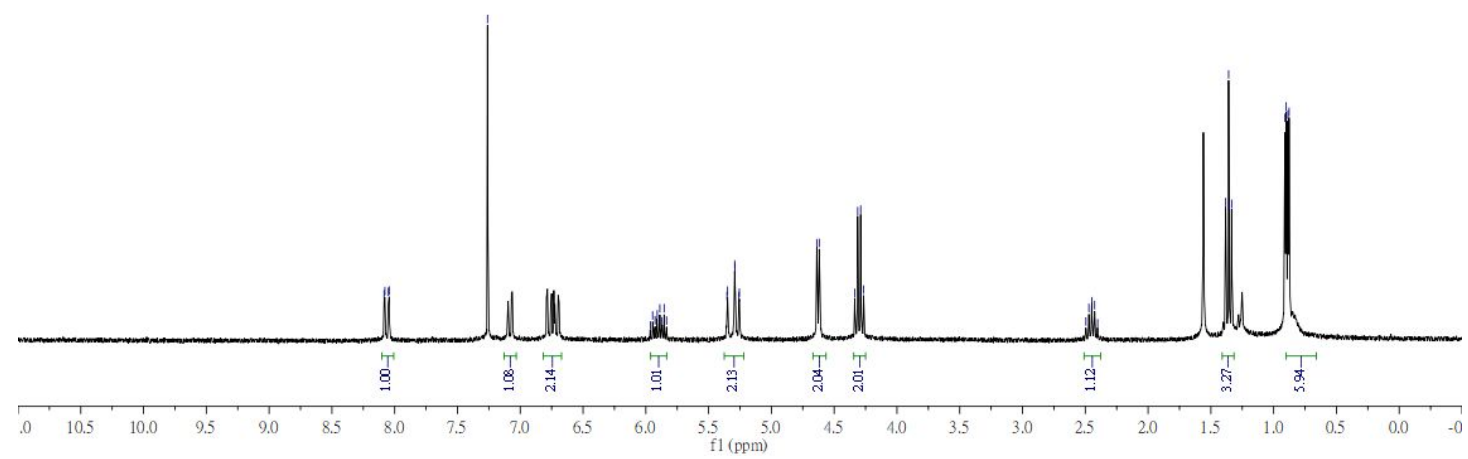

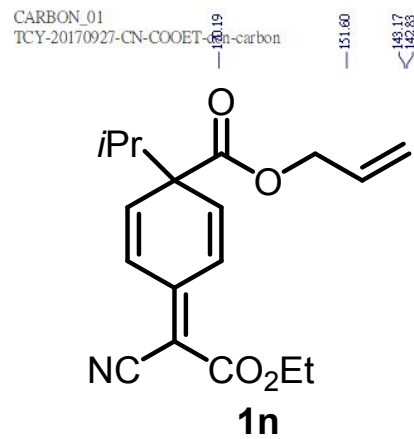

${ }^{13} \mathrm{C}\left\{{ }^{1} \mathrm{H}\right\}$ NMR $75 \mathrm{MHz}, \mathrm{CDCl}_{3}$ 

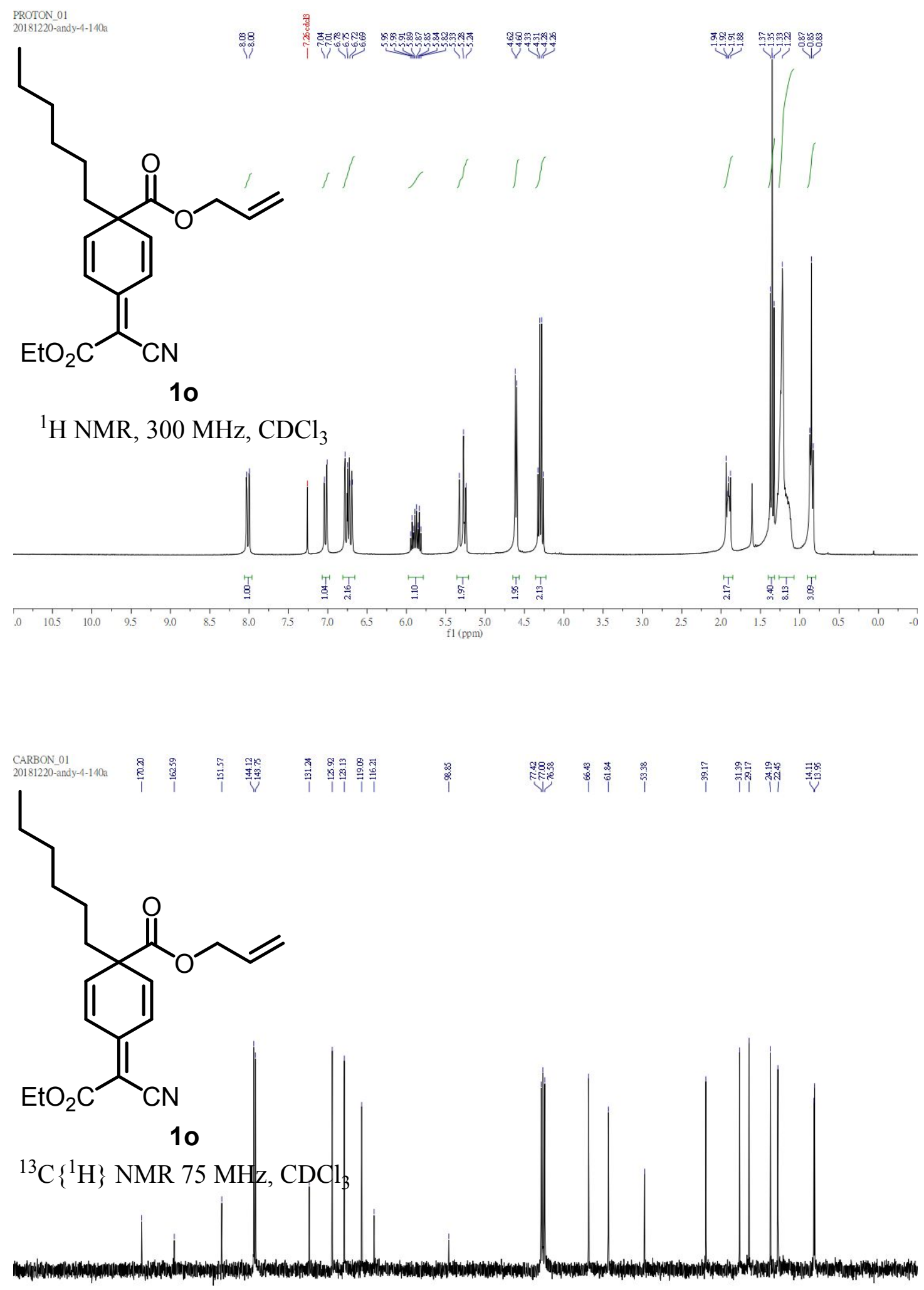

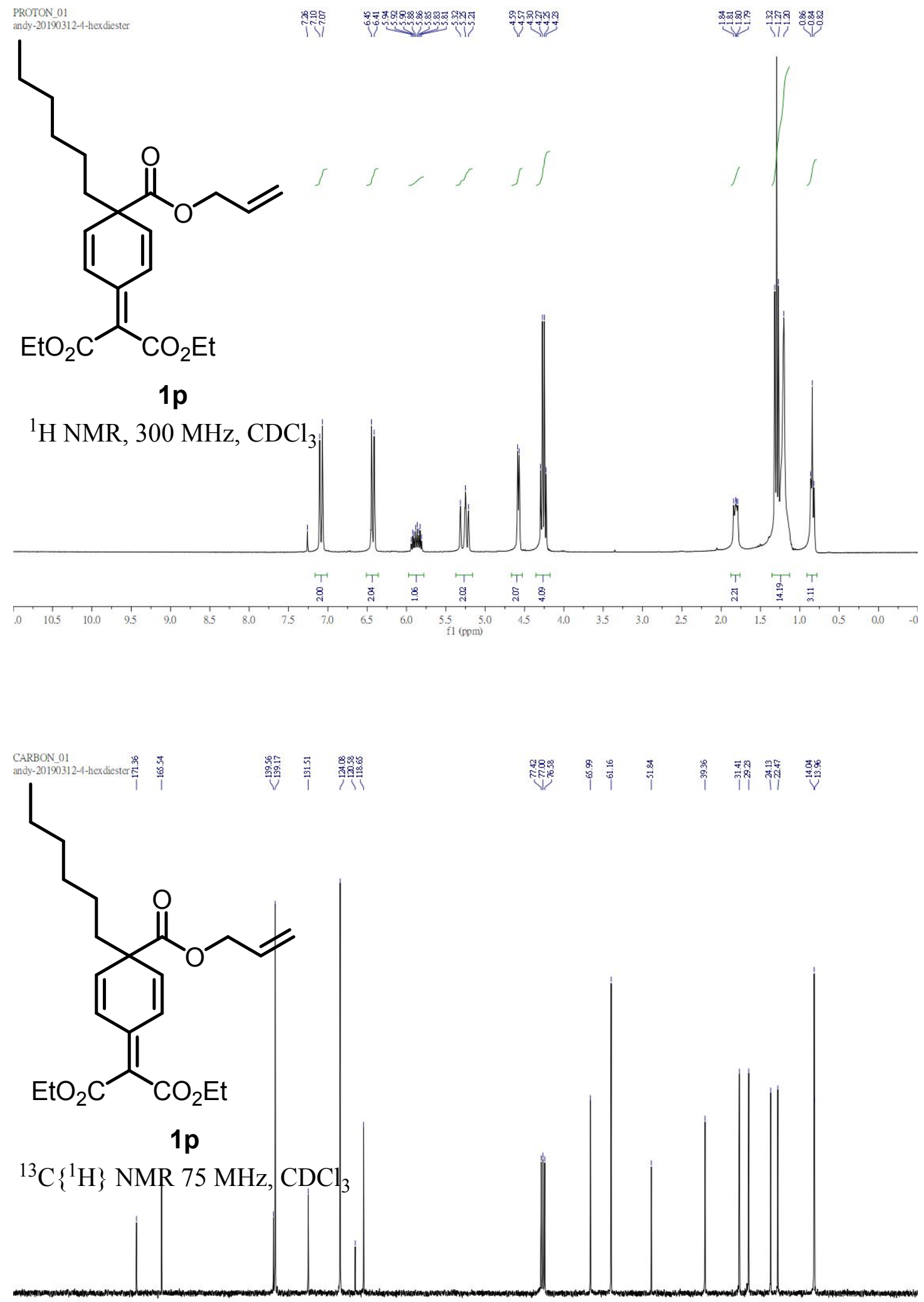

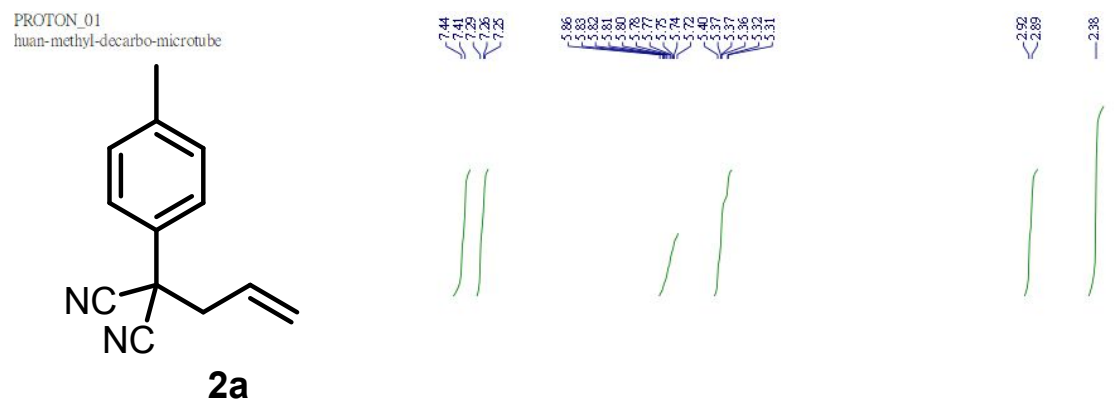

${ }^{1} \mathrm{H} \mathrm{NMR}, 300 \mathrm{MHz}, \mathrm{CDCl}_{3}$
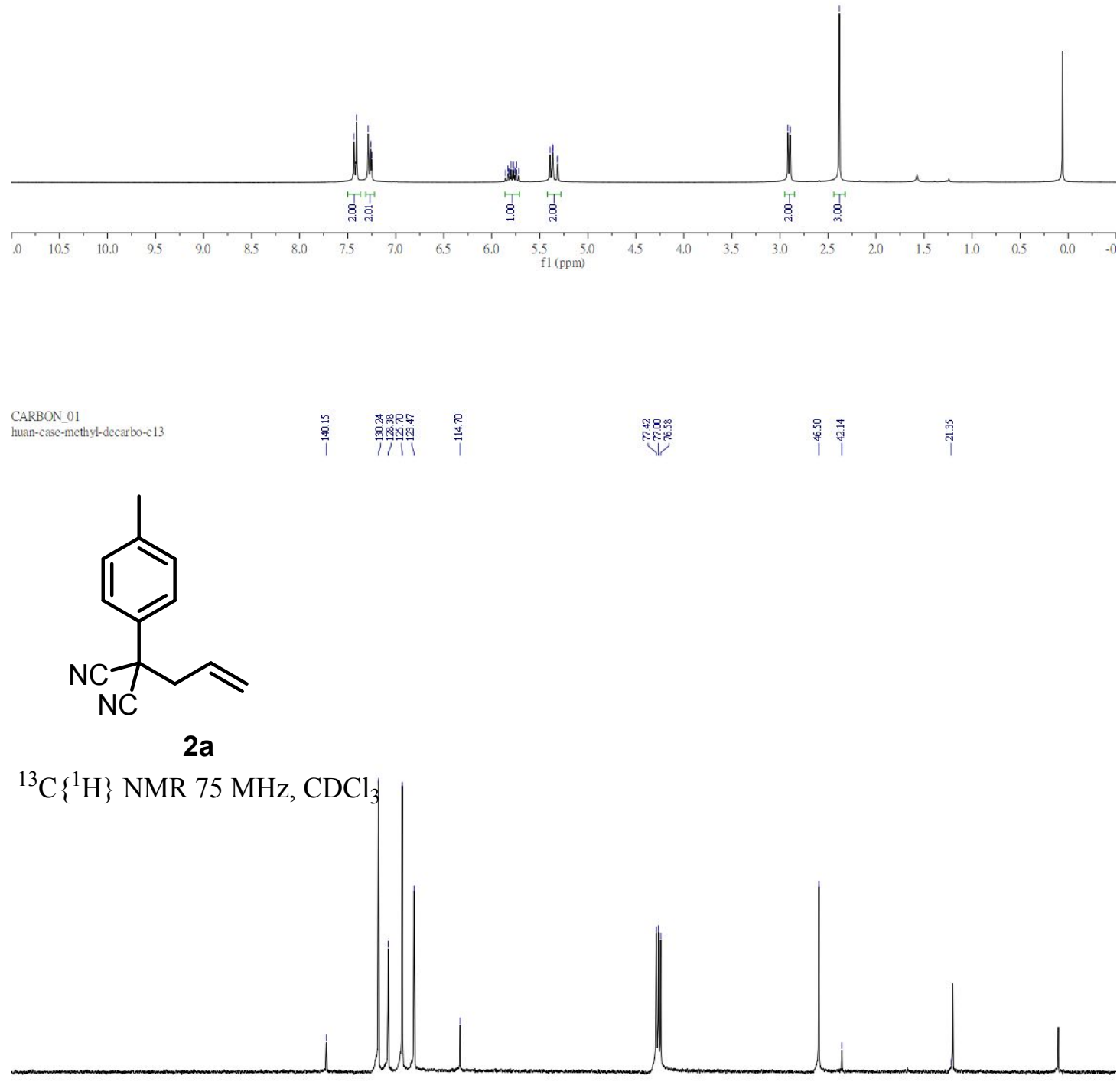

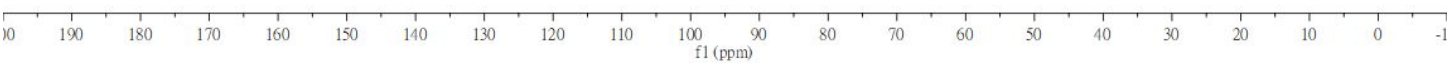


PROTON 02
TCY-2017022<smiles>C=CCC(C#N)(C#N)c1ccc(CC(C)C)cc1</smiles>

2b

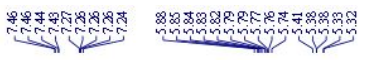

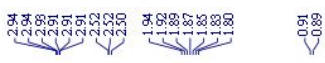
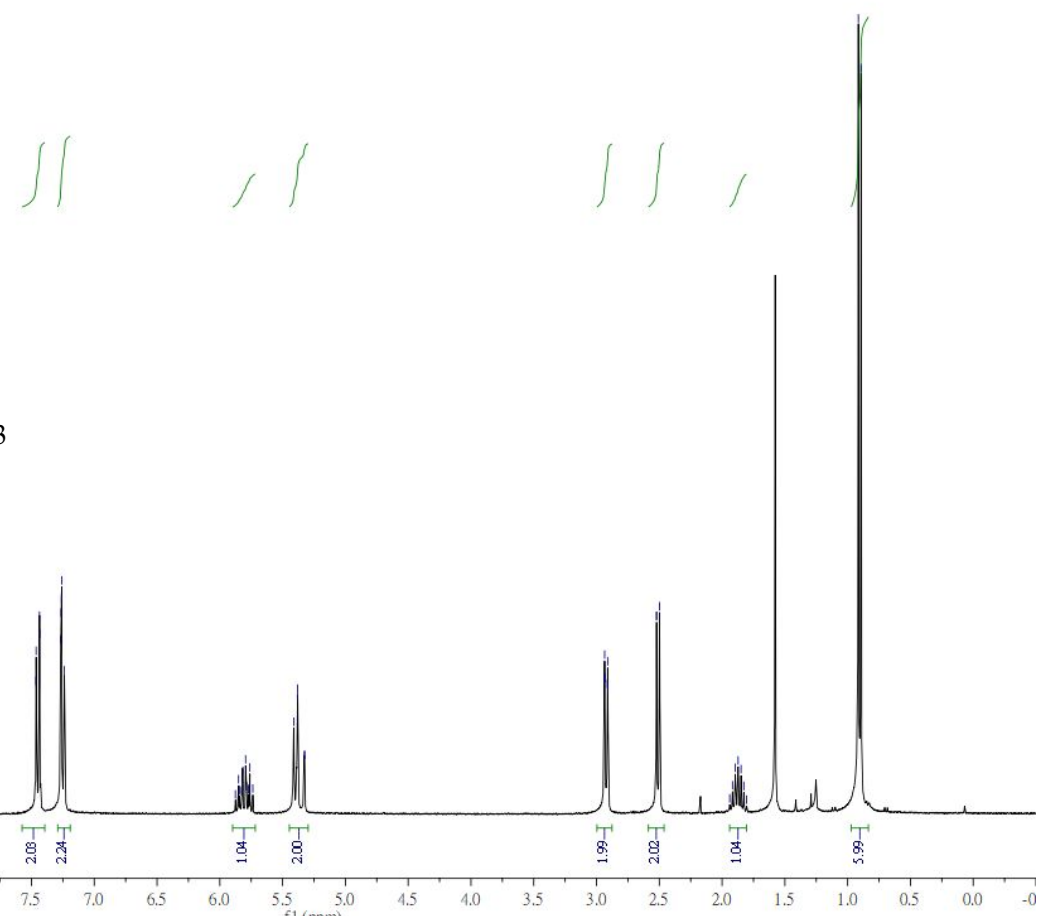

CARBON 01

TCY-20170221-se-butyl-migration-carbon

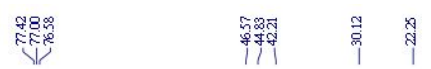<smiles>C=CCC(C#N)(C#N)c1ccc(CC(C)C)cc1</smiles>

2b

${ }^{13} \mathrm{C}\left\{{ }^{1} \mathrm{H}\right\}$ NMR $75 \mathrm{MHz}, \mathrm{CDCl}_{3}$

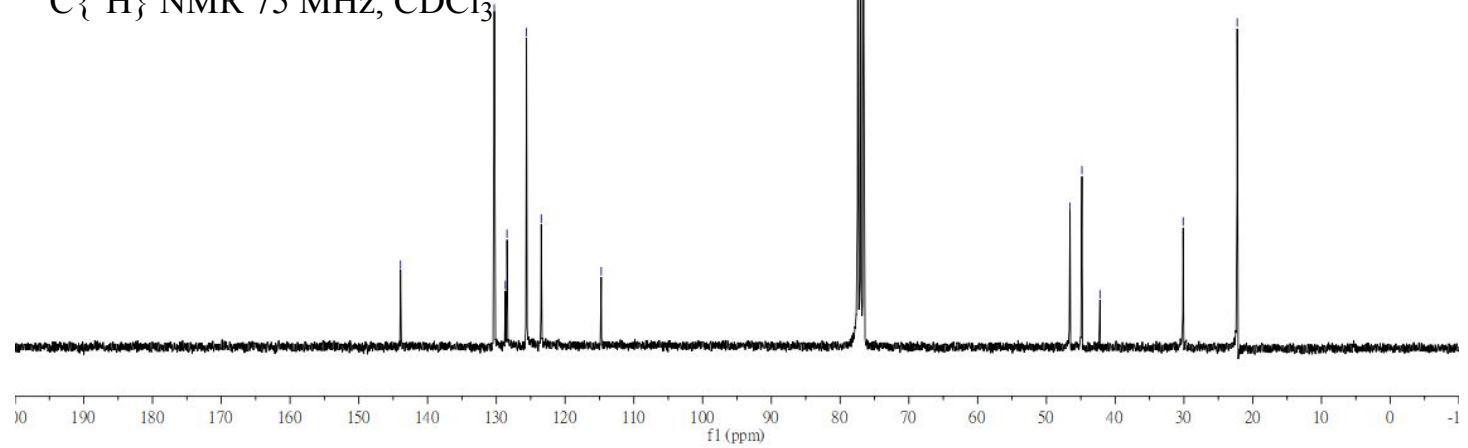



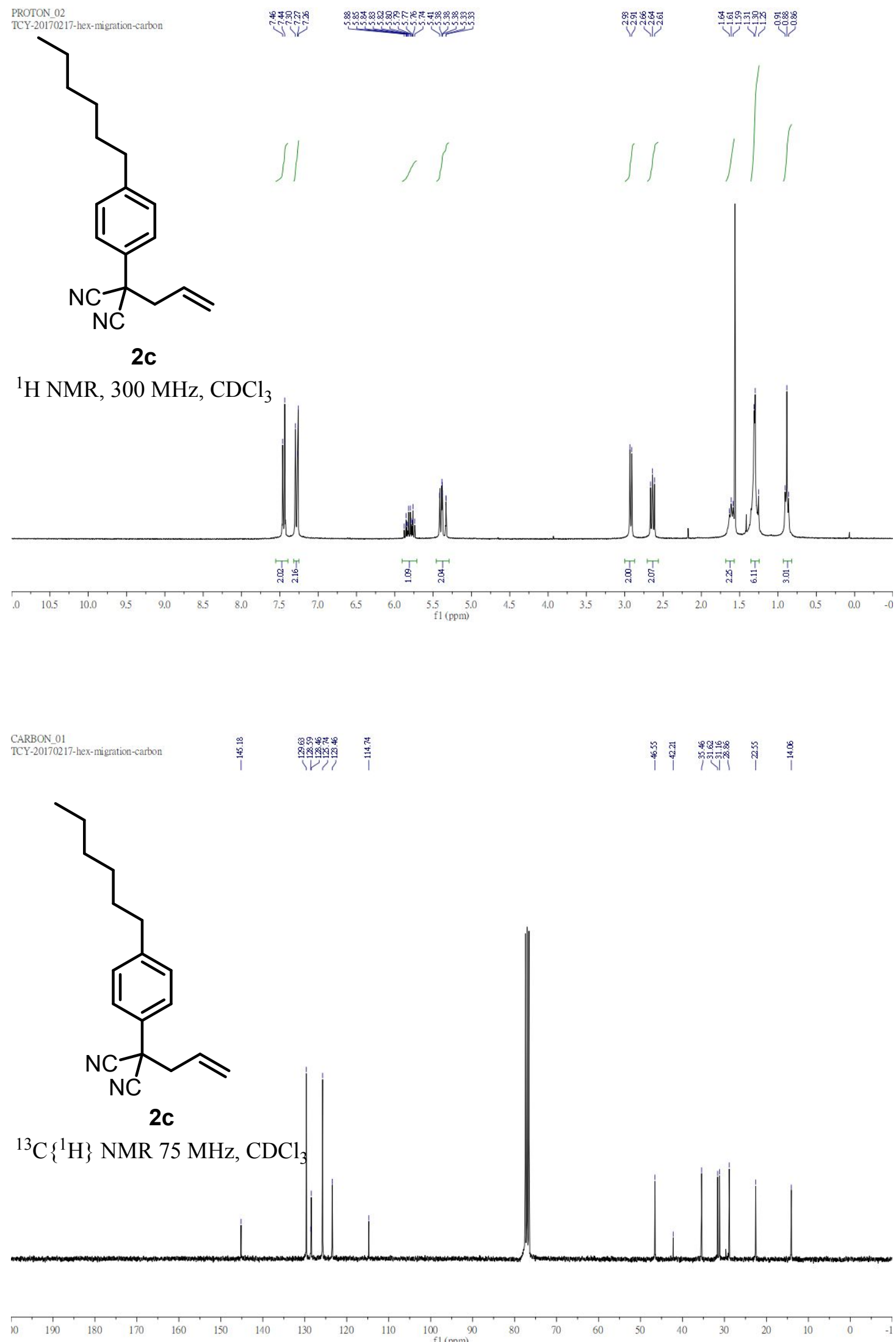


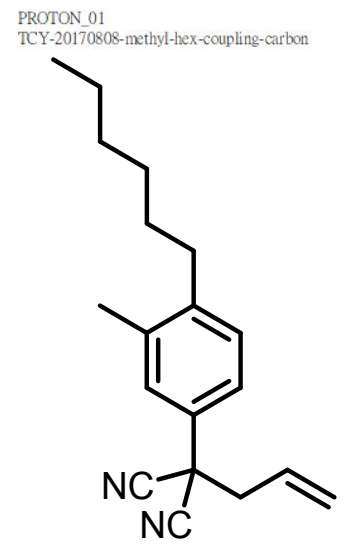

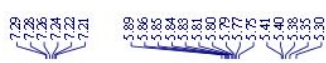

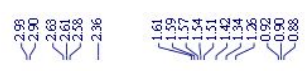

2d

${ }^{1} \mathrm{H} \mathrm{NMR}, 300 \mathrm{MHz}, \mathrm{CDCl}_{3}$
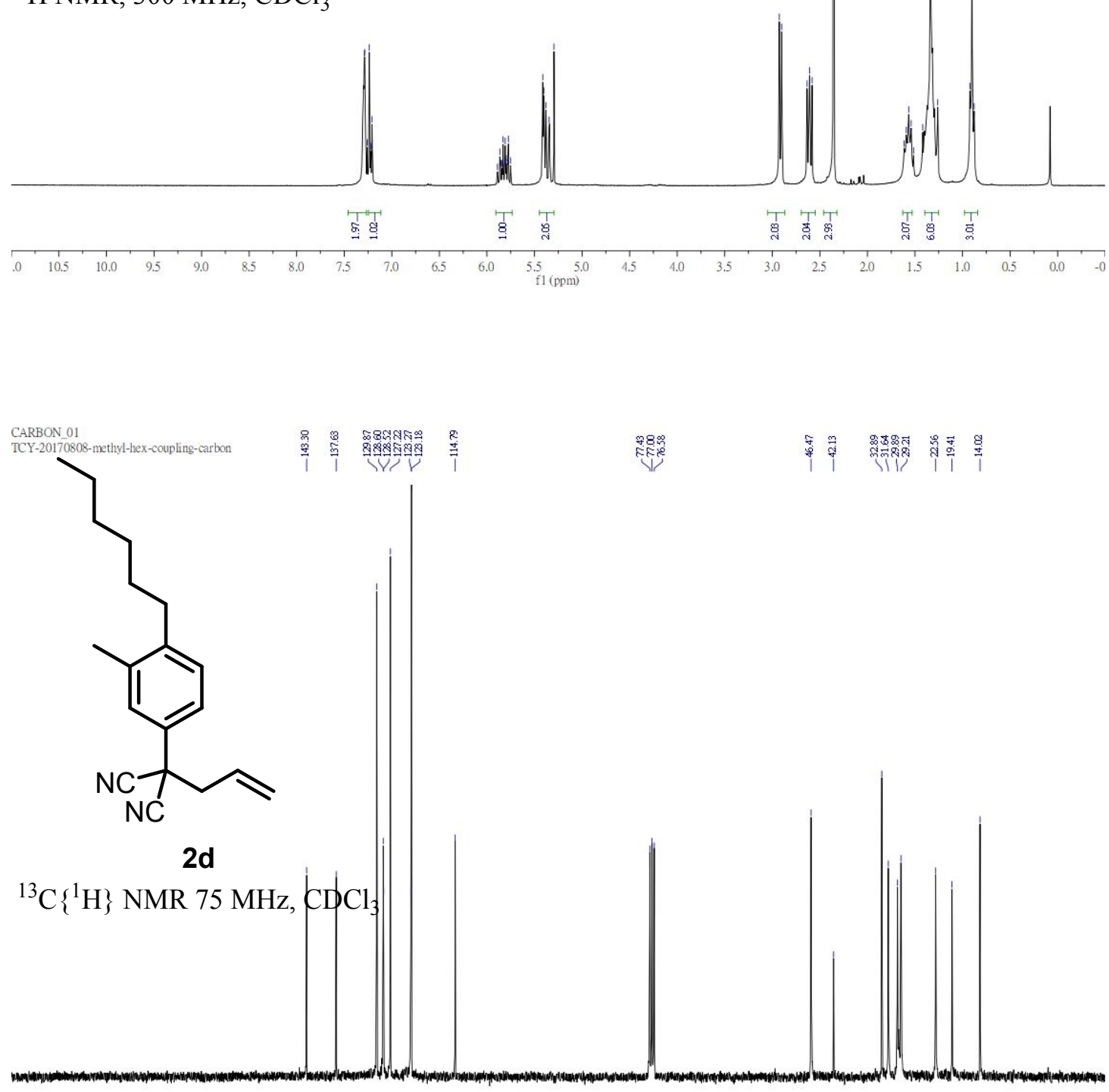

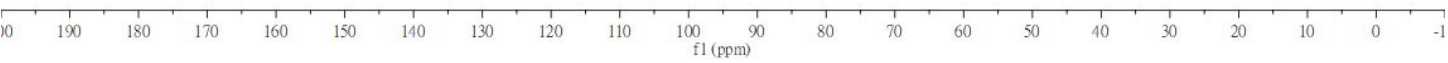



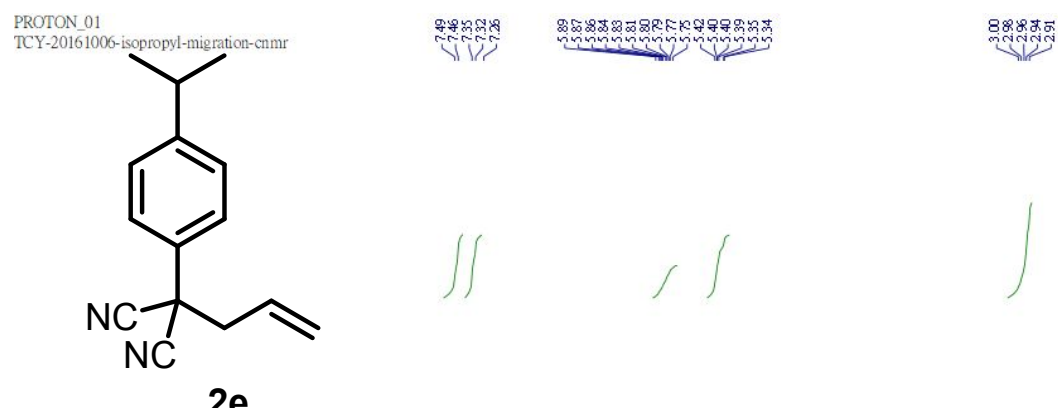

${ }^{1} \mathrm{H} \mathrm{NMR}, 300 \mathrm{MHz}, \mathrm{CDCl}_{3}$
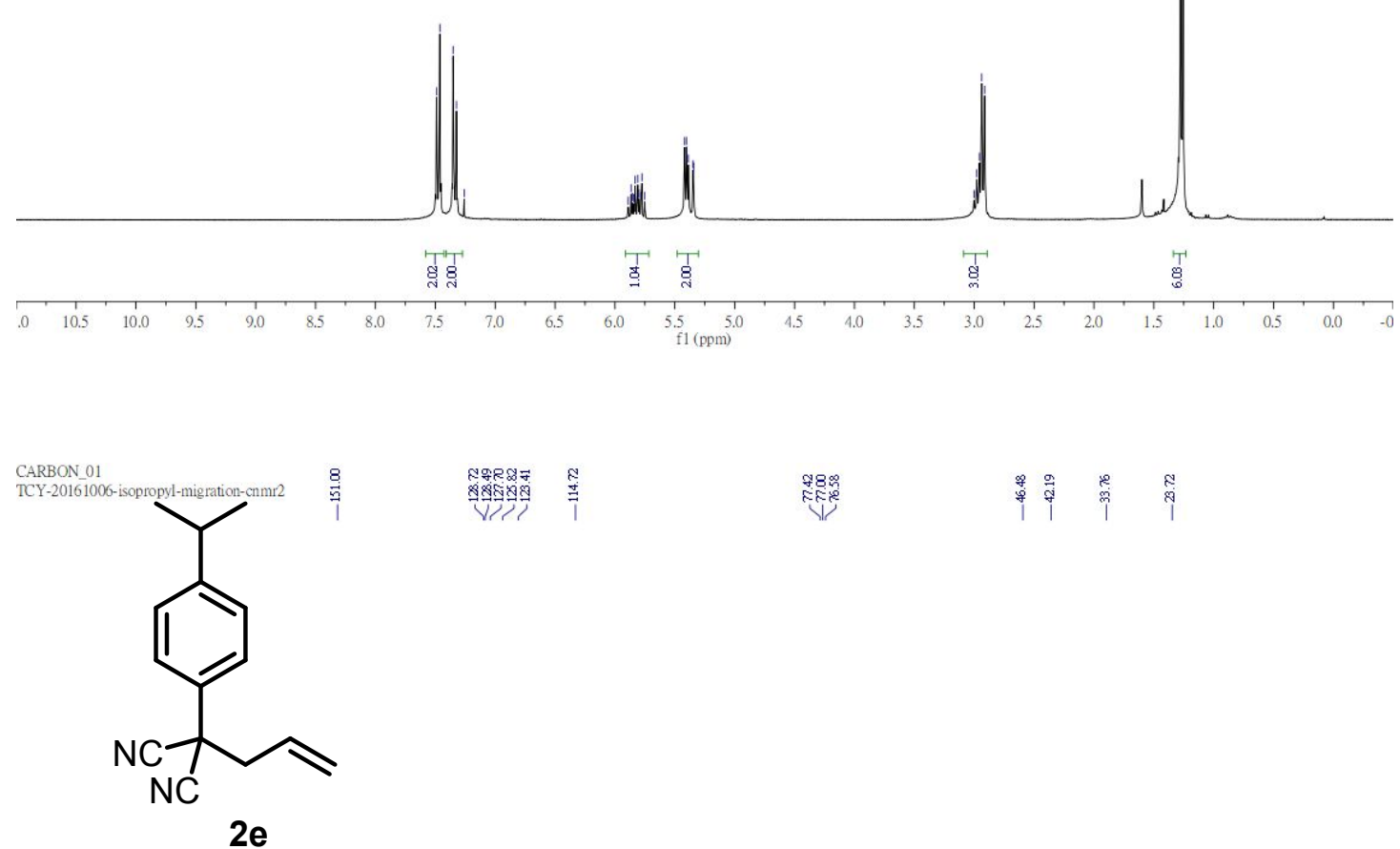

${ }^{13} \mathrm{C}\left\{{ }^{1} \mathrm{H}\right\}$ NMR $75 \mathrm{MHz}, \mathrm{CDCl}_{3}$
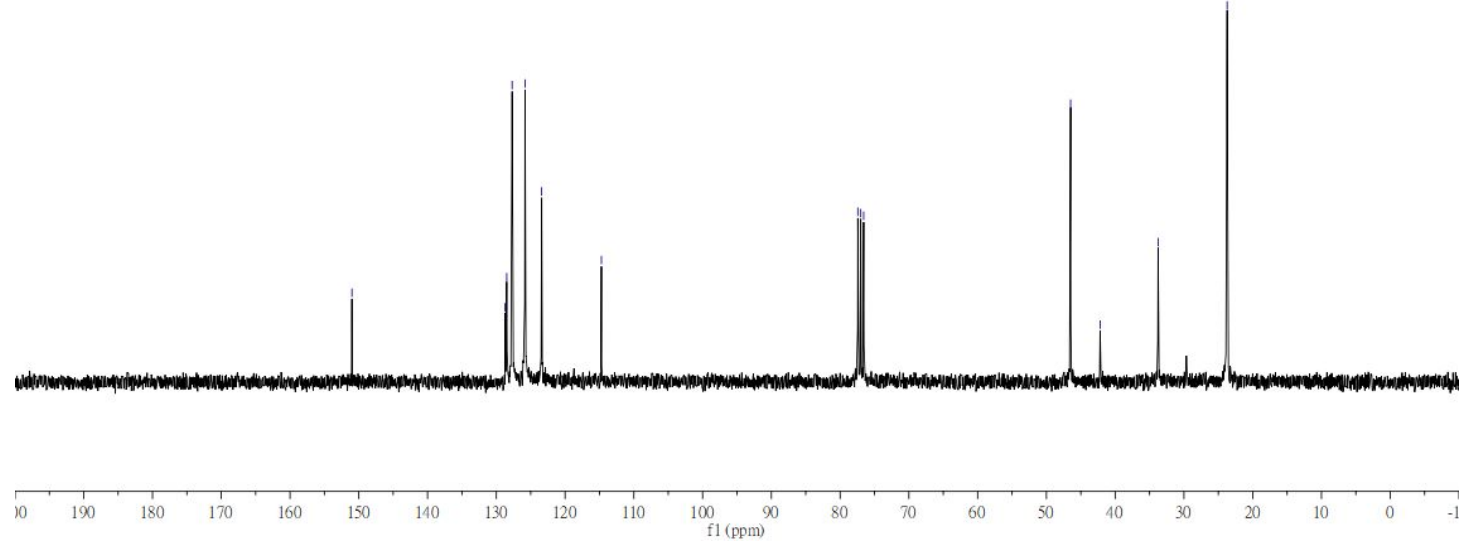
PROTON_01<smiles>C=CCC(C)(C#N)c1ccc(C(C)C)c(C)c1</smiles>

$2 f$

${ }^{1} \mathrm{H} \mathrm{NMR}, 300 \mathrm{MHz}, \mathrm{CDCl}_{3}$

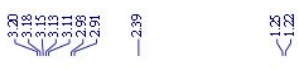

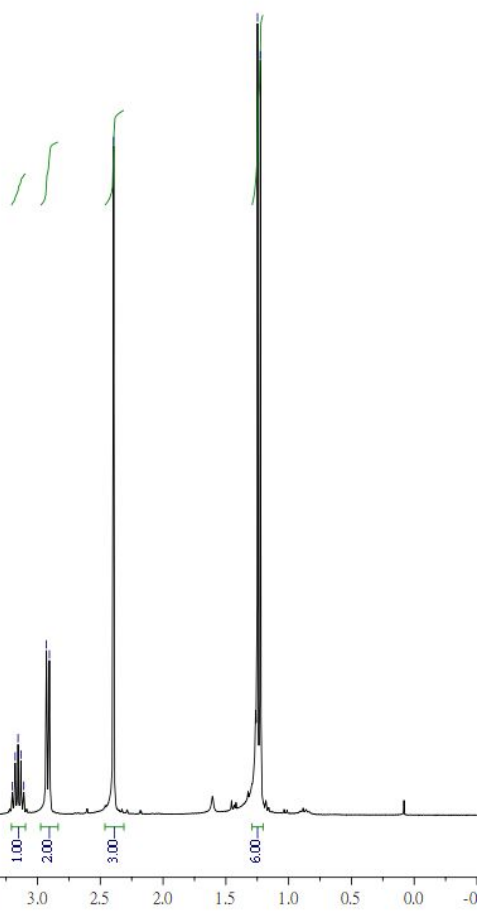

CARBON_01

huan-isopropyl-decarbo-c 13

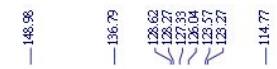

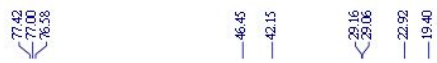<smiles>C=CCC(C)(C#N)c1ccc(C(C)C)c(C)c1</smiles>

$2 f$

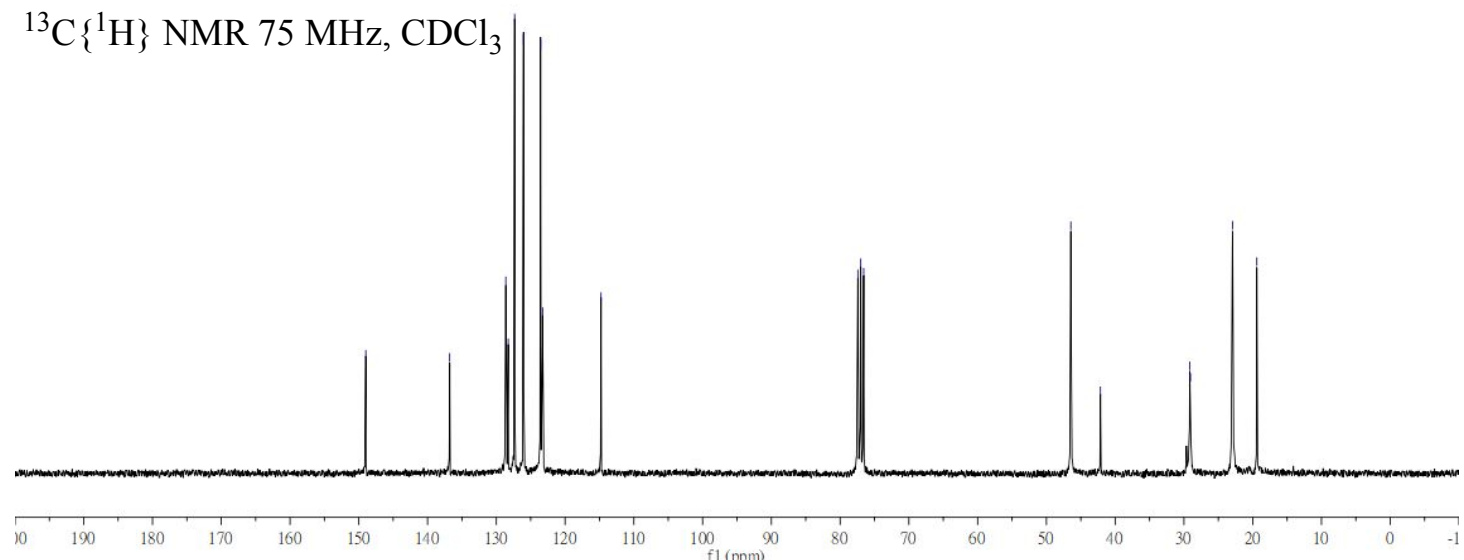




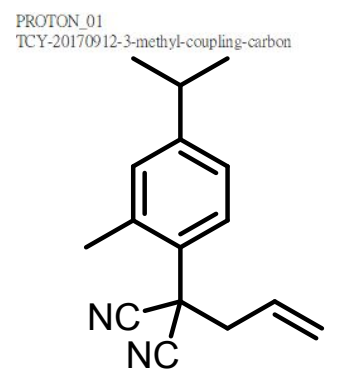

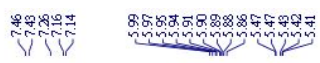

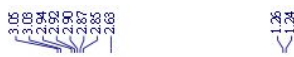

$2 \mathrm{~g}$

${ }^{1} \mathrm{H}$ NMR, $300 \mathrm{MHz}, \mathrm{CDCl}_{3}$
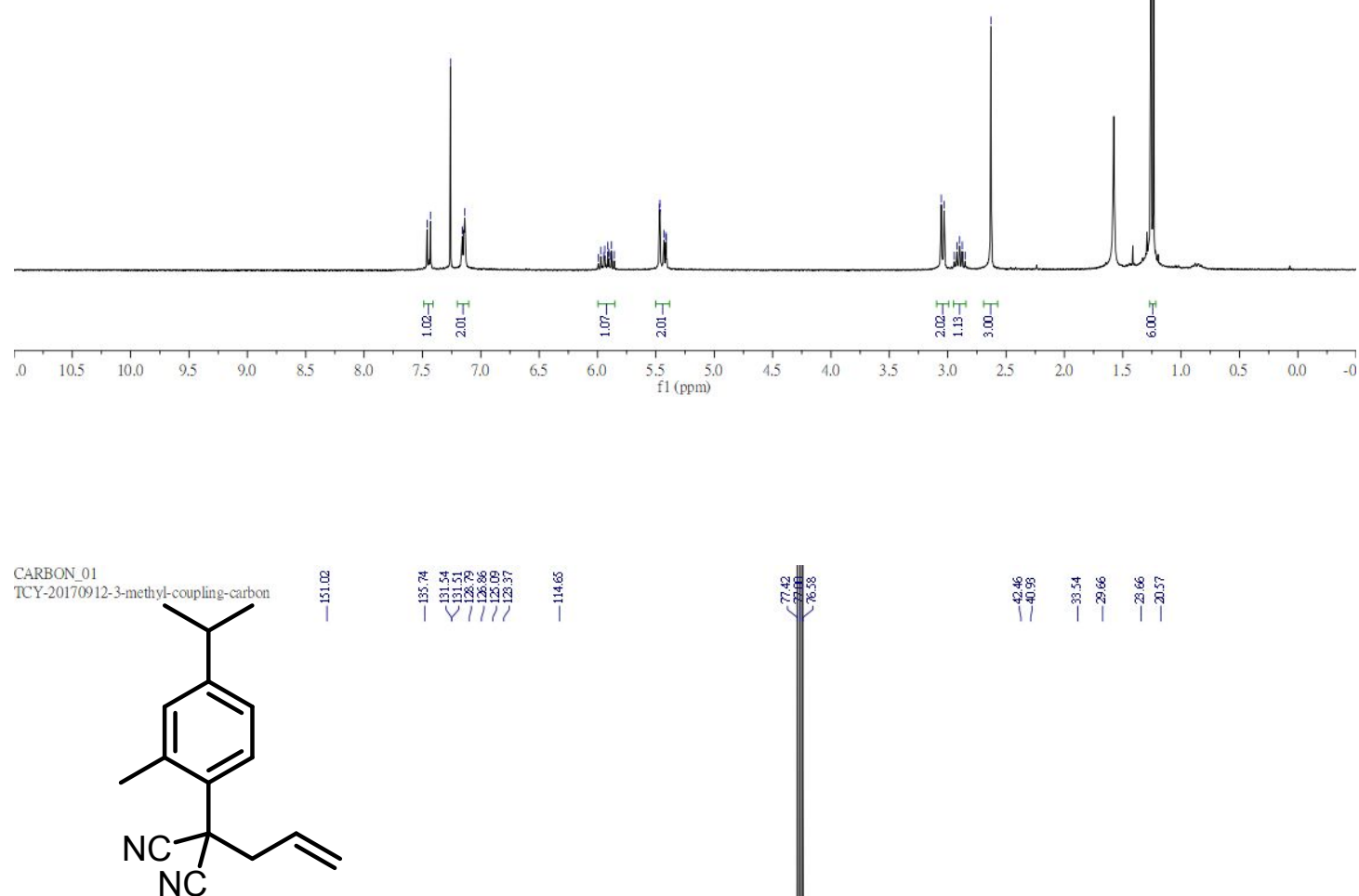

2g

${ }^{13} \mathrm{C}\left\{{ }^{1} \mathrm{H}\right\}$ NMR $75 \mathrm{MHz}, \mathrm{CDCl}_{3}$

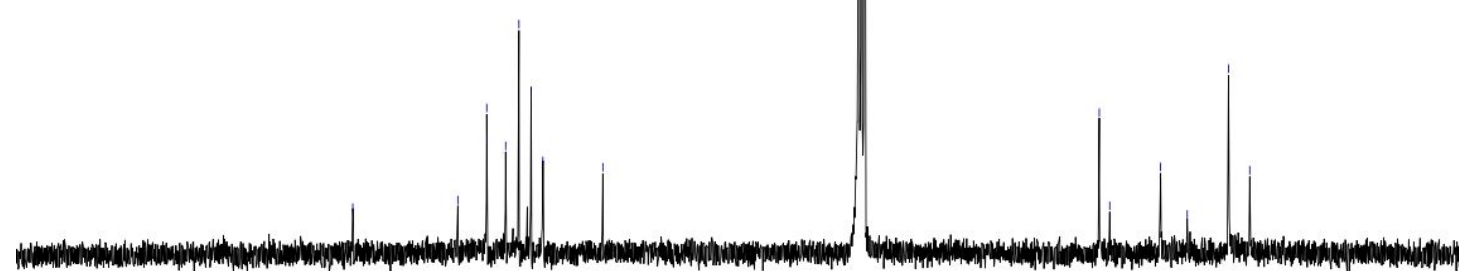

$\begin{array}{llllllllll}190 & 180 & 170 & 160 & 150 & 140 & 130 & 120 & 110 & 100 \\ \mathrm{f} 1(\mathrm{ppm}) & 100\end{array}$ 


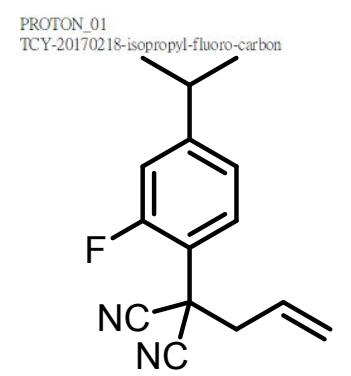

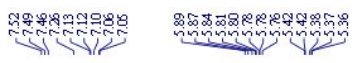

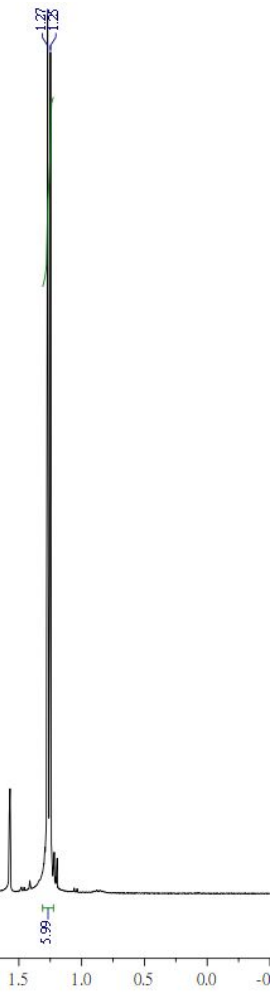

${ }^{1} \mathrm{H}$ NMR, $300 \mathrm{MHz}, \mathrm{CDCl}_{3}$

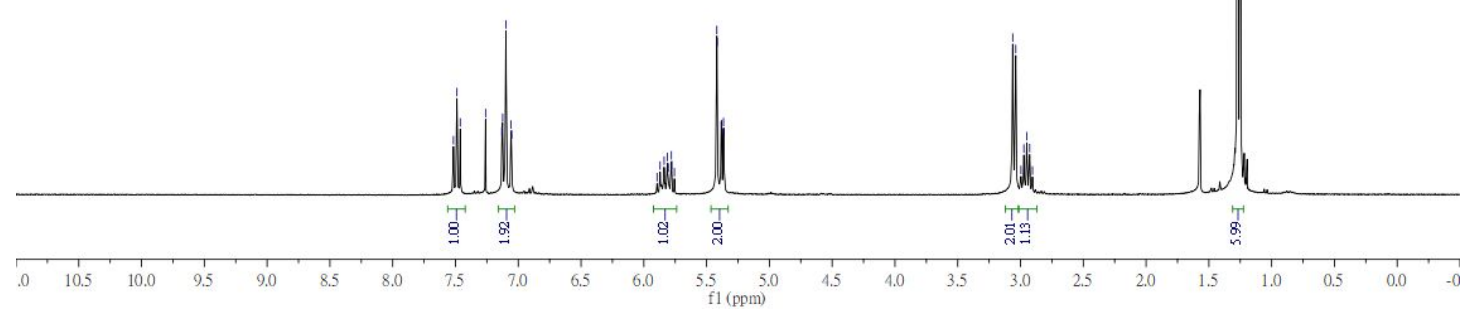

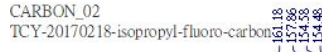

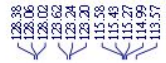

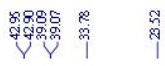<smiles>C=CCC(C)(C#N)c1ccc(C(C)C)cc1F</smiles>

$2 \mathrm{~h}$

${ }^{13} \mathrm{C}\left\{{ }^{1} \mathrm{H}\right\}$ NMR $75 \mathrm{MHz}, \mathrm{CDCl}_{3}$

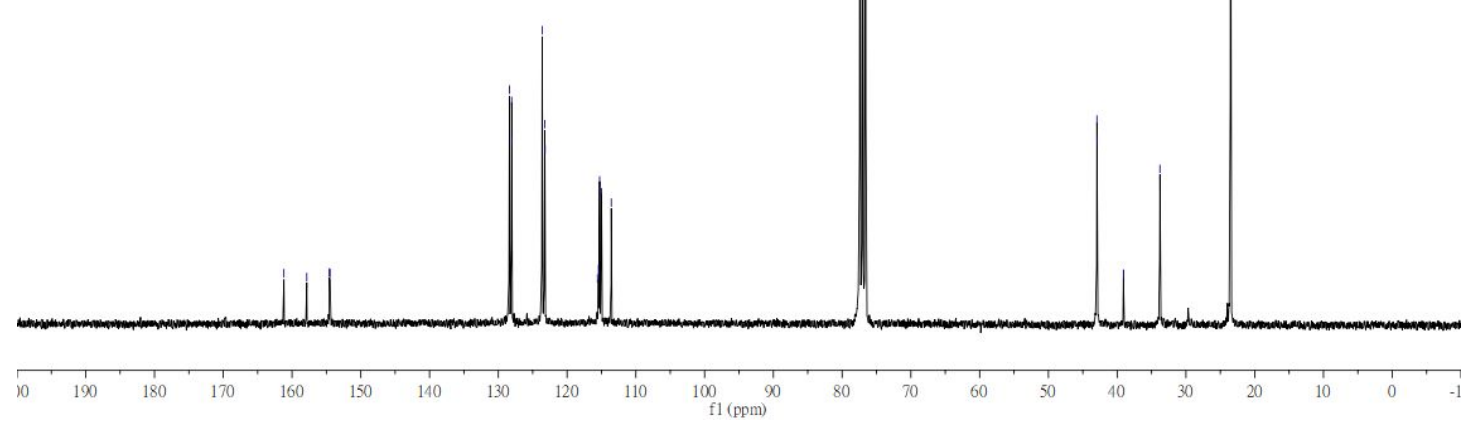


FLUORINE 01
STANDARD FLUORINE PARAMETERS<smiles>C=CCC(C)(C#N)c1ccc(C(C)C)cc1F</smiles>

2h

${ }^{19} \mathrm{~F} \mathrm{NMR,} 282 \mathrm{MHz}, \mathrm{CDCl}_{3}$

\begin{tabular}{llllllllllllllllllllll}
\hline 0 & 0 & -10 & -20 & -30 & -40 & -50 & -60 & -70 & -80 & -90 & -100 & -110 & -120 & -130 & -140 & -150 & -160 & -170 & -180 & -190 & 1 \\
\hline
\end{tabular}




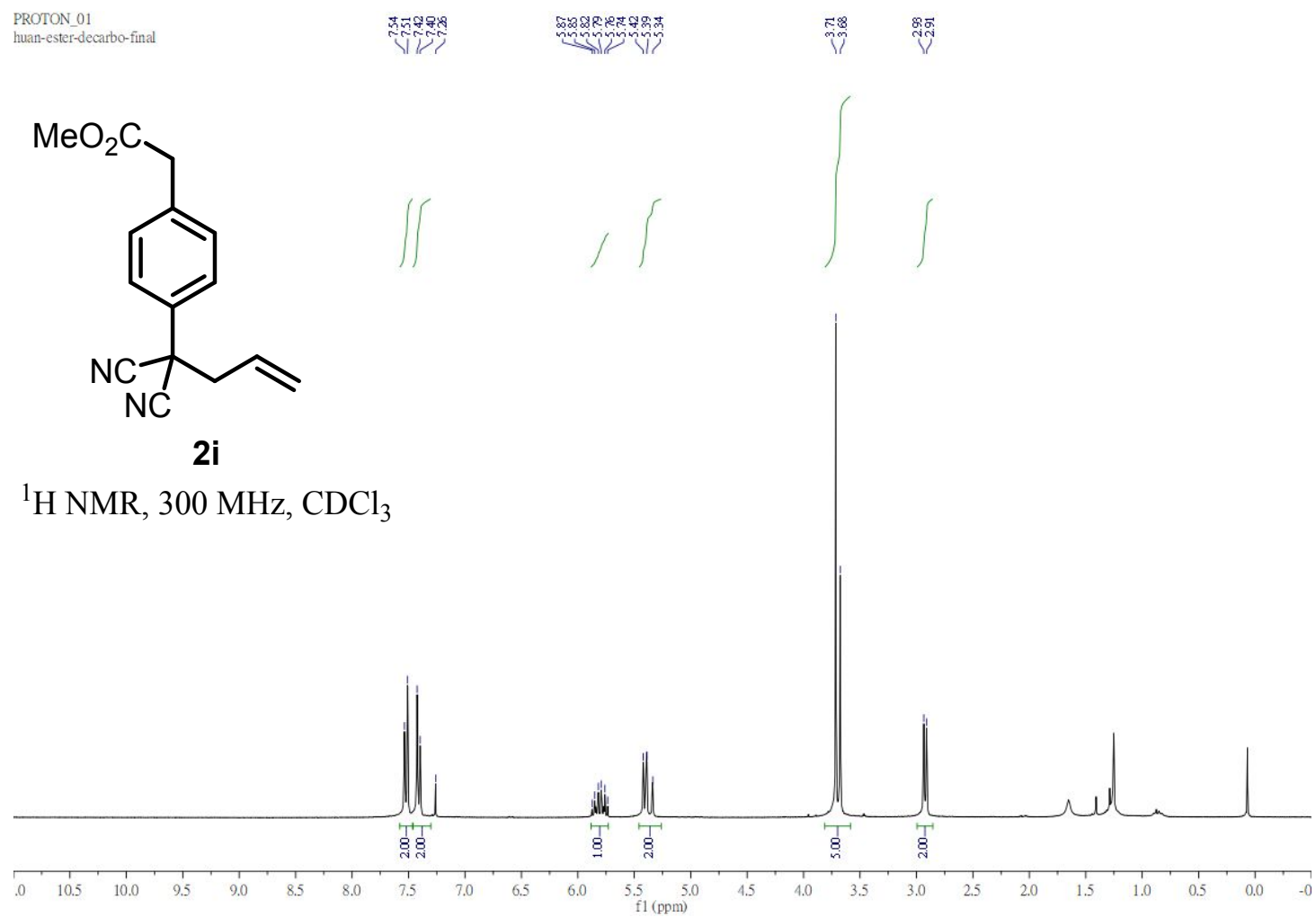

2i

${ }^{1} \mathrm{H} \mathrm{NMR}, 300 \mathrm{MHz}, \mathrm{CDCl}_{3}$
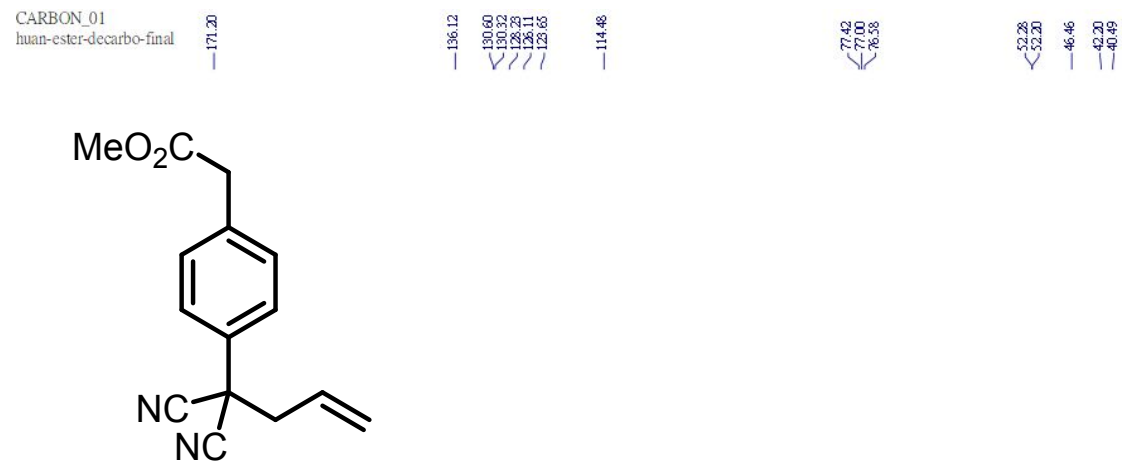

2i

$\left.{ }^{13} \mathrm{C}\left\{{ }^{1} \mathrm{H}\right\} \mathrm{NMR} 75 \mathrm{MHz}, \mathrm{CDCl}\right\}$

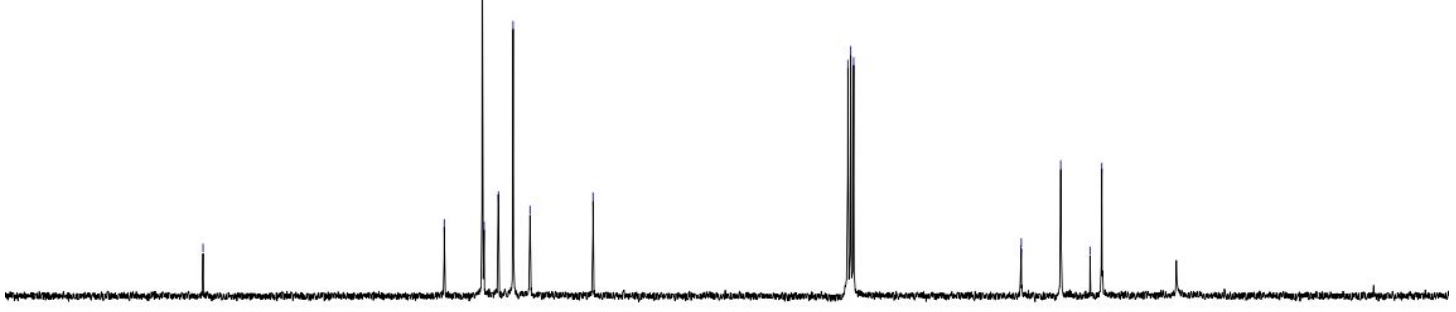

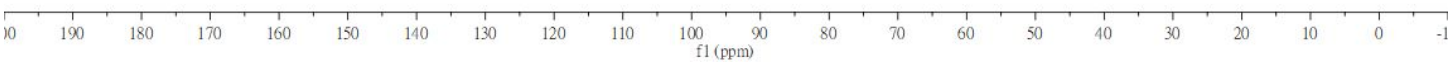



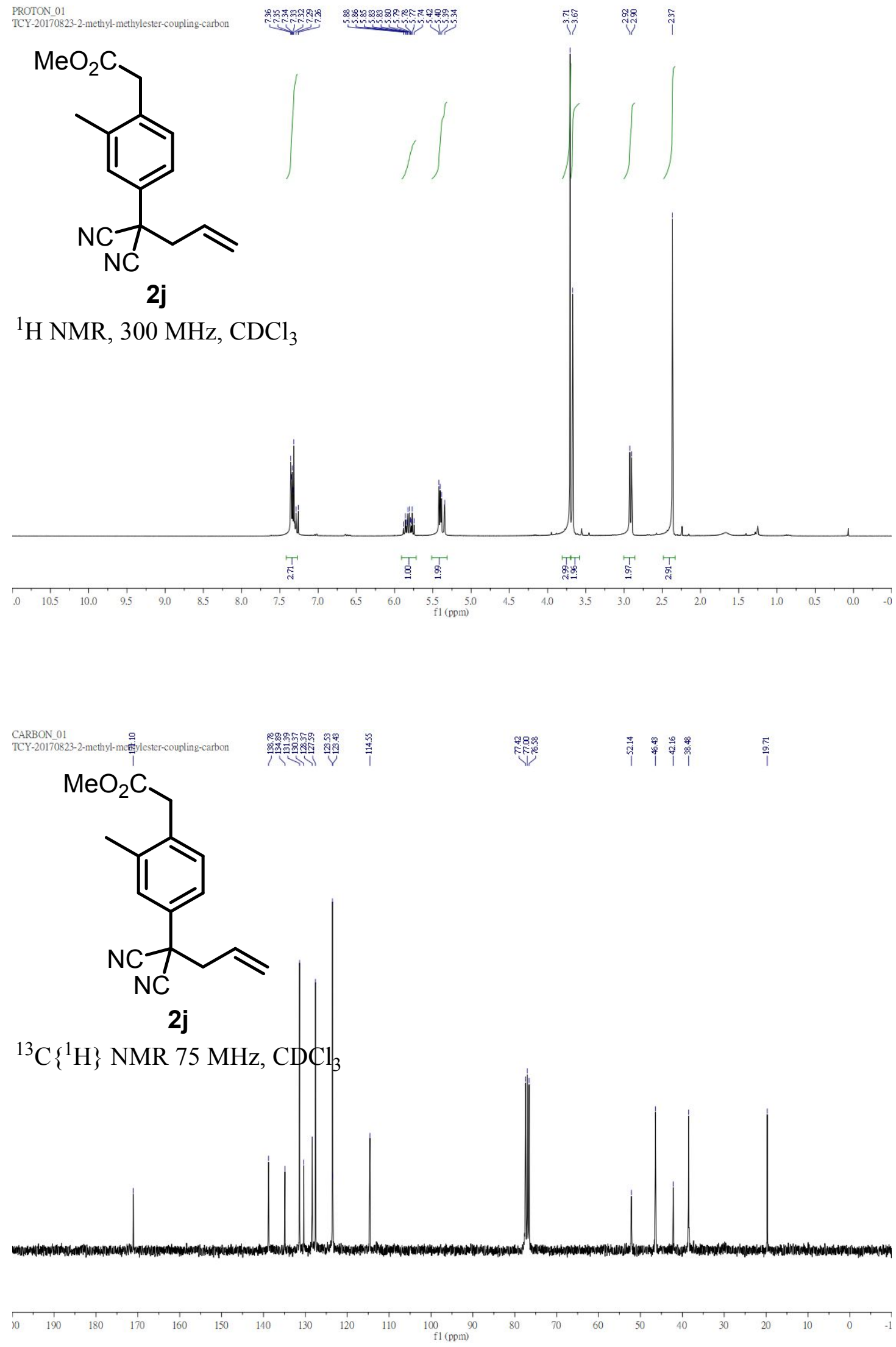


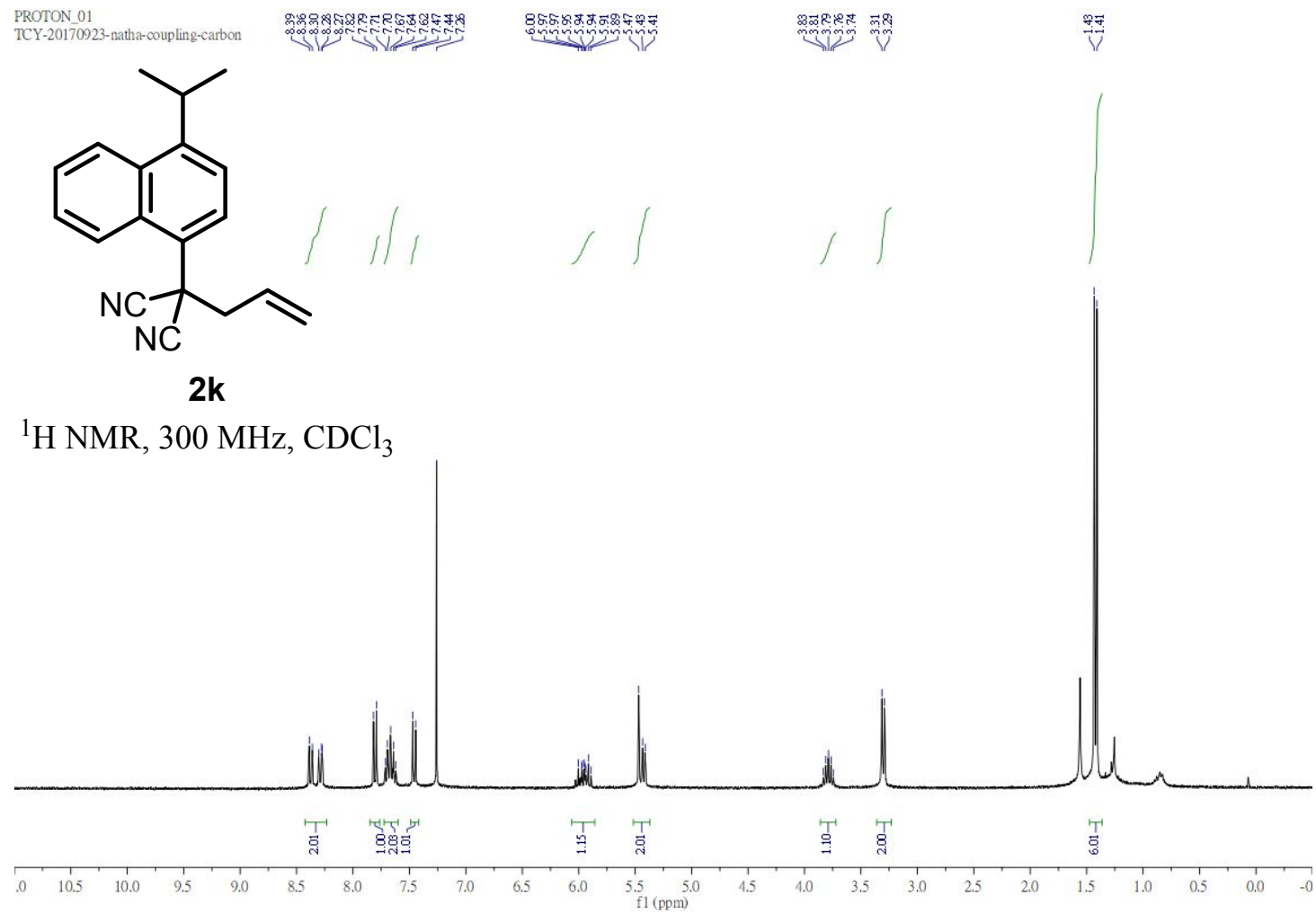

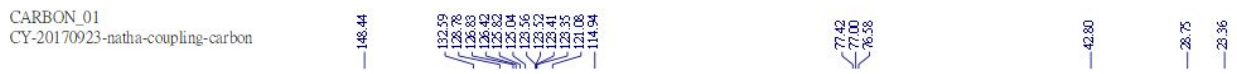<smiles>C=CCC(C)(C#N)c1ccc(C(C)C)c2ccccc12</smiles>

2k

${ }^{13} \mathrm{C}\left\{{ }^{1} \mathrm{H}\right\}$ NMR $75 \mathrm{MHz}, \mathrm{CDCl}_{3}$ 

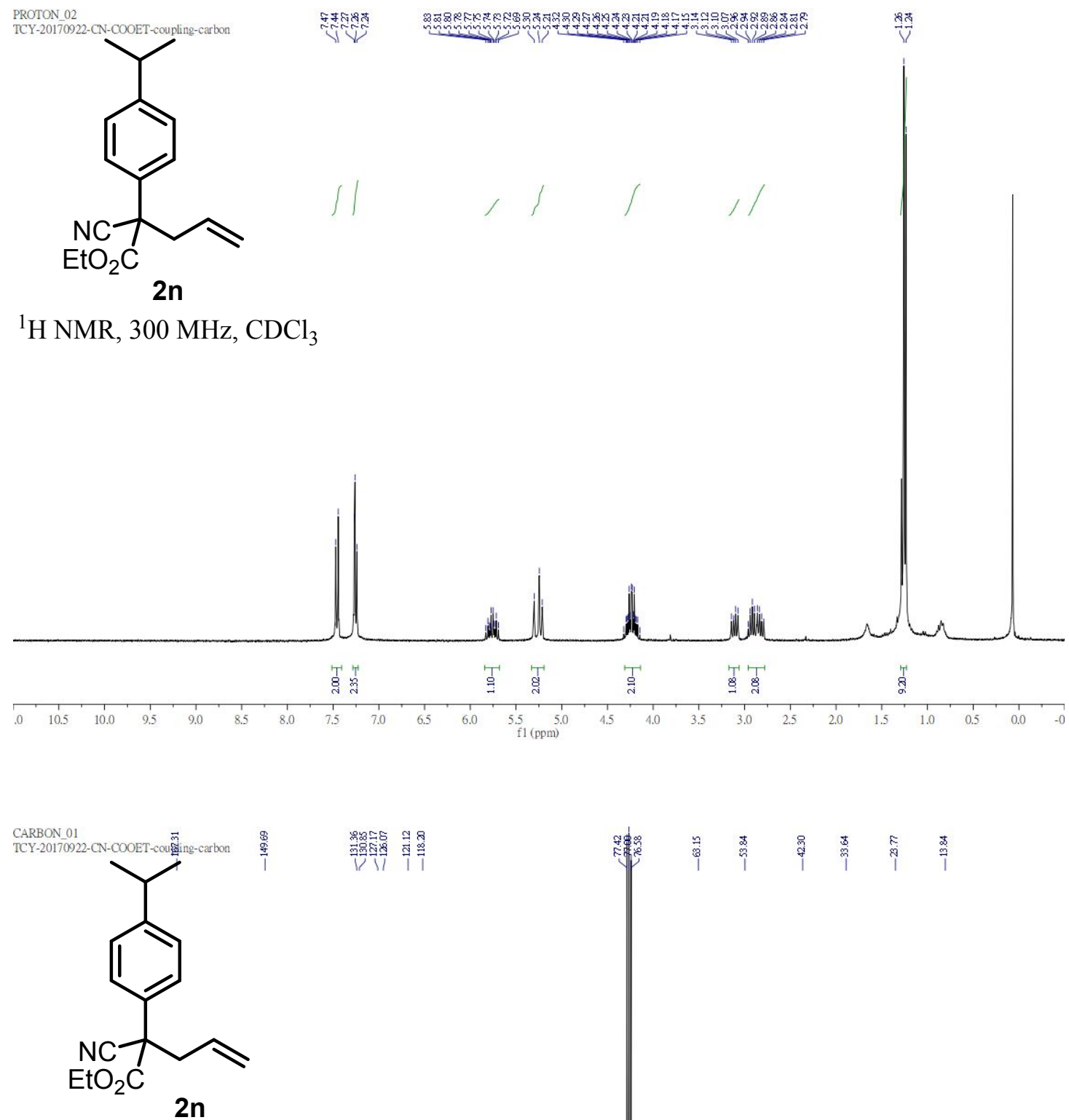

${ }^{13} \mathrm{C}\left\{{ }^{1} \mathrm{H}\right\}$ NMR $75 \mathrm{MHz}, \mathrm{CDCl}_{3}$
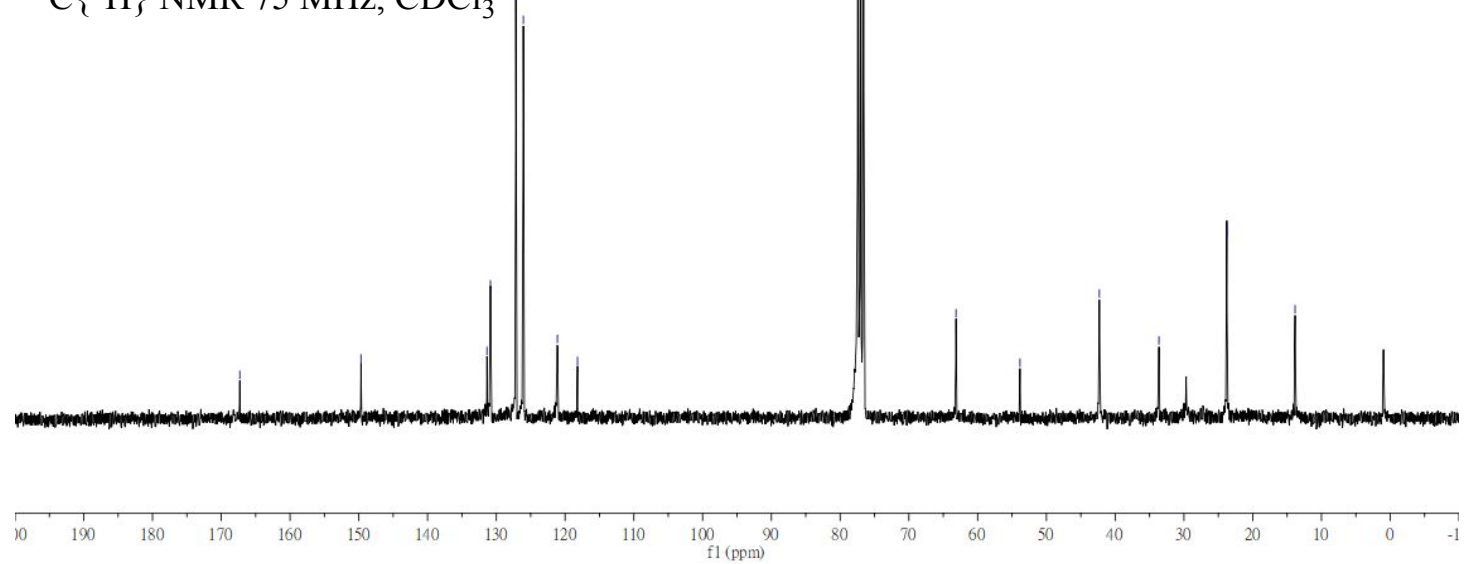

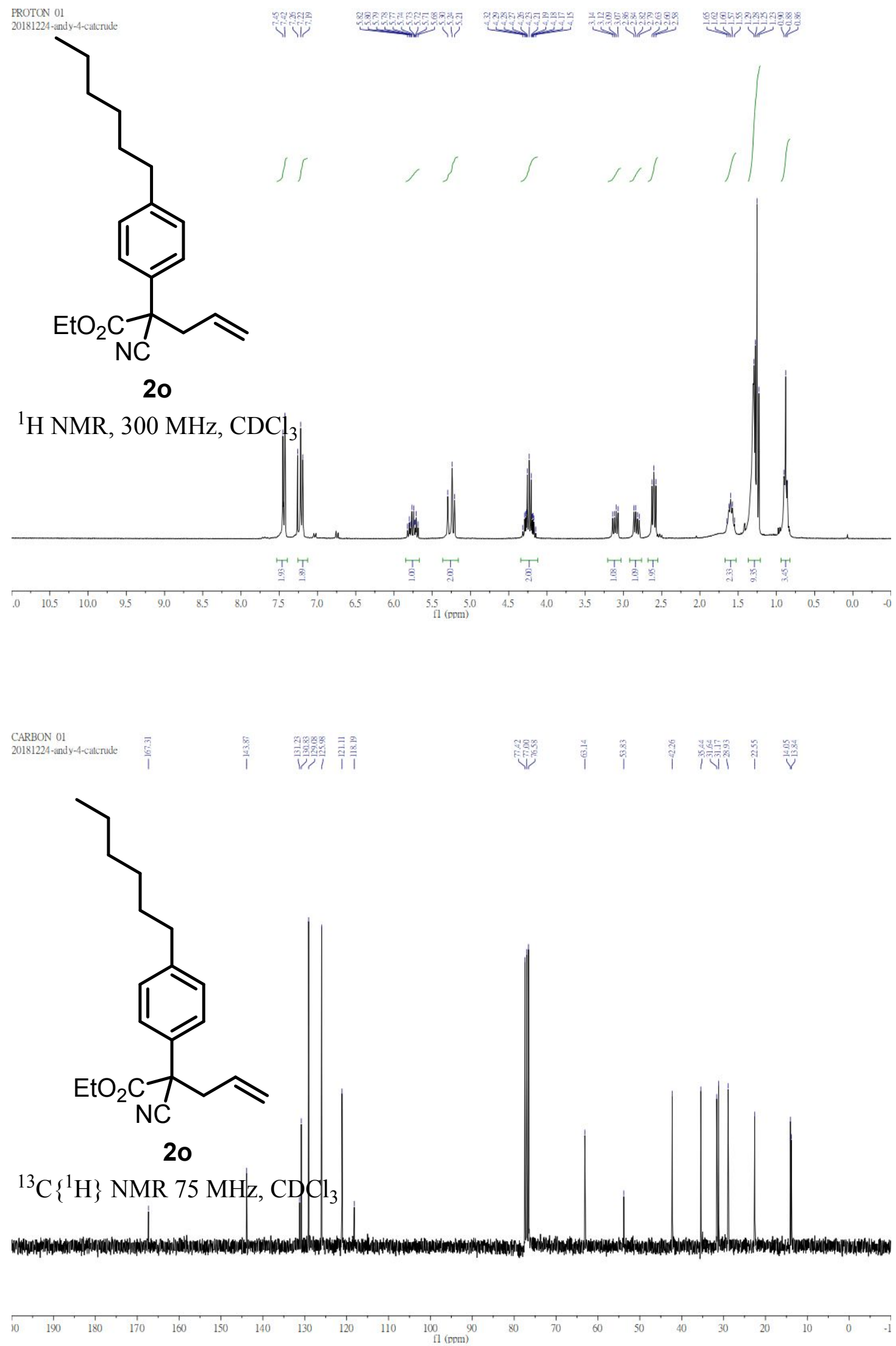

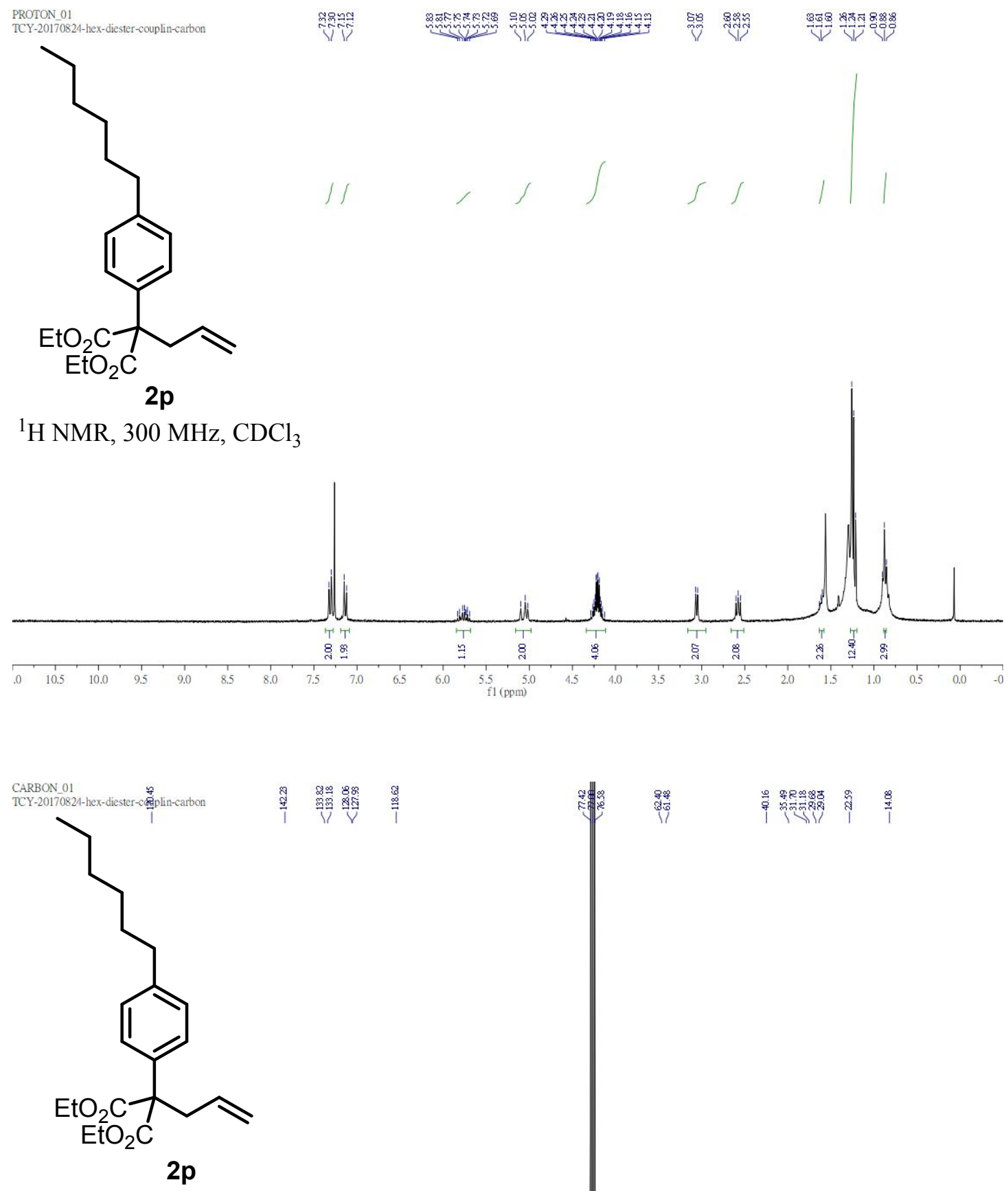

${ }^{13} \mathrm{C}\left\{{ }^{1} \mathrm{H}\right\}$ NMR $75 \mathrm{MHz}, \mathrm{CDCl}_{3}$ 

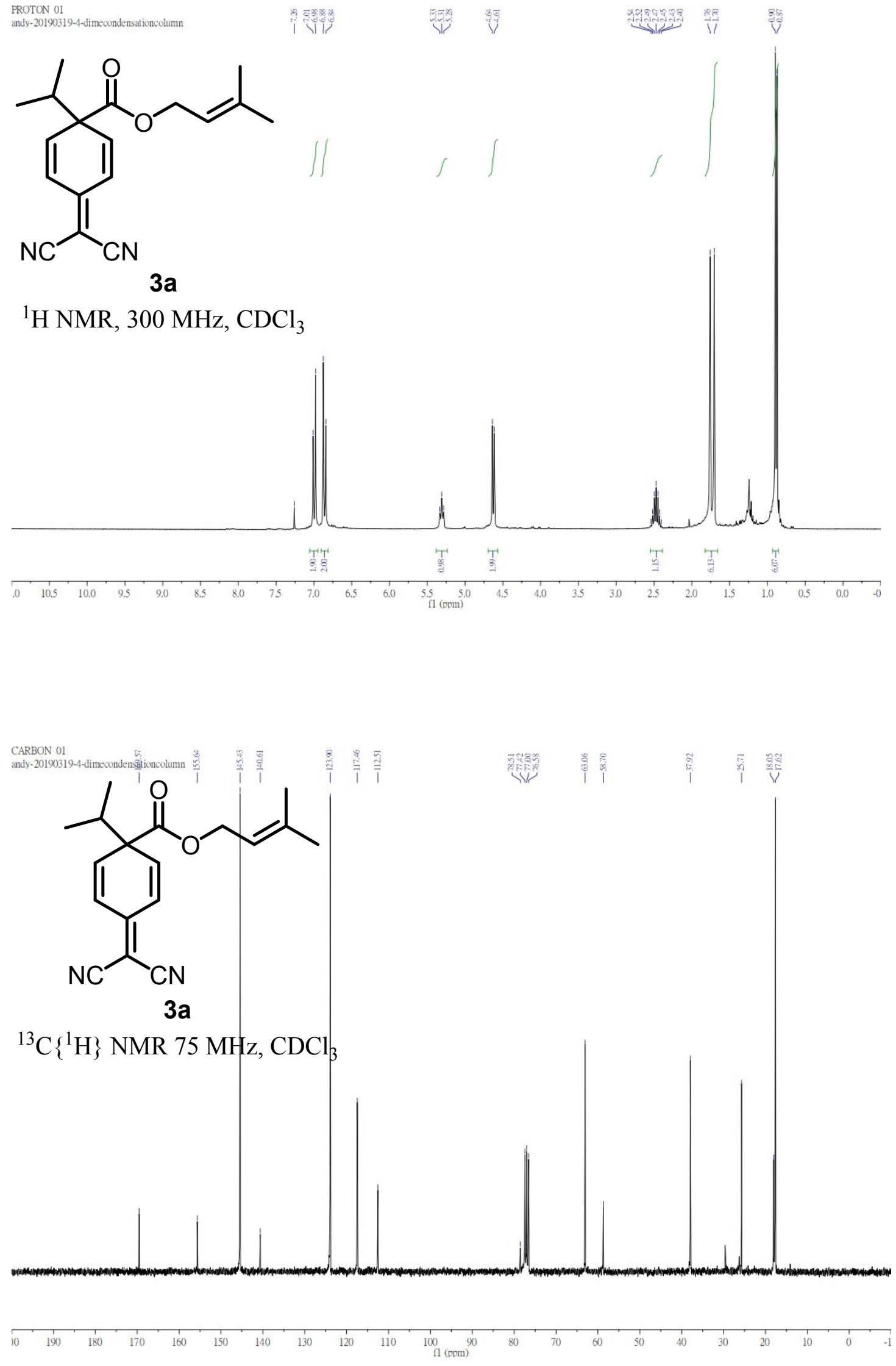
<smiles>CCOC(=O)C(C#N)=C1C=CC(C(=O)OCC=C(C)C)(C(C)C)C=C1</smiles>

$3 b$

${ }^{1} \mathrm{H} \mathrm{NMR}, 300 \mathrm{MHz}, \mathrm{CDCl}_{3}$
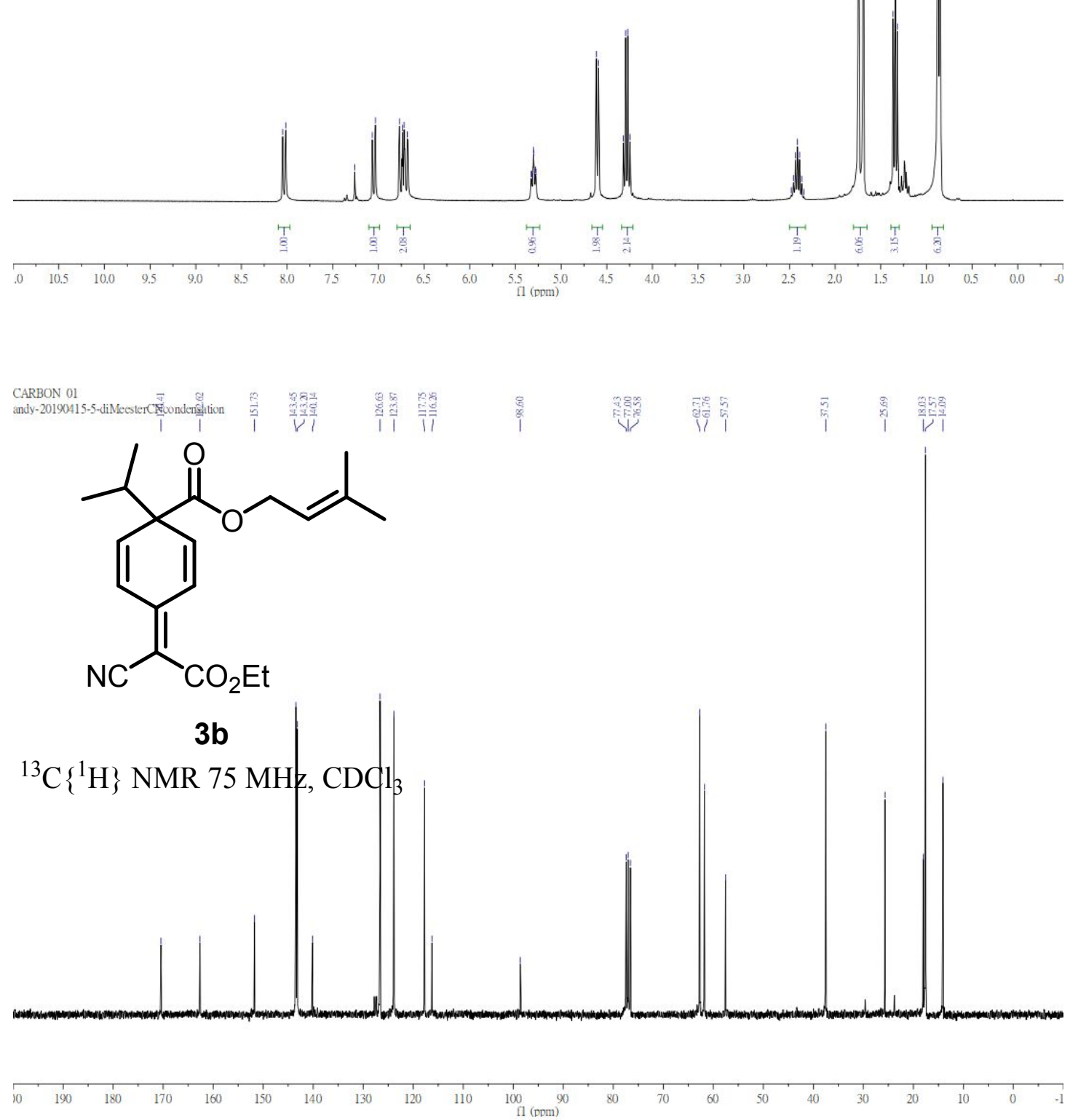
<smiles>C=CC(C)OC(=O)C1(C(C)C)C=CC(=C(C#N)C#N)C=C1</smiles>

${ }^{1} \mathrm{H} \mathrm{NMR}, 300 \mathrm{MHz}, \mathrm{CDCl}_{3}$

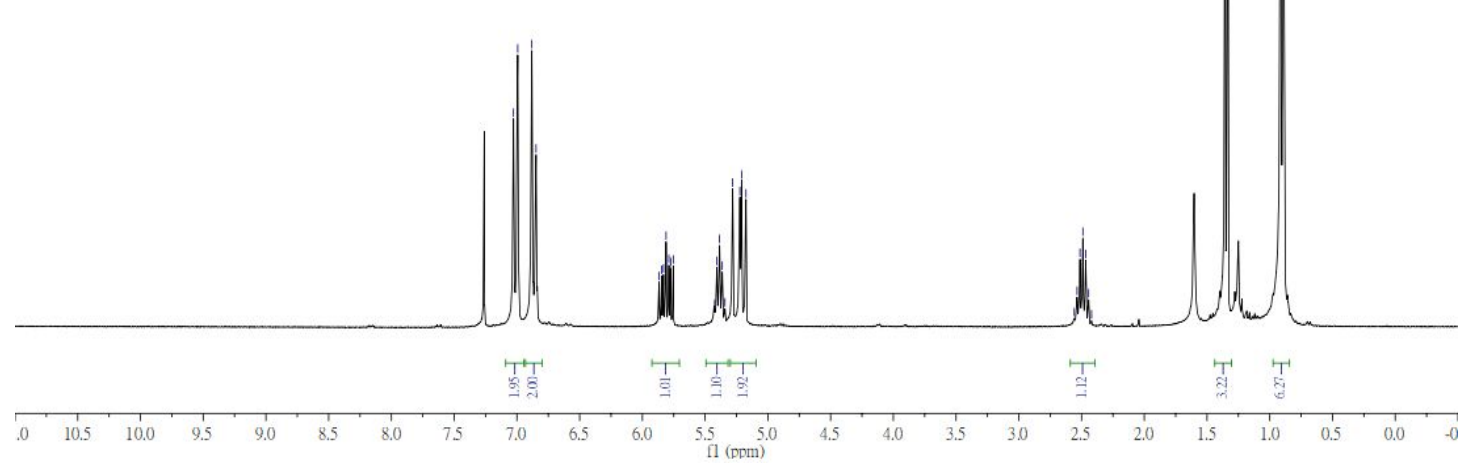

CARBON 01<smiles>C=CC(C)OC(=O)C1(C(C)C)C=CC(=C(C#N)C#N)C=C1</smiles>

${ }^{13} \mathrm{C}\left\{{ }^{1} \mathrm{H}\right\}$ NMR $75 \mathrm{MHz}, \mathrm{CDCl}{ }_{3}$

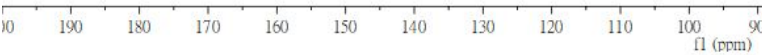


PROTON 02<smiles>C=CC(C)OC(=O)C1(C(C)C)C=CC(=C(C#N)C(=O)OCC)C=C1</smiles>

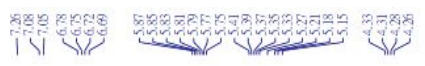

$3 d$

${ }^{1} \mathrm{H} \mathrm{NMR}, 300 \mathrm{MHz}, \mathrm{CDCl}_{3}$

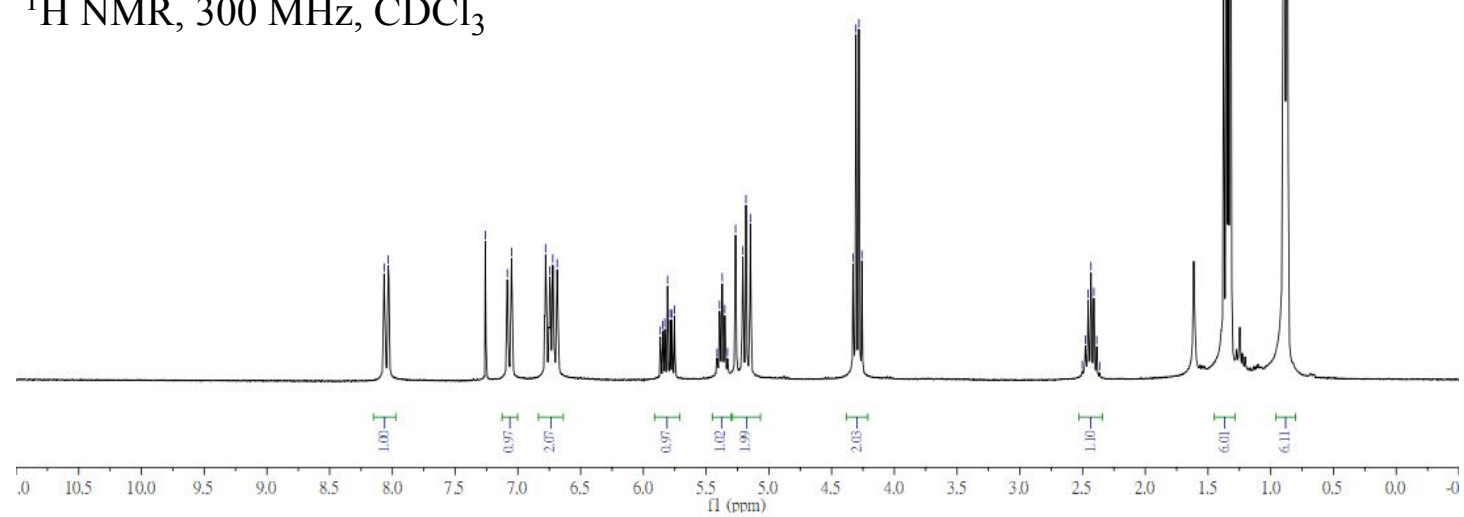

CARBON 01
andy-20190423-5-1MeCNesteraitumn<smiles>C=CC(C)OC(=O)C1(C(C)C)C=CC(=C(C#N)C(=O)OCC)C=C1</smiles>

3d

${ }^{13} \mathrm{C}\left\{{ }^{1} \mathrm{H}\right\} \mathrm{NMR} 75 \mathrm{MHz}, \mathrm{CDCl}_{3}$

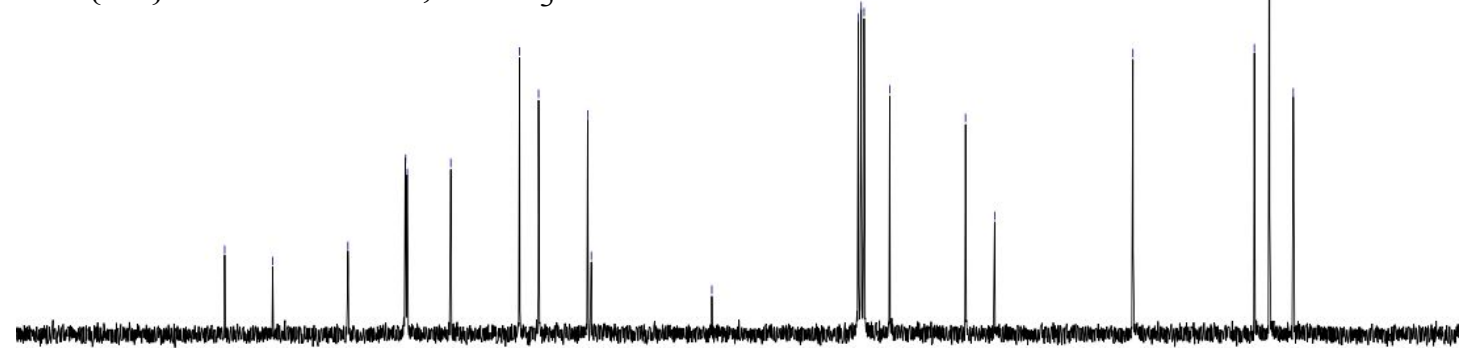

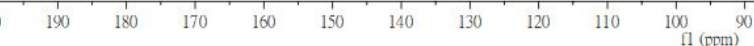



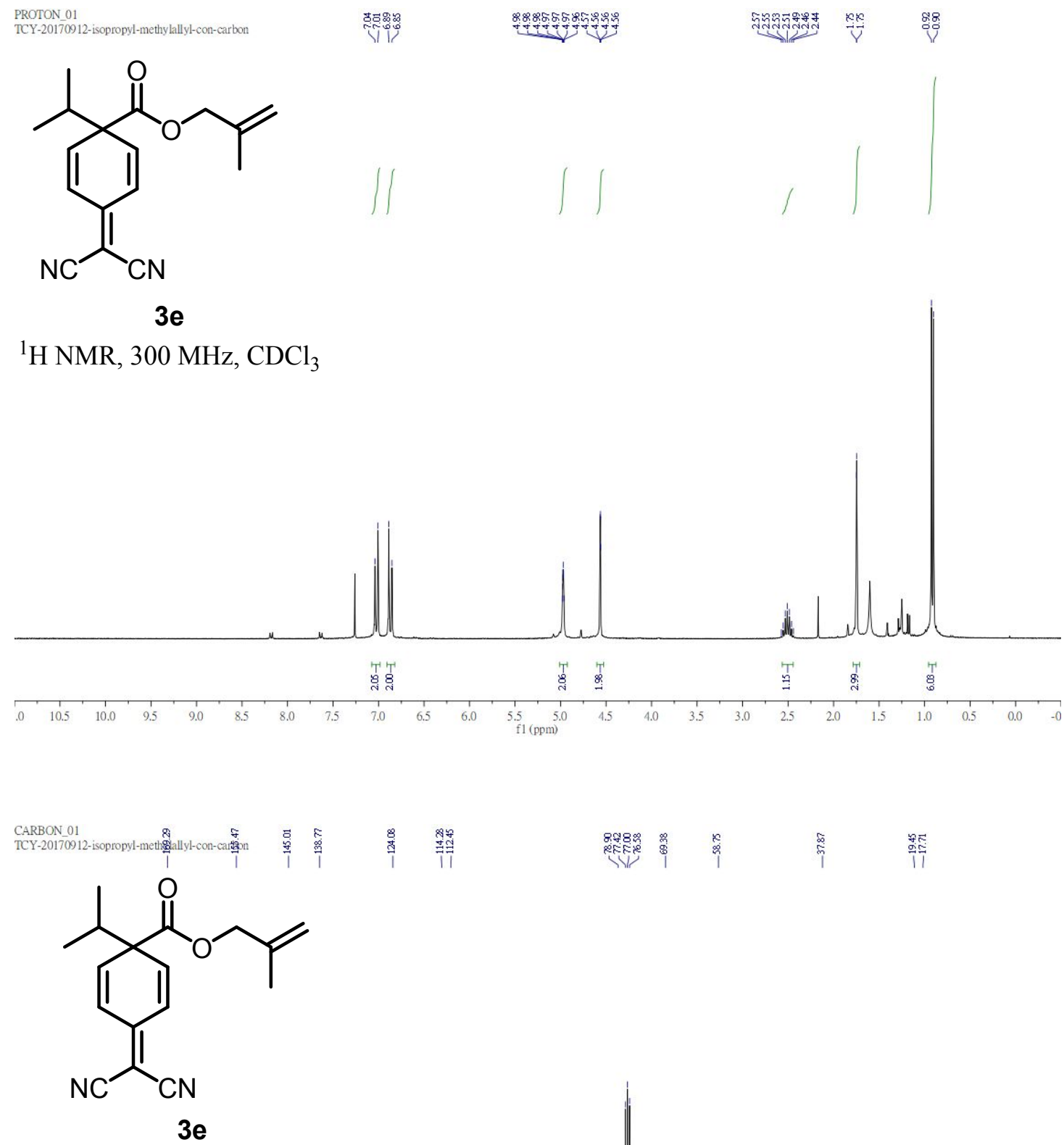

${ }^{13} \mathrm{C}\left\{{ }^{1} \mathrm{H}\right\}$ NMR $75 \mathrm{MHz}, \mathrm{CDCl}_{3}$
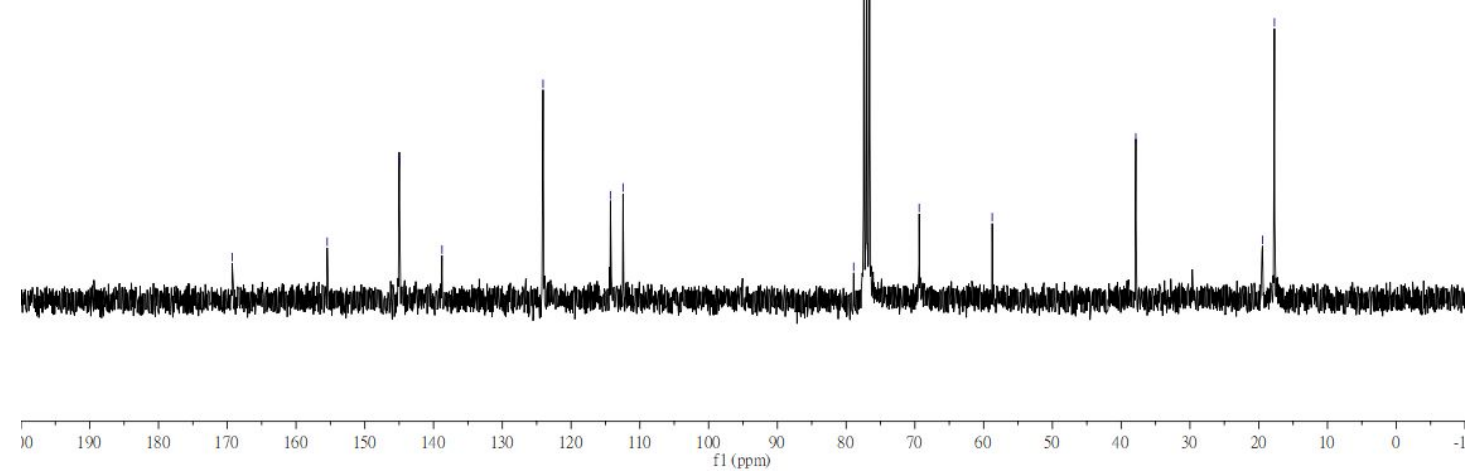

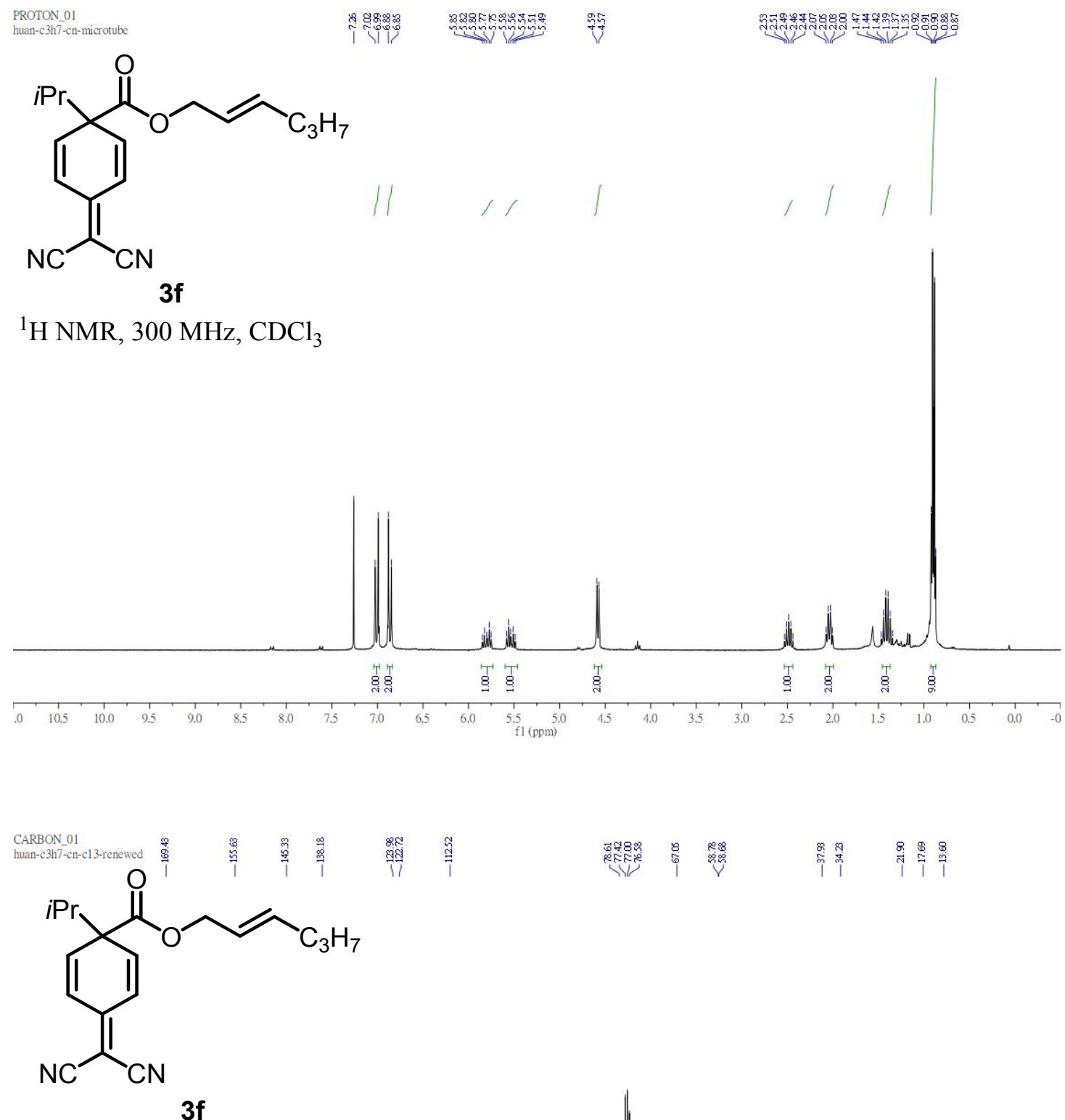

${ }^{13} \mathrm{C}\left\{{ }^{1} \mathrm{H}\right\}$ NMR $75 \mathrm{MHz}, \mathrm{CDCl}_{3}$

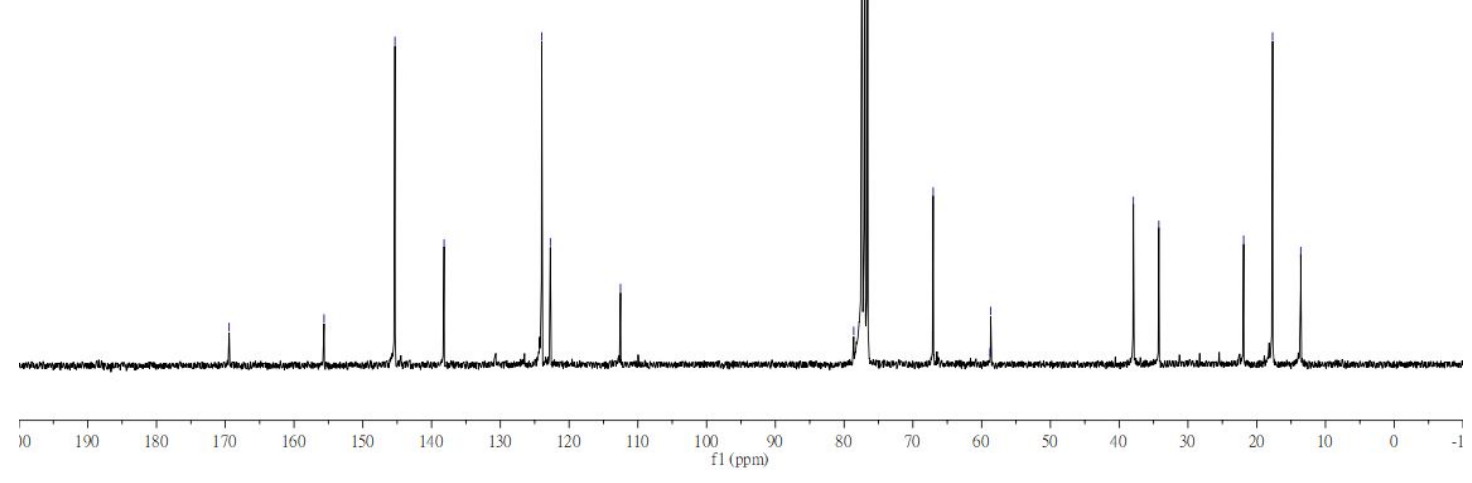




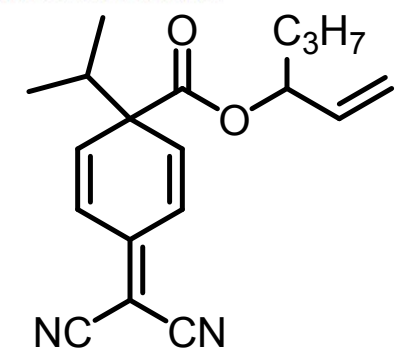

${ }^{1} \mathrm{H} \mathrm{NMR}, 300 \mathrm{MHz}, \mathrm{CDCl}_{3}$

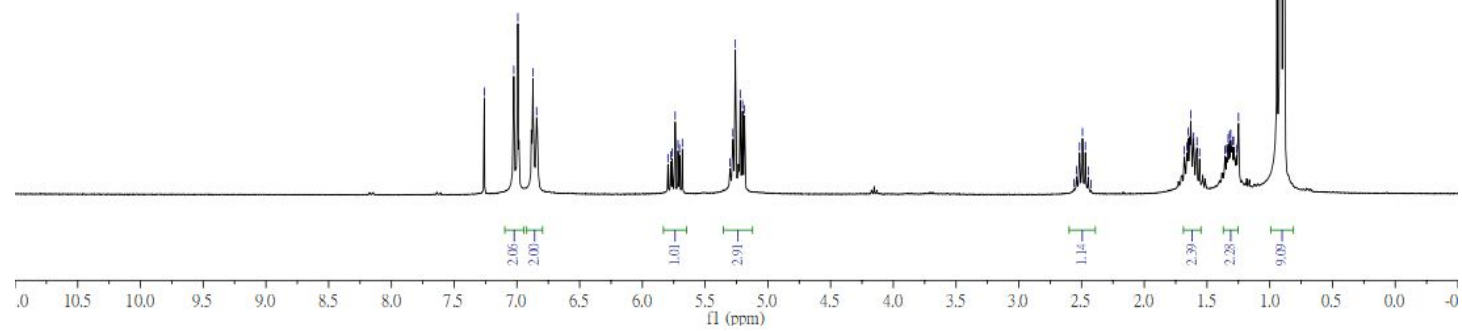

CARBON 02
andy-20190724-5-C3H7CNcolutin<smiles>C=CC(CCCCCCCCCCCCCCC#N)OC(=O)C1(C(C)C)C=CC(=C(C#N)C#N)C=C1</smiles>

${ }^{13} \mathrm{C}\left\{{ }^{1} \mathrm{H}\right\}$ NMR $75 \mathrm{MHz}, \mathrm{CDCl}{ }_{3}$
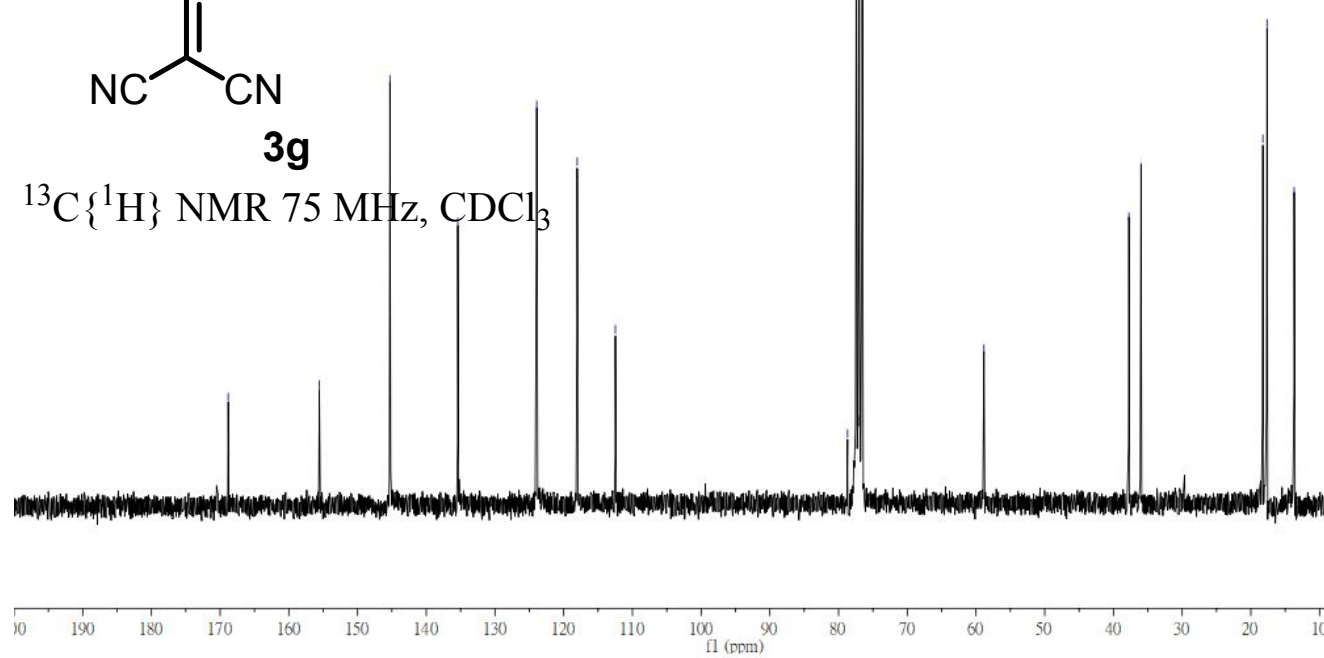


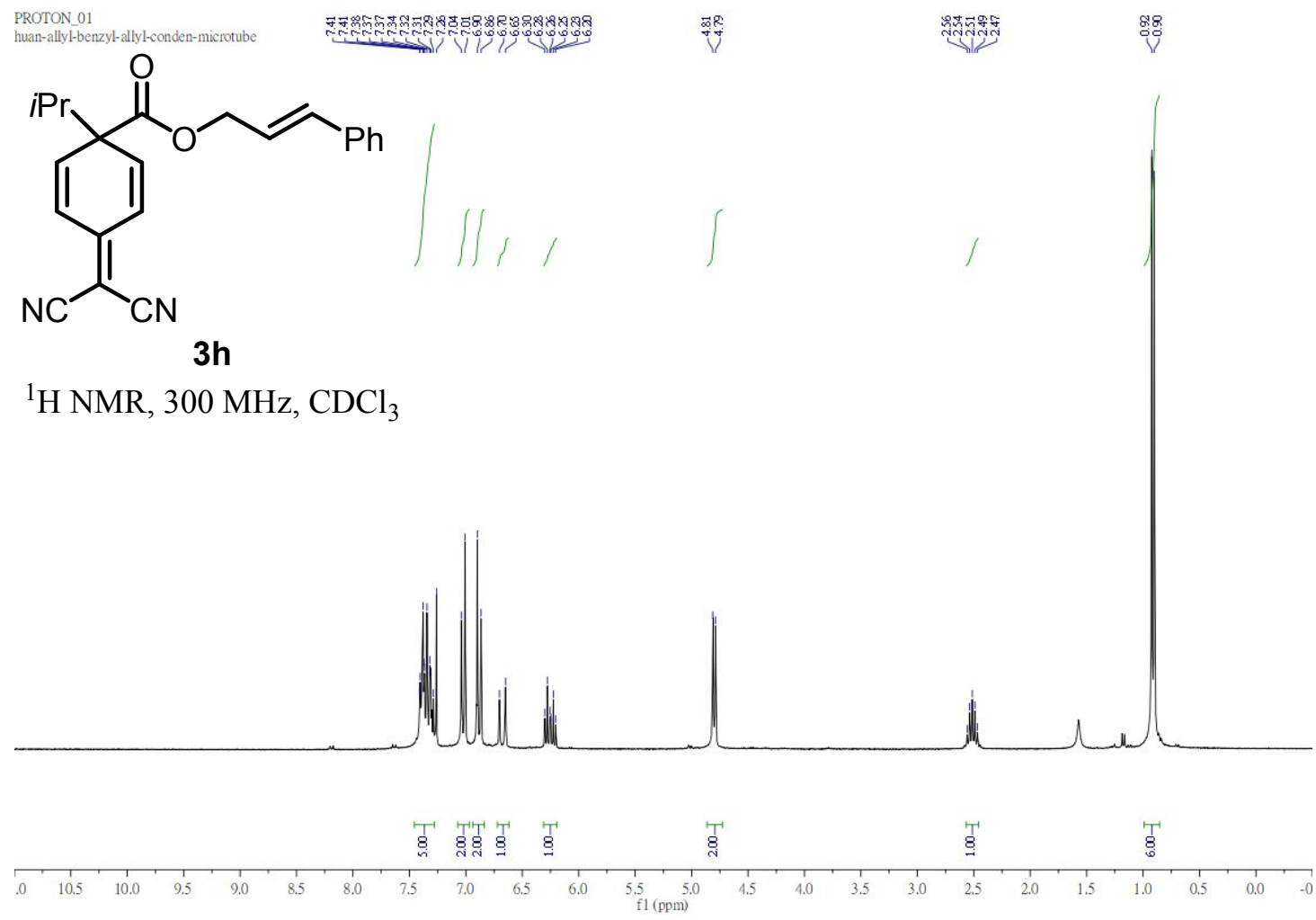

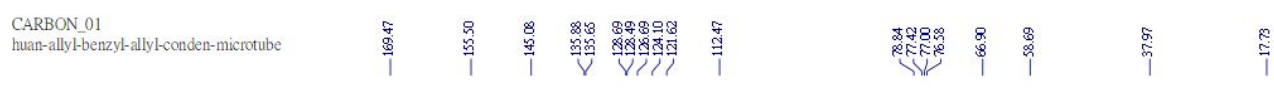<smiles>CC(C)C1(C(=O)OC/C=C/c2ccccc2)C=CC(=C(C#N)C#N)C=C1</smiles>

3h

${ }^{13} \mathrm{C}\left\{{ }^{1} \mathrm{H}\right\}$ NMR $75 \mathrm{MHz}, \mathrm{CDCl}_{3}$

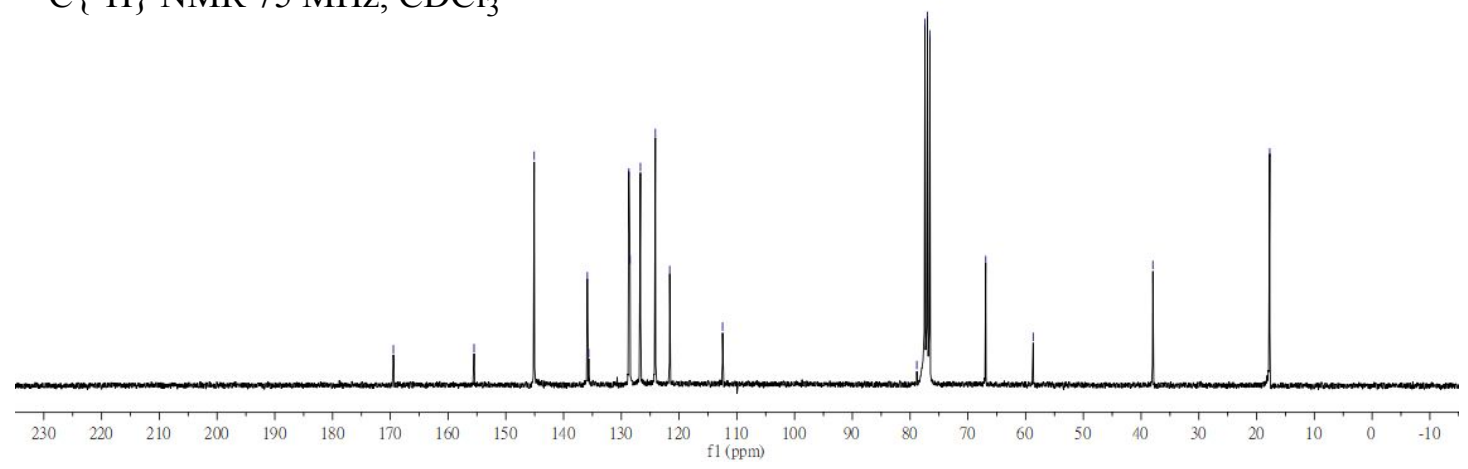


<smiles>C=CC(OC(=O)C1(C(C)C)C=CC(=C(C#N)C#N)C=C1)c1ccccc1</smiles>

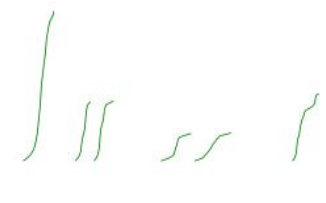

$3 \mathbf{i}$

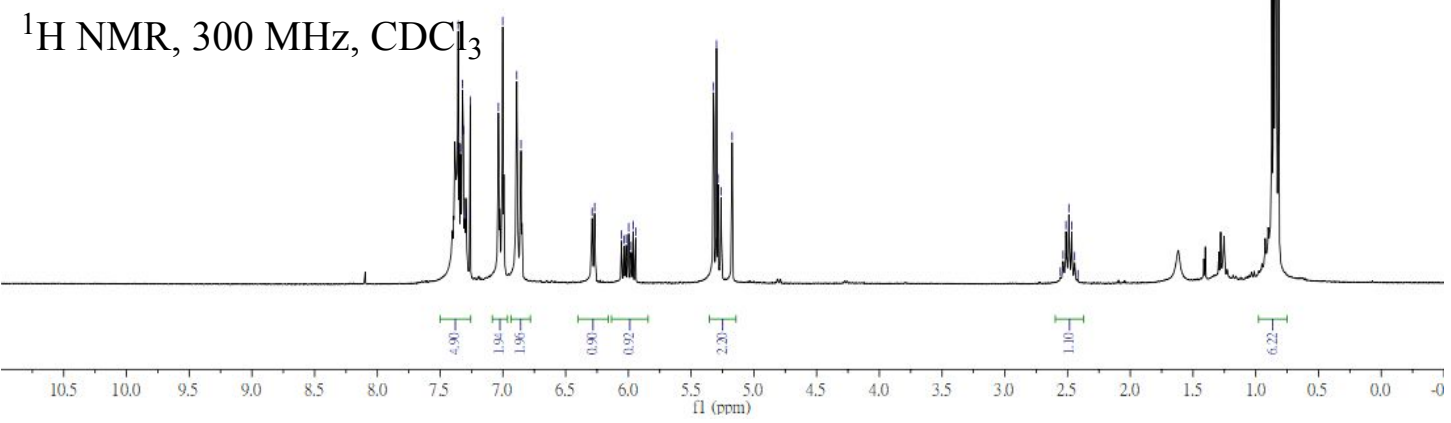

CARBON 01

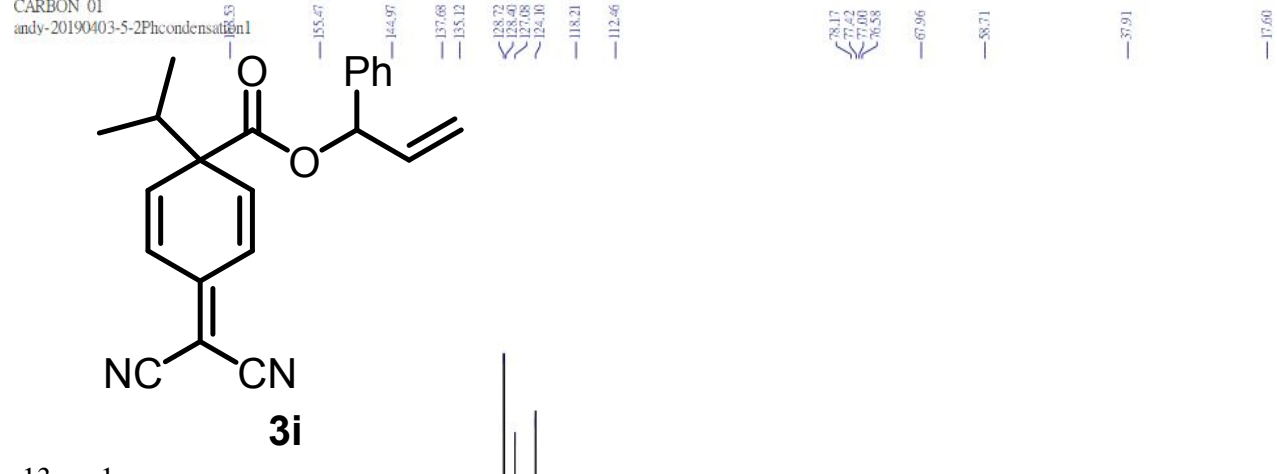

${ }^{13} \mathrm{C}\left\{{ }^{1} \mathrm{H}\right\}$ NMR $\left.75 \mathrm{MHz}, \mathrm{CDCl}\right\}_{3}$

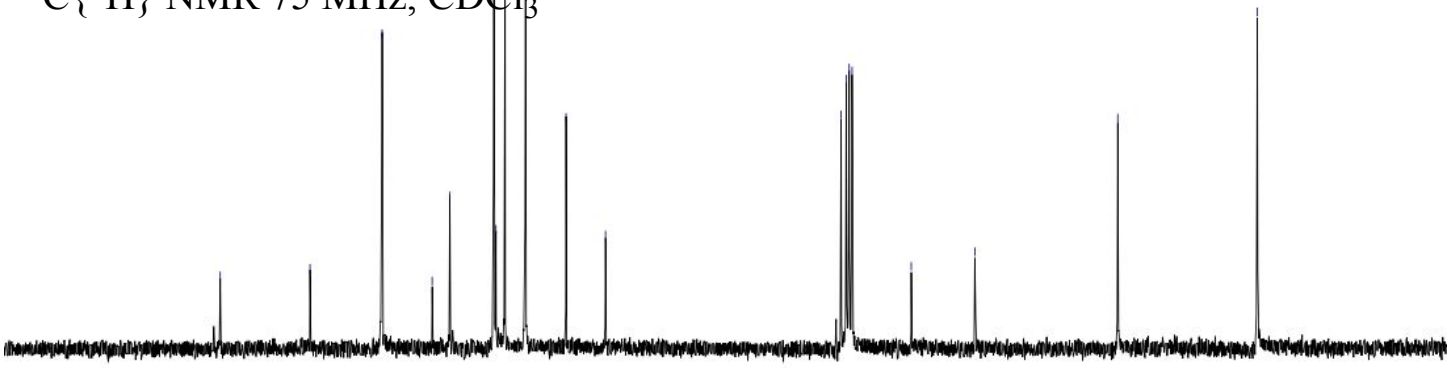

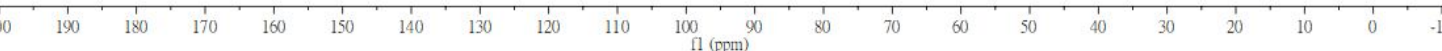


PROTON 01

TCY-20170818-dimethyl-coupling-carbon

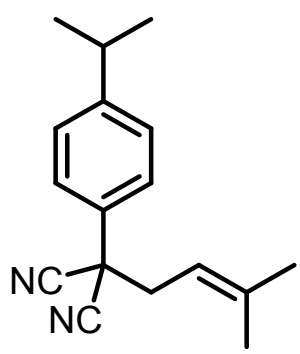

$4 a$

${ }^{1} \mathrm{H}$ NMR, $300 \mathrm{MHz}, \mathrm{CDCl}_{3}$
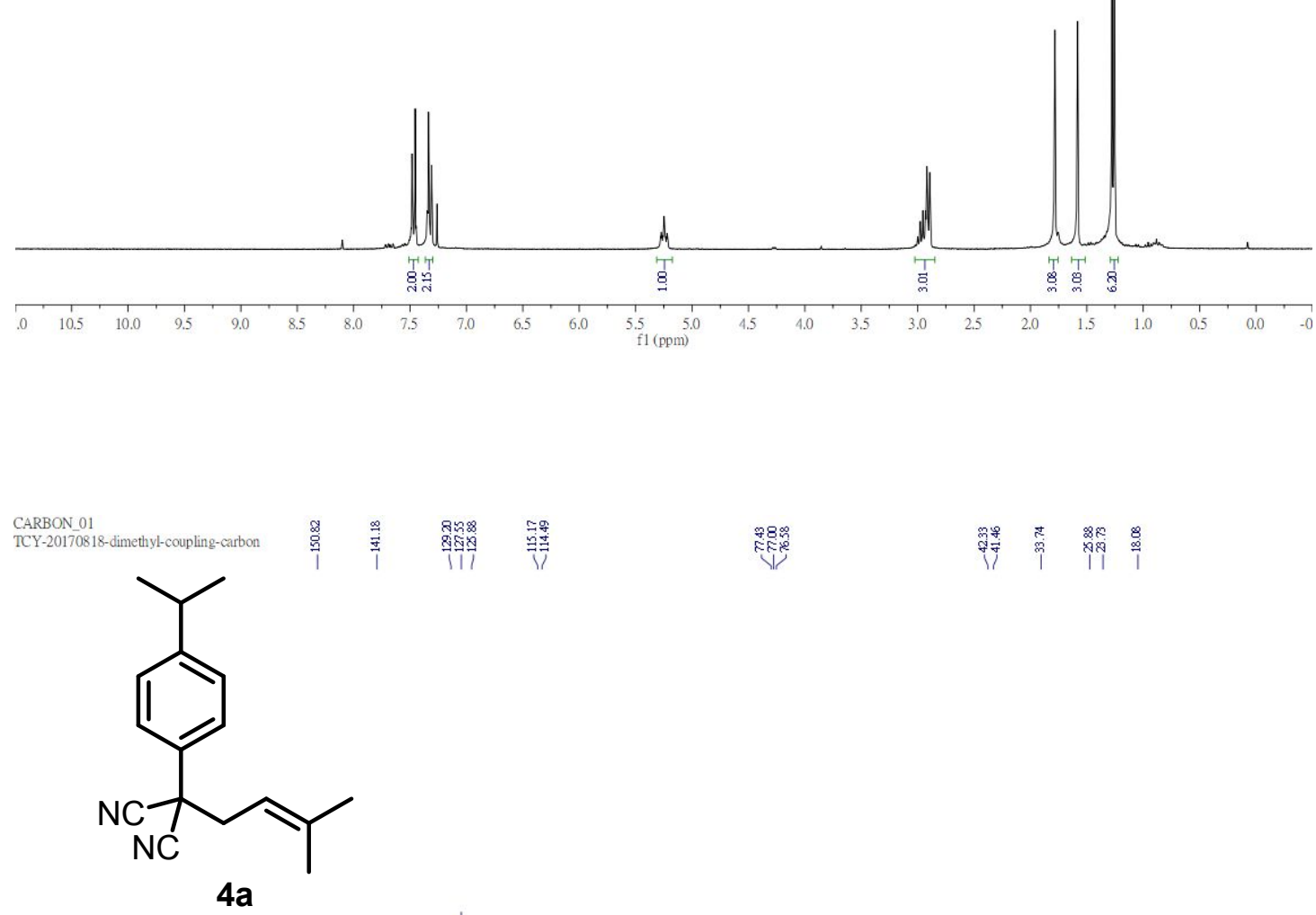

${ }^{13} \mathrm{C}\left\{{ }^{1} \mathrm{H}\right\}$ NMR $75 \mathrm{MHz}, \mathrm{CDCl}_{3}$ 

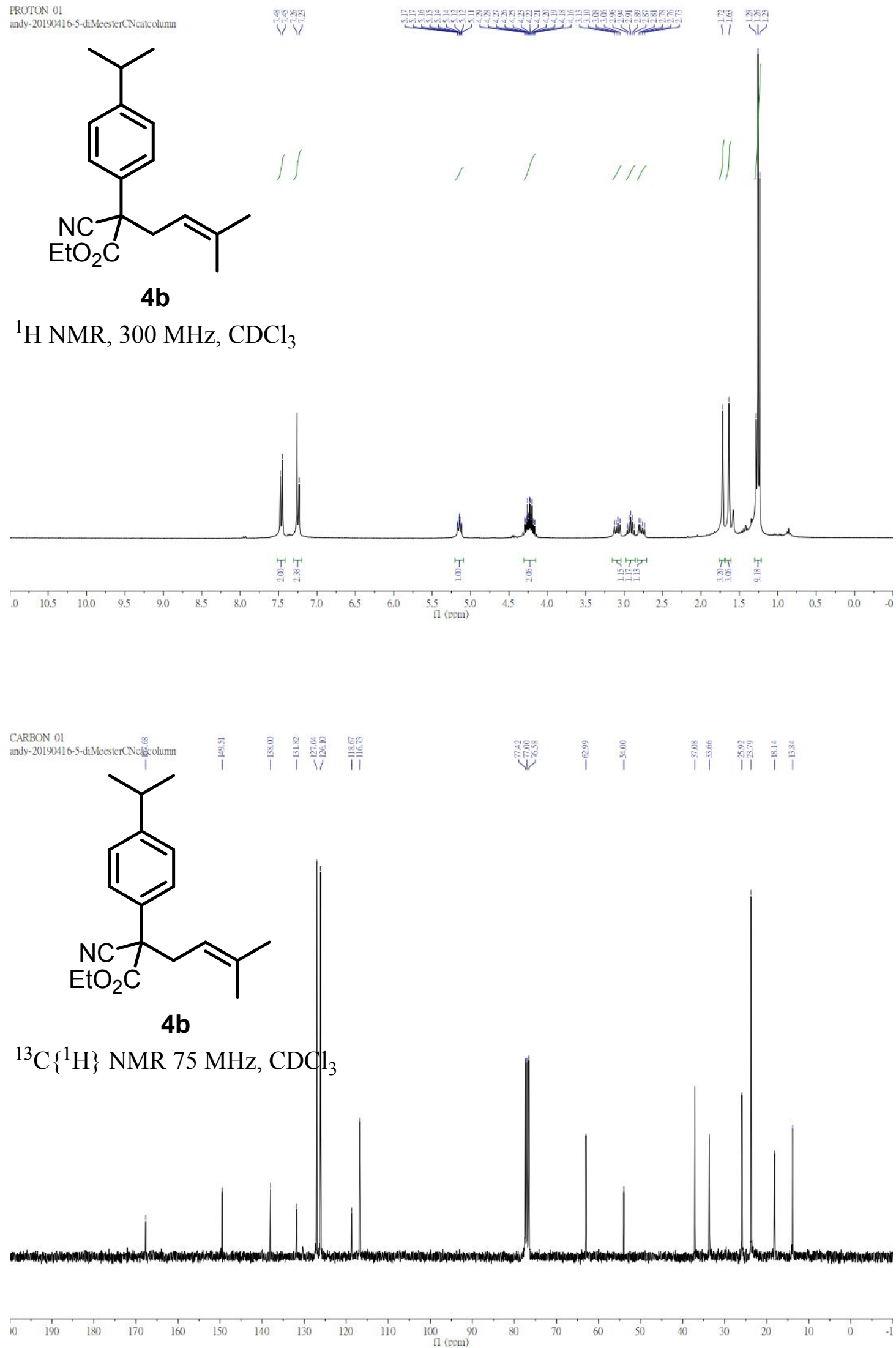

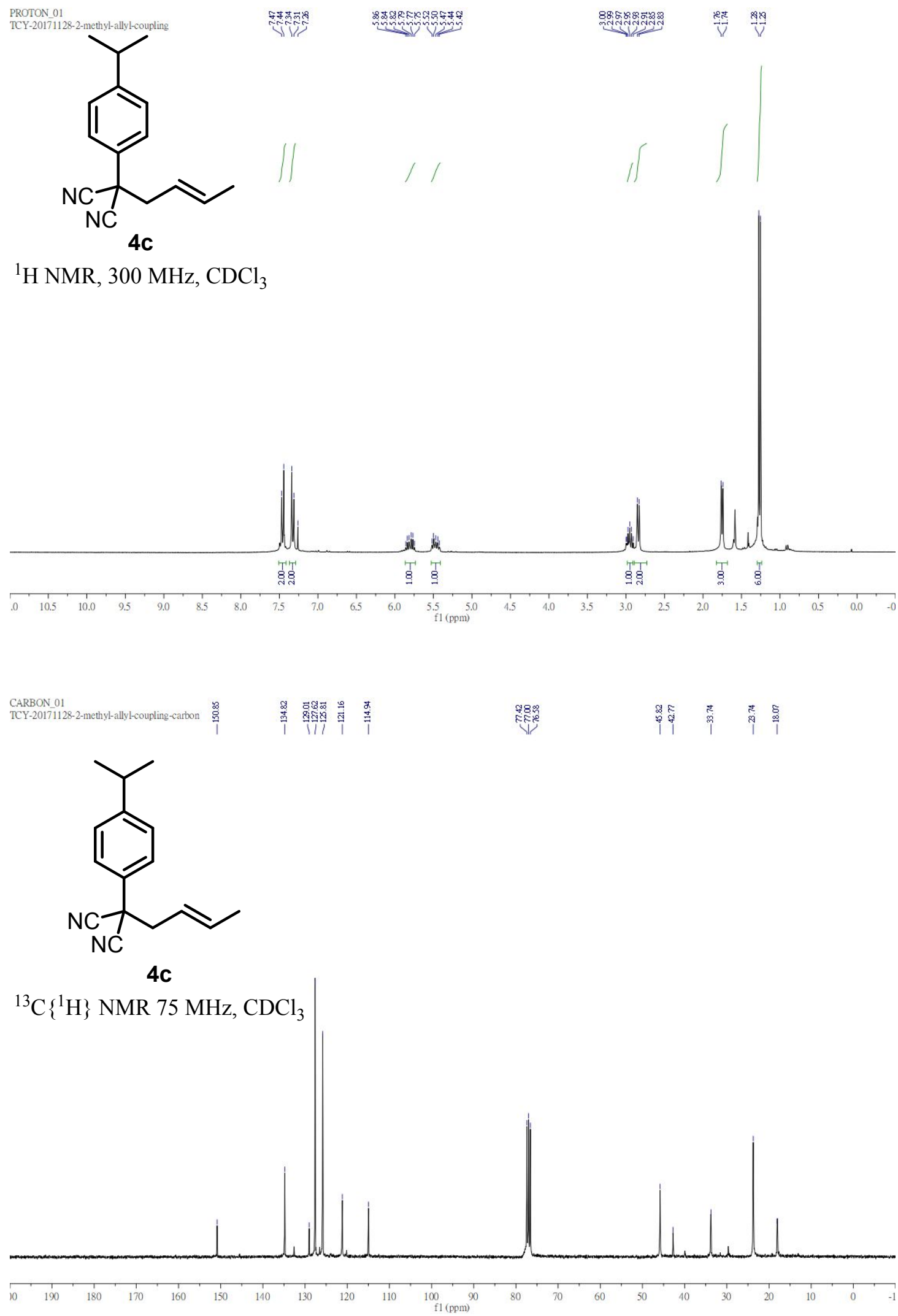


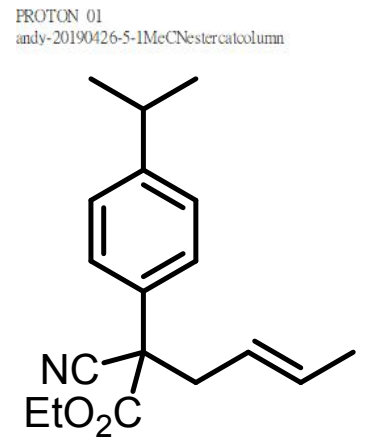

4d
(1)

$\underset{\mathrm{EtO}_{2} \mathrm{C}}{\mathrm{NC}}$

4d' 4d' Branch

${ }^{1} \mathrm{H}$ NMR, $300 \mathrm{MHz}, \mathrm{CDCl}_{3}$

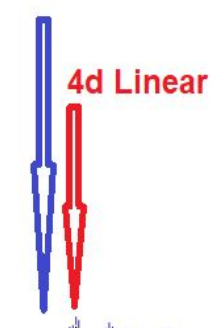

Wullinith willin

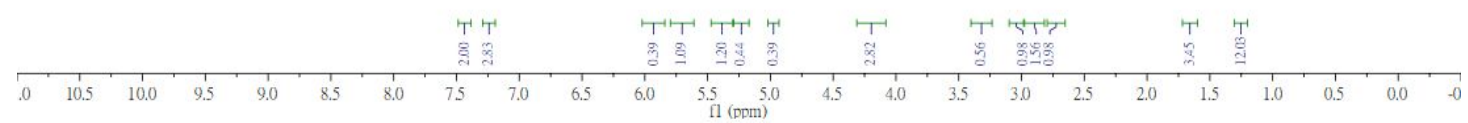



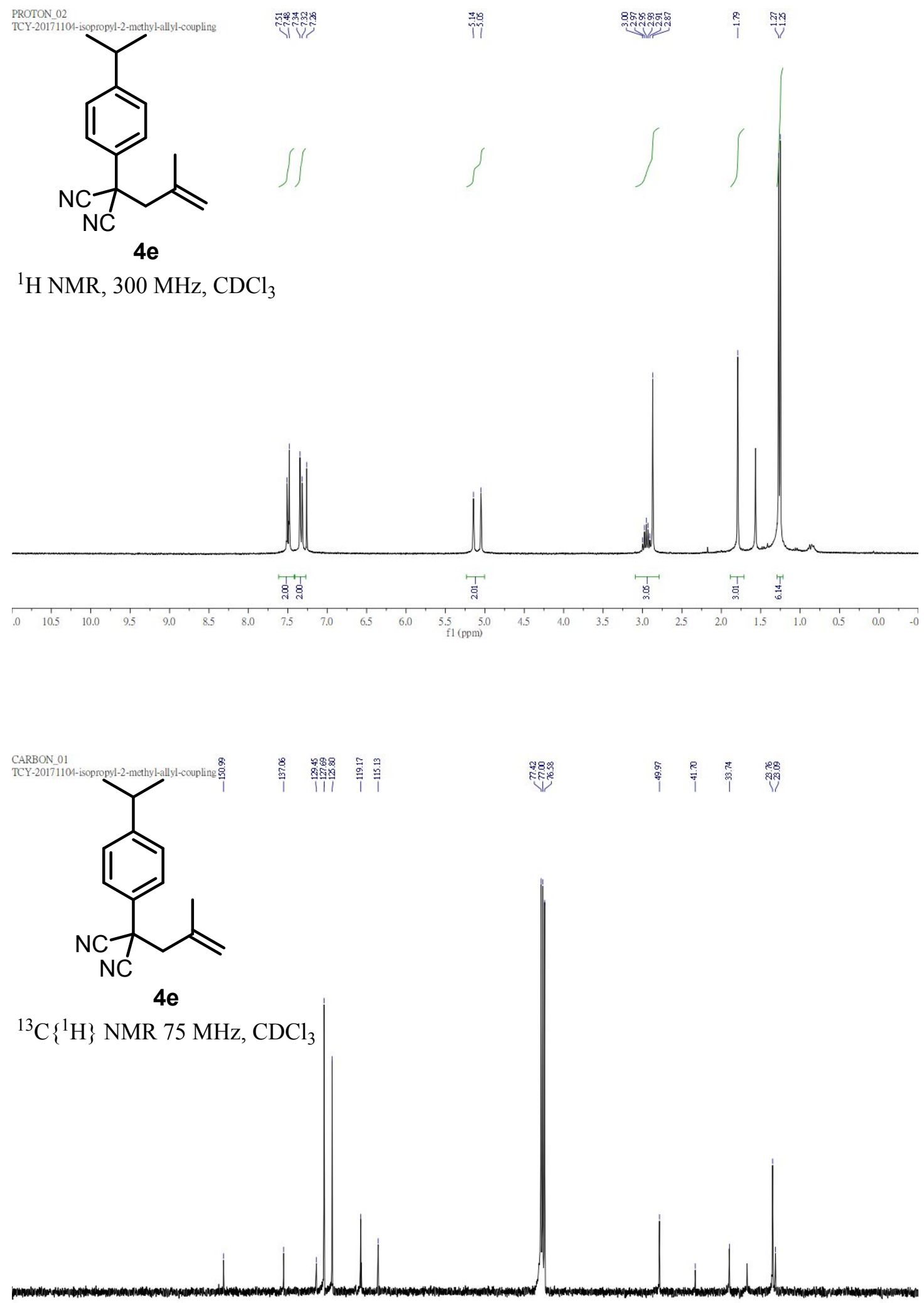

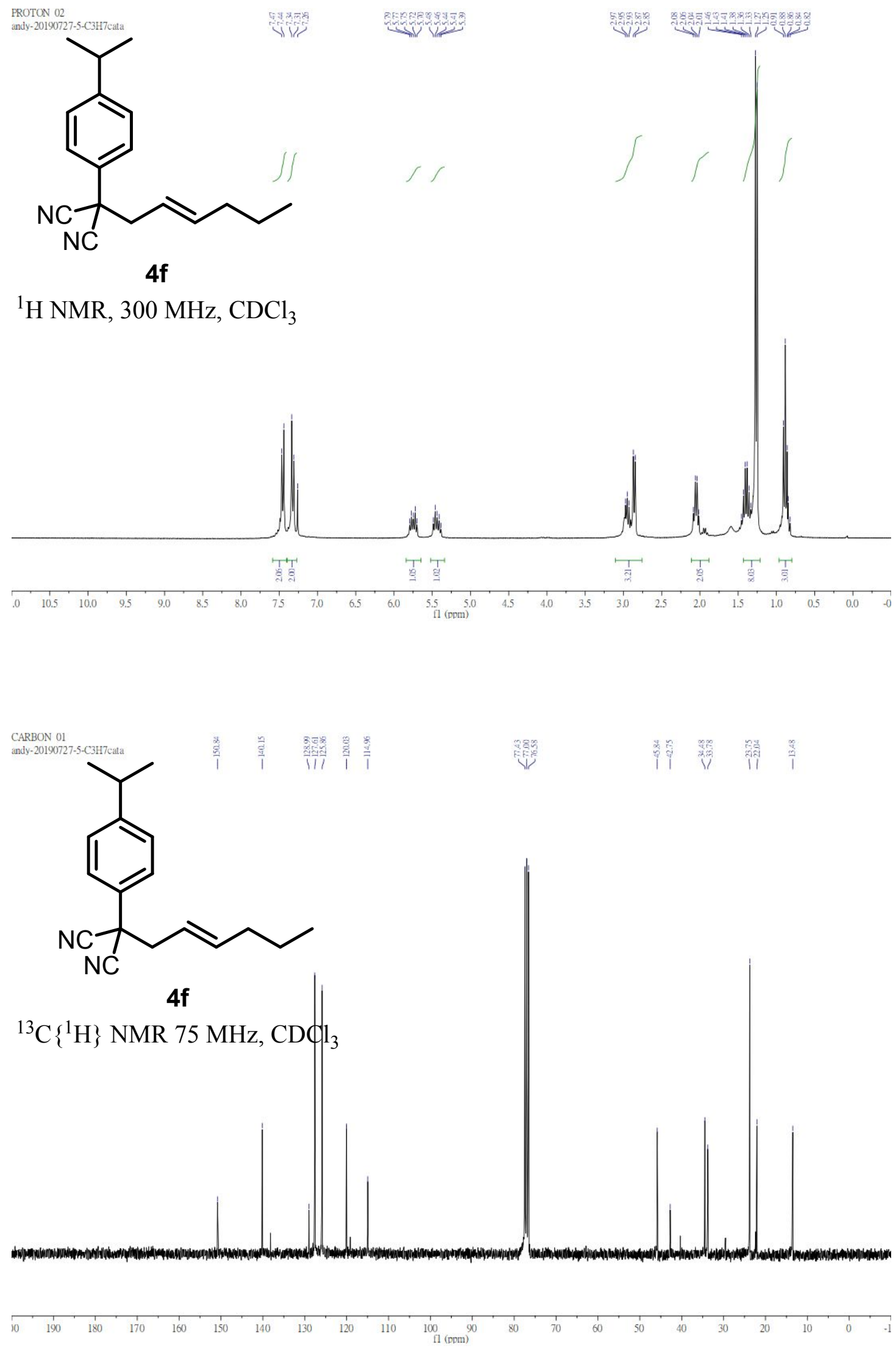

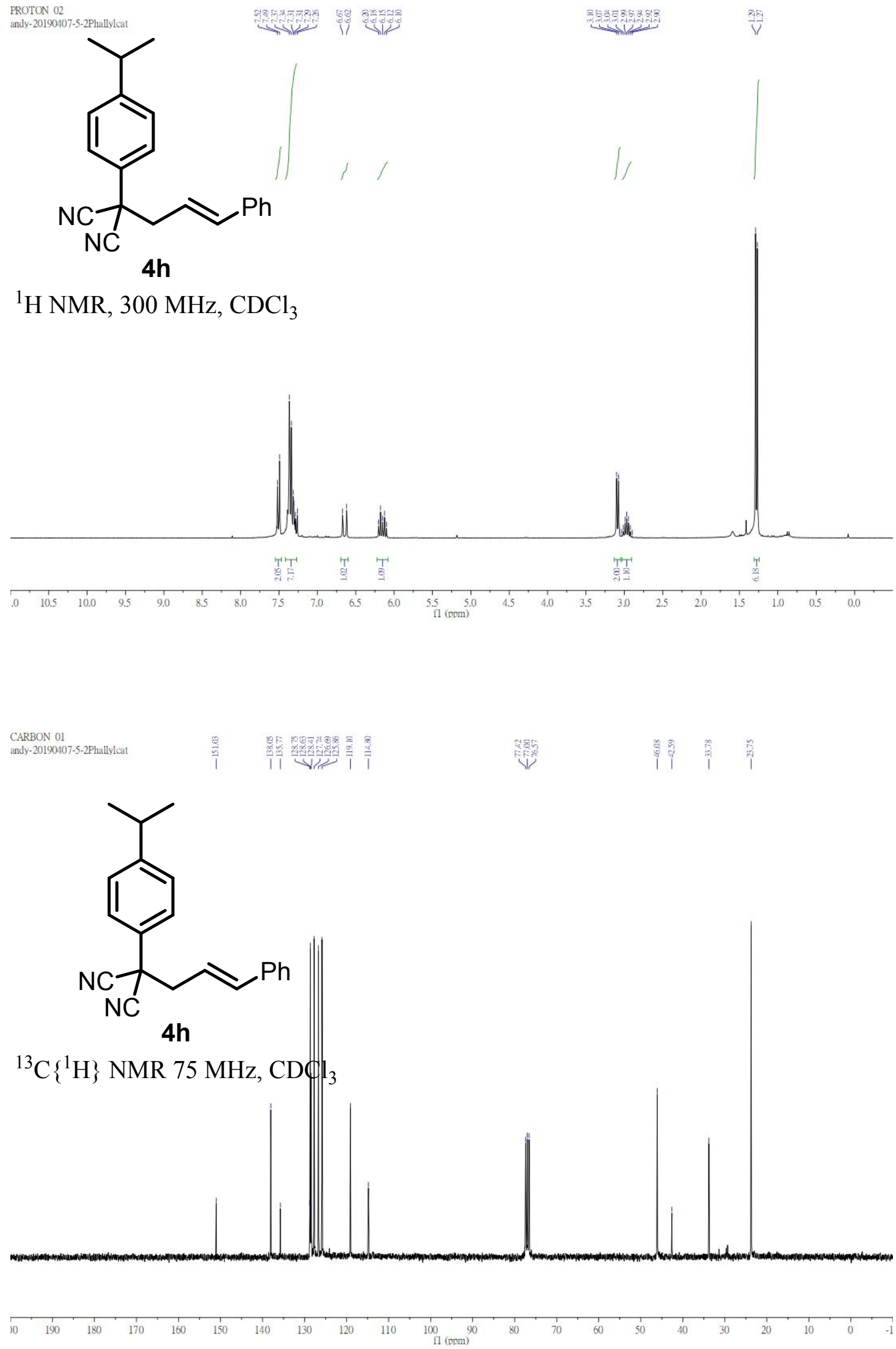

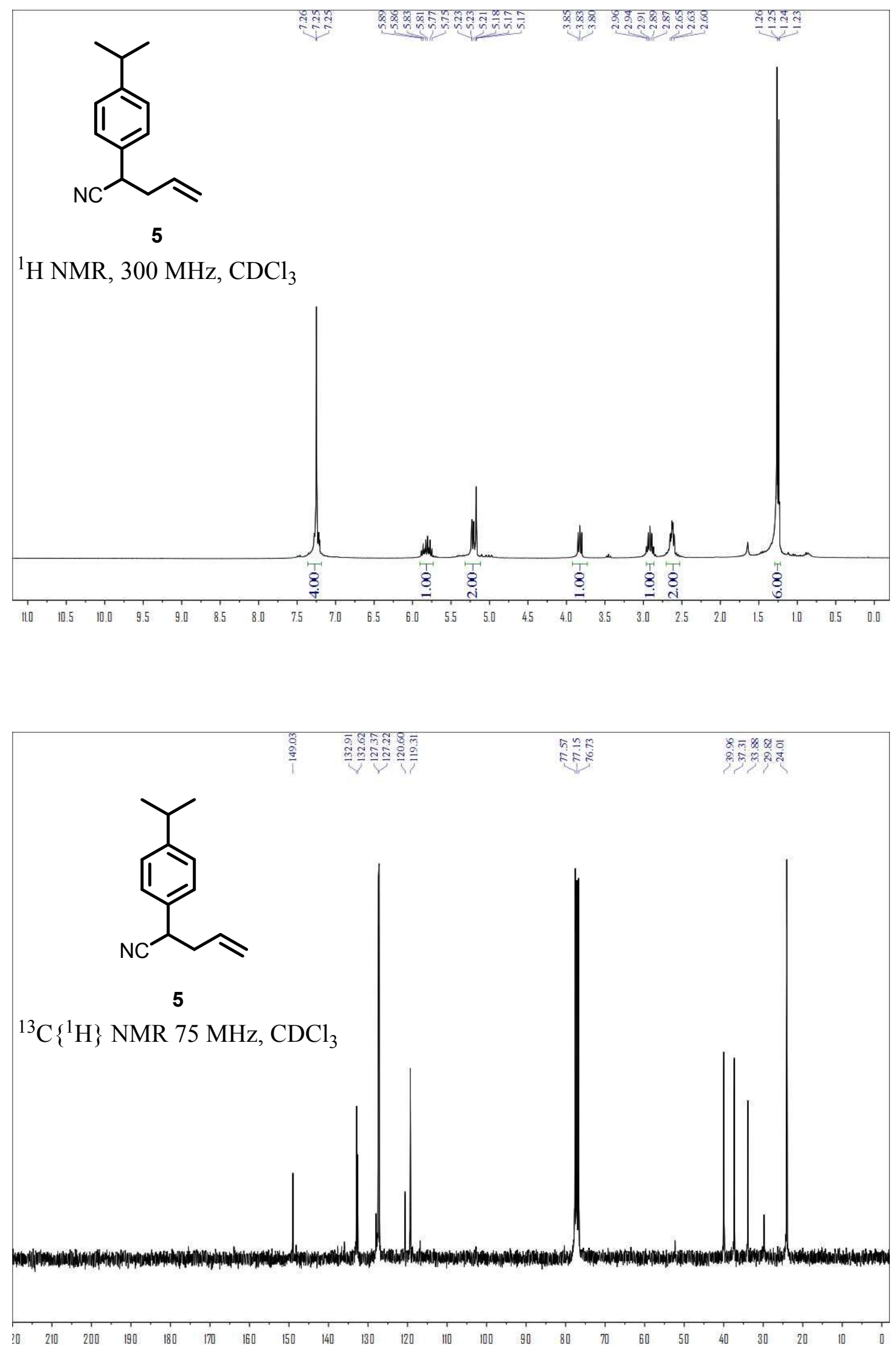

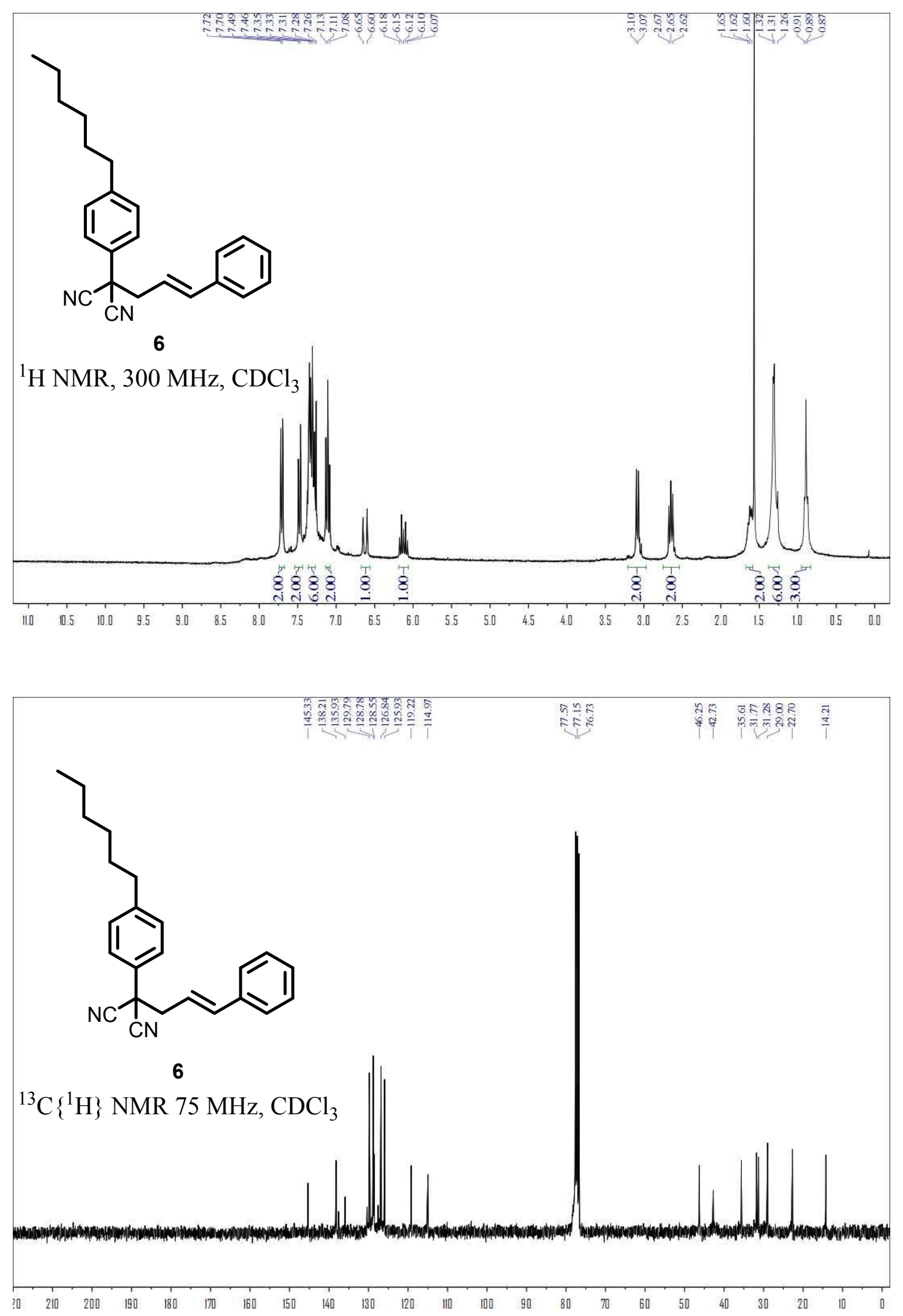
Table S1. Optimization of Enantioselective Decarboxylative $C$-Allylation ${ }^{a}$<smiles>C=CCOC(=O)C1([18O])C=CC(=C(C#N)C(=O)OCC)C=C1</smiles><smiles>C=CCC(C)(C#N)c1ccc(OCC)cc1</smiles>

(S)-PHOX Ligand

$(R, R)$-DACH Trost Ligand

$(R, R)$-ANDEN-phenyl Trost Ligand<smiles>[R]C1COC(c2ccccc2P)=N1</smiles>

$\mathrm{L1}, \mathrm{R}=i-\mathrm{Pr}$

$\mathrm{L2}, \mathrm{R}=t-\mathrm{Bu}$<smiles>O=C(NC1CCCCC1)c1c(P)ccc2ccccc12</smiles>

L3 = naphthyl

L4 = phenyl

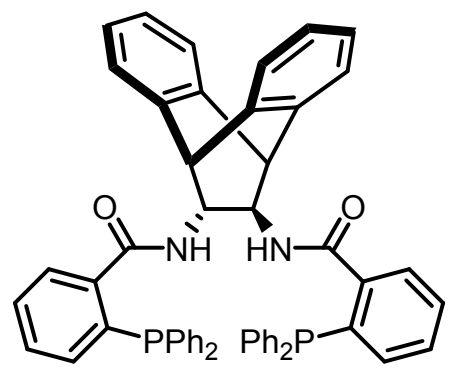

L5

$\begin{array}{llllll}\text { Entry } & \text { Solvent } & \mathrm{T}\left({ }^{\circ} \mathrm{C}\right) & \text { Ligand } & \text { Yield }(\%)^{b} & e e(\%)^{b} \\ 1 & \mathrm{CH}_{2} \mathrm{Cl}_{2} & \text { r.t. } & \mathbf{L 1} & 94 & 3 \\ 2 & \mathrm{CH}_{2} \mathrm{Cl}_{2} & \text { r.t. } & \mathbf{L 2} & 93 & 4 \\ 3 & \mathrm{CH}_{2} \mathrm{Cl}_{2} & \text { r.t. } & \mathbf{L 3} & 92 & 20 \\ 4 & \mathrm{CH}_{2} \mathrm{Cl}_{2} & \text { r.t. } & \mathbf{L 4} & 84 & 24 \\ 5 & \mathrm{CH}_{2} \mathrm{Cl}_{2} & \text { r.t. } & \mathbf{L 5} & 54 & 8 \\ 6 & \mathrm{Et}_{2} \mathrm{O} & \text { r.t. } & \mathbf{L 5} & 90 & 15 \\ 7 & \mathrm{CH}_{2} \mathrm{Cl}_{2} & -10 & \mathbf{L 4} & 85 & 25 \\ 8 & \mathrm{Et}_{2} \mathrm{O} & \text { r.t. } & \mathbf{L 4} & 64 & 45 \\ 9 & 1,4-\text { Dioxane } & \text { r.t. } & \mathbf{L 4} & 7 & 7 \\ 10 & \mathrm{CH}_{3} \mathrm{CN} & \text { r.t. } & \mathbf{L 4} & 91 & 12 \\ 11 & \mathrm{Cyclohexane}_{12} & \text { r.t. } & \mathbf{L 4} & 72 & 49 \\ 13 & \text { Benzene } & \text { r.t. } & \mathbf{L 4} & 82 & 51 \\ & \text { Toluene } & -78 & \mathbf{L 4} & 70 & 53\end{array}$

${ }^{a}$ Reaction was performed with $10(0.03 \mathrm{mmol}), 5 \mathrm{~mol} \%$ of $\mathrm{Pd}(\mathrm{dba})_{2}$, and $6 \mathrm{~mol} \%$ ligand in 0.3 M. ${ }^{b}$ Determined by chiral HPLC. 


\section{Chiral HPLC traces}

Chiral HPLC conditions of 2o: Regis $(\mathrm{S}, \mathrm{S})$ Whelk-O 1, isopropanol/hexanes $=5 / 9$, flow rate $=$ $1.0 \mathrm{~mL} / \mathrm{min}, \mathrm{I}=254 \mathrm{~nm}), \mathrm{t}_{\mathrm{R}}=8.13 \mathrm{~min}, 9.18 \mathrm{~min}$.
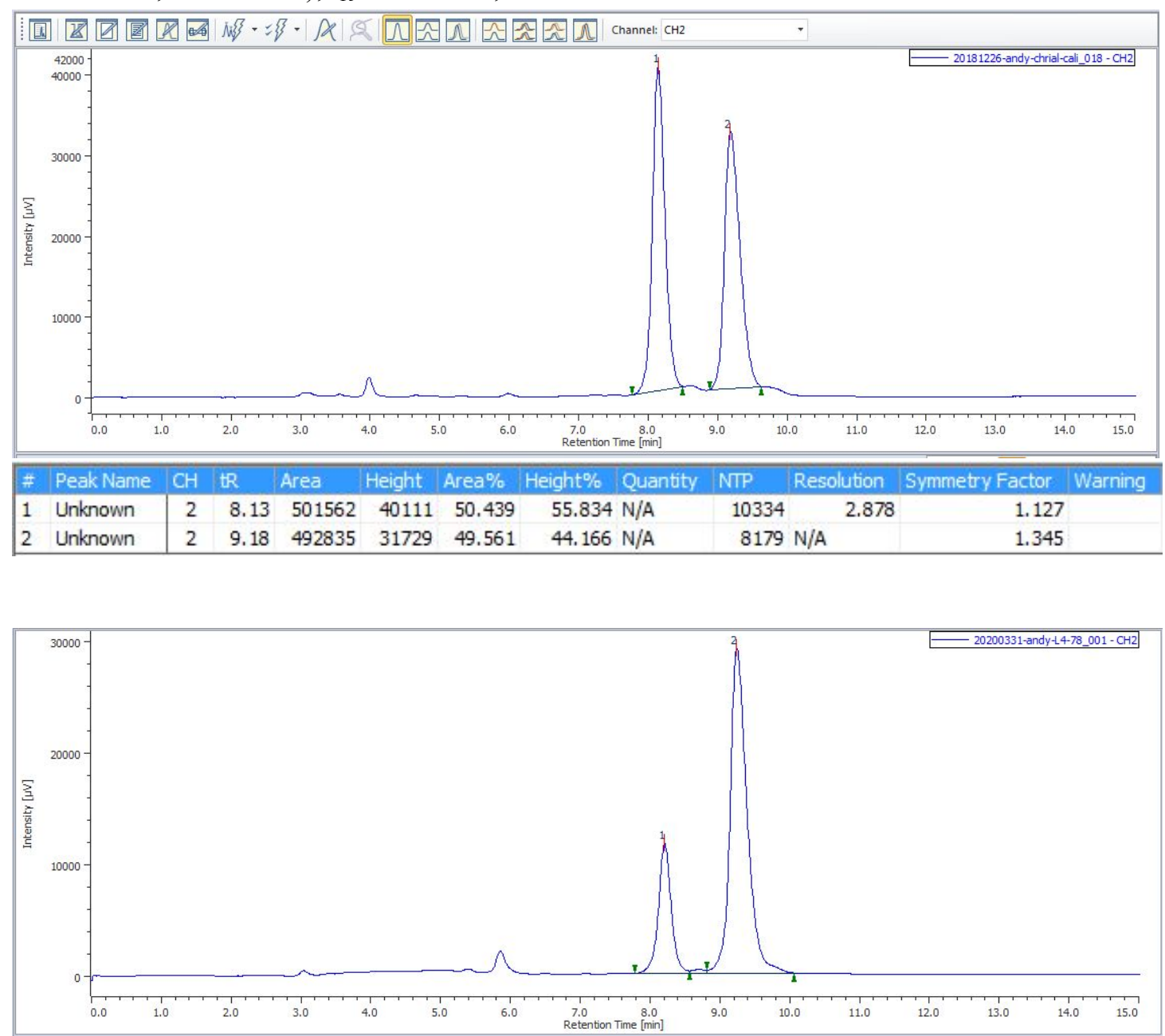

\begin{tabular}{|l|l|l|l|l|l|l|l|r|r|r|r|}
\hline \# & Peak Name & CH & tR & Area & Height & Area $\%$ & Height \% & Quantity & NIP & Resolution & Symmetry Factor Warning \\
\hline 1 & Unknown & 2 & 8.20 & 149157 & 11660 & 23.362 & 28.624 & N/A & 10947 & 2.853 & 1.028 \\
\hline 2 & Unknown & 2 & 9.23 & 489297 & 29074 & 76.638 & 71.376 & N/A & 8004 N/A & 1.255 & \\
\hline
\end{tabular}

